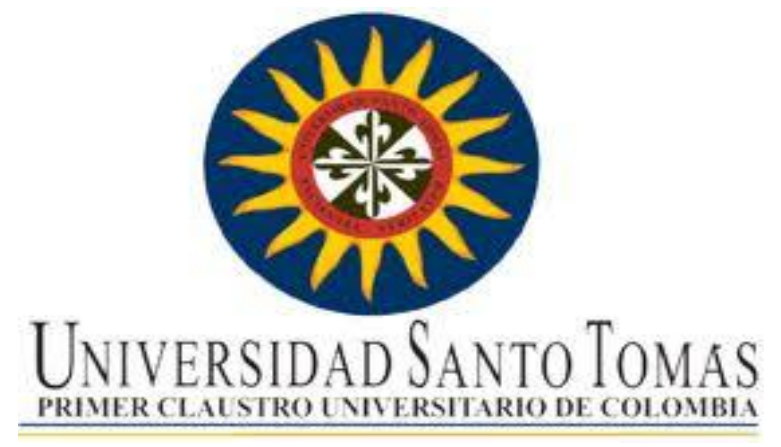

\title{
"Incidencia de la política agropecuaria en la producción de alimentos, para garantizar la seguridad alimentaria en la población rural de Puente Nacional - Santander en el periodo 2002 al 2010".
}

Lina Yibi Santamaría Burgos

Universidad Santo Tomás

Facultad de Economía

Maestría en Ciencias Económicas

Bogotá D.C., Colombia

2014 

"Incidencia de la política agropecuaria en la producción de alimentos, para garantizar la seguridad alimentaria en la población rural de Puente Nacional - Santander en el periodo 2002 al 2010”.

Lina Yibi Santamaría Burgos

Tesis presentada como requisito parcial para optar al título de:

Magíster en Ciencias Económicas

Director:

Dr. Gustavo Adolfo Díaz Valencia

Universidad Santo Tomás

Facultad de Economía

Maestría en Ciencias Económicas

Bogotá D.C., Colombia

2014 
Dedicatoria...
A Dios, ¡Oh creador inefable!, Tú que eres la verdadera fuente de luz y el soberano principio de la sabiduría, dígnate de infundir en las tinieblas de mi entendimiento un rayo de tu claridad, apartando de mí la doble oscuridad en la que he nacido: el pecado y la ignorancia.

Tú que haces elocuente la lengua de los niños, instruye mi lengua e infunde en mis labios la gracia de tu bendición.

Dame agudeza, para entender, capacidad para asimilar, método y facilidad para aprender, sutileza para interpretar y gracia copiosa para hablar.

Dame acierto al empezar, dirección al progresar y perfección al acabar.

Tú que eres el verdadero Dios y hombre que vives y reinas por los siglos de los siglos amén.

A mi esposo Omar y mi hija Samara, por su incondicional amor, manifestación pura del poder Divino que da sentido a mi existir.

A mi Padre, mi Madre y mis Hermanos por su legado y enseñanza de amor a la naturaleza, al trabajo y la vida en el campo.

A millones de campesinos Colombianos, que trabajan por un campo fuente de alimento para el mundo $\mathrm{y}$ luchan incansablemente por una vida digna para sus familias.

Al SENA, por mi experiencia, y su interés en el bienestar de la población rural Colombiana.

A la Universidad Santo Tomás, por mi formación y crecimiento intelectual en la Economía Social. 


\section{Resumen}

El presente trabajo de grado es un análisis acerca de las acciones de política para el sector agropecuario dirigidas a logro de la seguridad alimentaria. Bajo la premisa que, la agricultura y la producción de alimentos son importantes para una nación, al representar la generación de ingresos de la población rural y por consiguiente, posibilita la seguridad alimentaria de los mismos y del resto de la población.

Se estudiaron los distintos enfoques teóricos acerca de la agricultura y seguridad alimentaria, para conocer diferentes planteamientos acerca del problema agroalimentario a nivel mundial, latinoamericano y nacional. En tal sentido articular las contribuciones teóricas a la investigación.

El trabajo se centró en los hogares rurales y agricultores del municipio de Puente Nacional - Santander; donde se analizó cuál ha sido la incidencia de la política agropecuaria en la producción de alimentos, como condición necesaria para que la población rural tenga seguridad alimentaria.

Cabe señalar que parte de la investigación toma aspectos del contexto general de Seguridad Alimentaria, para ir al estudio particular de fenómeno desde la oferta, es decir, desde la producción o la "disponibilidad de los alimentos". Continuando, con la explicación de los efectos que se generan sobre la posibilidad de acceso a los alimentos en la población rural.

Durante el desarrollo, se evaluaron los dos gobiernos del presidente Álvaro Uribe Vélez, periodo 2002 a 2006 y 2006 a 2010, a la luz de sus disposiciones para el sector agropecuario y desde distintos escenarios económicos y sociales. Por lo anterior, se analizó el desempeño del sector para determinar si dichas disposiciones incidencieron positiva o negativamente en la seguridad alimentaria de la población.

La investigación construyó un modelo econométrico, donde definieron las variables que explican la producción, para identificar su comportamiento en la región en estudio. Posteriormente la evaluación de la acciones de política desarrolladas por el gobierno, son valoradas de cara al desempeño de las variables. En esa misma línea, se analizó si los resultados del fomento de la producción de alimentos son coherentes con los objetivos propuestos en la política de seguridad alimentaria. Dicho en otras palabras, "si las acciones desde lo agropecuario correspondieron a los requerimientos de la seguridad alimentaria".

La recolección de información primaria de pequeños y medianos productores del municipio, permitió la proximidad de la realidad que tal vez viven millones de pobladores rurales, donde el accionar del Gobierno llega con dificultad, llega pero es insuficiente o en algunos casos no llega. De igual manera, la consulta de diversas fuentes de información secundaria pública y privada, dan cuenta de los intentos de política 
agropecuaria que Colombia ha tenido, los cuales distan de una política sectorial clara e integrada con el resto de la economía.

Como resultado, en el municipio de Puente Nacional - Santander, es claro la disminución de la producción explicado por el comportamiento significativamente desfavorable de algunas variables; por consiguiente, la primera afectación que esto generó es la disminución de los ingresos de los productores y como consecuencia la dificultad de las familias para acceder a una la alimentación adecuada y sostenible. Situación que pone en riesgo de forma inmediata la seguridad alimentaria de la población rural y de manera indirecta advierte que lentamente se va gestando el riesgo de la seguridad alimentaria de la población urbana.

En consecuencia, se llega a la comprobar que: "La política agropecuaria para la producción de alimentos no es suficiente para atender las necesidades de seguridad alimentaria de la población rural del municipio de Puente Nacional (S)".

Respecto de las recomendaciones, son referidas a la formulación de política pública para el sector agropecuario con el fin de trabajar en la causa del problema y no en el efecto. Indicando que ésta debe lograr influencia directa en las decisiones de comportamiento de los agentes sociales y agentes económicos. Se debe recurrir para esto a los distintos instrumentos con que cuenta, cómo el liderazgo político, la potestad de regular, la capacidad de crear instituciones, la capacidad de hacer inversiones en bienes públicos, e inclusive intervenir en la economía.

Finalizo considerando que "La agricultura y por consiguiente la producción de alimentos, significa al interior de las familias rurales un camino para salir de la pobreza, en realidad, muchas veces el único de que disponen, es la fuente principal de ingresos y derechos, que da como mínimo, la posibilidad de alcanzar una alimentación adecuada y sostenible." Por ello, Colombia necesita con urgencia una Política agropecuaria con visión de desarrollo Rural y en particular que responda a la seguridad alimentaria tanto de pobladores rurales como urbanos.

Palabras clave: Seguridad alimentaria, Soberanía alimentaria, roblema agroalimentario, pobladores rurales, productores de alimentos, agricultores, producción de alimentos, disponibilidad de alimentos, acceso a los alimentos, política agropecuaria, desarrollo rural, agricultura, dependencia alimentaria. 


\section{Contenido}

\section{Introducción}

Capítulo 1. Consideraciones teóricas y conceptuales.

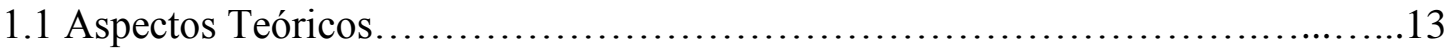

1.1.1 Enfoques Teóricos sobre Agricultura ….................................13

1.1.2 Enfoques Teóricos sobre Seguridad Alimentaria. ...........................17

1.2 Autores que han contribuido con el desarrollo del problema. .....................20

Capítulo 2. Análisis de las política agropecuaria y de seguridad alimentaria en Colombia.

2.1. Cuadro comparativo entre las Políticas de Países Latinoamericanos..............26

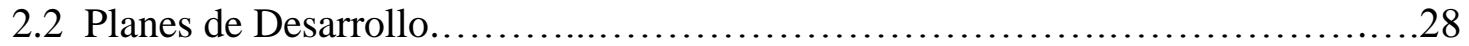

2.3 Características de las acciones desarrolladas para el sector agropecuario...........32

2.3.1 La Empresarización del campo en manos de Grandes Capitales.....................33

2.3.2 Las restricciones para los pequeños productores de alimentos..................34

2.3.3 Alimentos para los carros no para los humanos..............................35

2.3.4 Cereales y leguminosas importadas no producidas por nosotros..................36

2.3.5 Los tratados de Libre Comercio............................................... 37

2.3.6 La pobreza no retrocede y crece en nuestros campos...........................37

2.4 Aspectos Macroeconómicos de la Producción de Alimentos........................38

2.5 Características Sociodemográficas de la Población Rural..........................40

2.6 Análisis del Entorno Local......................................................41

Capítulo 3. Aspectos metodológicos y desarrollo del modelo.

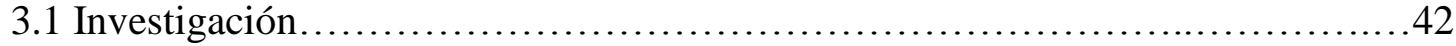

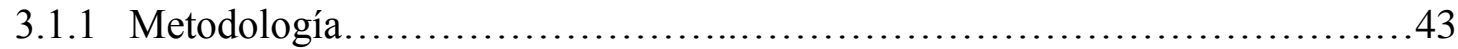

3.2. Procedimiento de Recolección de Información...............................44

3.2.1 Métodos e instrumentos de recolección de información.............................44

3.2 El Análisis de Datos....................................................... 44

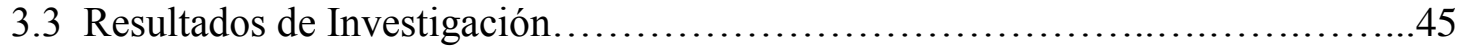

3.4.1 Incentivos Institucionales................................................

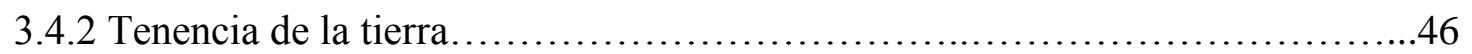

3.4.3 Sistemas de producción de alimentos........................................46

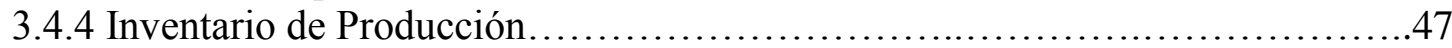

3.4.5 Acceso a mercados y eficiencia económica...................................47

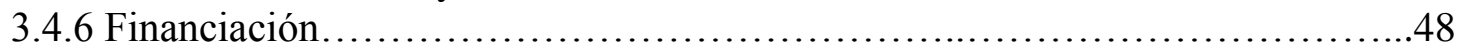

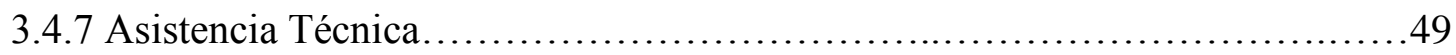


Capítulo 4. Análisis cuantitativo de la Incidencia de la política agropecuaria en La disponibilidad de alimentos para garantizar la seguridad alimentaria.

4.1 Modelo econométrico.....................................................51

4.2 Lo esperado del modelo.............................................52

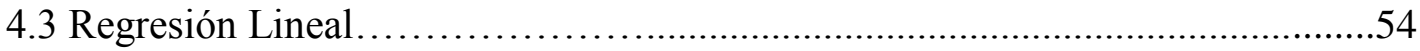

4.3.1 Regresión Lineal Múltiple Medianos Productores de Alimentos..............54

4.3.2 Regresión Lineal Múltiple Pequeños Productores de Alimentos.....................55

4.3.3 Regresión Lineal Múltiple Productores de Alimentos en tierra propia...........57

4.3.4 Regresión Lineal Múltiple Productores de Alimentos en tierra arrendada........58

4.4. Validación de la Hipótesis.............................................60

4.5 Incidencia de la Política Agropecuaria en la Producción de Alimentos y

La Seguridad Alimentaria................................................61

4.5.1 El Valor de la Producción de alimentos y el valor de los insumos...............61

4.5.2 El valor de la producción de alimentos y el valor de los incentivo...........62 62

4.5.3 El valor de la producción de alimentos y el margen de utilidad....................62

4.5.4 El valor de la producción de alimentos y el valor de las deudas................62

4.5.5 El valor de la producción de alimentos y otras actividades sustitutas.........63

4.5.6 El valor de la producción de alimentos y el valor de los subsidios...........63

4.5.7 El valor de la producción de alimentos y la tenencia de la tierra..............63

4.5.8 El valor de la Producción de Alimentos y la Seguridad Alimentaria............64

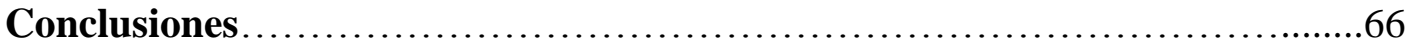

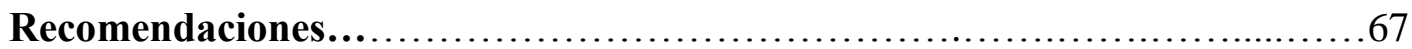

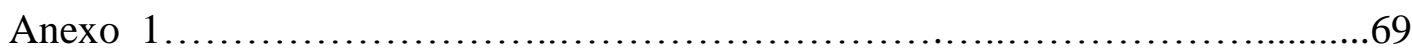

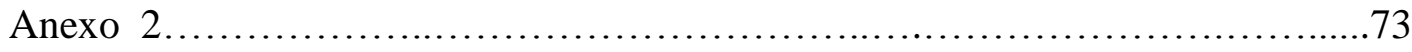

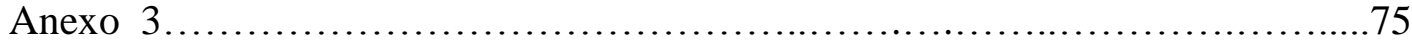

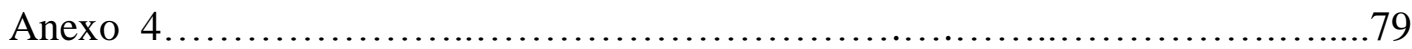

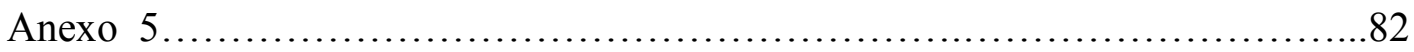

Lista de Referencias.................................................. 84

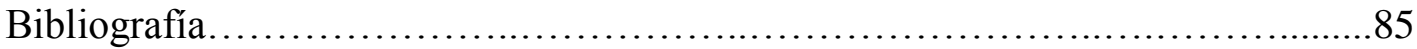

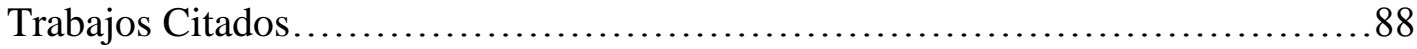




\section{Lista de Tablas}

Tabla 1.2 Diversas Contribuciones Teóricas Recientes página.................21

Tabla 1.1 Política Agropecuaria en Países Latinoamericanos 2002 al 2010.......26

Tabla 2.2. Ejes de la seguridad alimentaria y nutricional, sus dimensiones y

Determinantes según la PSAN...................................31

Tabla 3.1.1 Indicadores para evaluar la política agropecuaria en el municipio

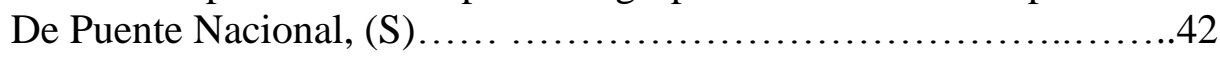

Tabla 3.1.2.Cálculo del tamaño de la muestra para población finita................43

Tabla 3.1.3.Muestreo Probabilístico -Aleatorio por Conglomerados..................43

Tabla.3.3.1 Análisis de datos...............................................45

Tabla.4.1 Composición del PIB desde la oferta de alimentos.....................51

Tabla.4.2 Variables en estudio............................................51

Tabla 4.3.1 Resultados del Modelo de Regresión en Medianos Productores de Alimentos....................................................54

Tabla 4.3.2 Resultados del Modelo de Regresión en Pequeños Productores de Alimentos....................................................55

Tabla 4.3.3 Resultados del Modelo de Regresión en Productores de Alimentos con Tierra Propia...............................................57

Tabla 4.3.4 Resultados del Modelo de Regresión en Productores de Alimentos con Tierra Arrendada ....................................................58

Tabla 4.5.1 Incidencia en el aumento o disminución del valor de la producción por efecto de las variables independientes...........................61 


\section{Lista de Ilustraciones}

Gráfica 2.4.1 Comportamiento del Pib Agropecuario entre el 2001 y el 2012.......38

Gráfica 2.4.2 Comportamiento de la Balanza Comercial Agropecuaria y

Agroindustrial................................................38

Gráfica 2.4.3 Comportamiento de la producción de alimentos y otros cultivos......39

Gráfica 2.4.4 Potencial para la producción agropecuaria en Colombia...............39

Gráfica 3.4.1.1 Entidades que ofrecieron incentivos.............................45

Gráfica 3.4.1.2 Incentivos recibidos ........................................45

Gráfica 3.4.2.1 Tenencia de la tierra...........................................46

Gráfica 3.4.2.2 Propiedad de la Tierra.......................................46

Gráfica 3.4.3.1 Sistemas de Producción........................................46

Gráfica 3.4.3.2 Área destinada a producir alimentos...........................46

Gráfica 3.4.3.2 Actividades sustitutas de la producción de alimentos..............46

Gráfica 3.4.4.1 Producción de alimentos....................................47

Gráfica 3.4.4.1 Destinación de los Alimentos.....................................47

Gráfica 3.4.5.1 Mercado los alimentos.........................................47

Gráfica 3.4.5.2 Ingresos por la venta de alimentos...........................47

Gráfica 3.4.5.3 Costos de producción de Alimentos al Mes........................48

Gráfica 3.4.5.4 Margen de utilidad en la producción de alimentos..................48

Gráfica 3.4.6.1 Financiación de la producción..................................48

Gráfica 3.4.6.2 Tipos de Crédito............................................49

Gráfica 3.4.6.3 Tipo de servicio adquirido..................................49

Gráfica 3.4.6.4 Deudas de los productores....................................49

Gráfica 3.4.7.1 Frecuencia de la Asistencia Técnica...............................49

Gráfica 3.4.7.2 Prestador de Asistencia Técnica..................................49 


\section{Introducción}

El presente trabajo de grado está enmarcado en la línea de investigación sobre Políticas Públicas en Colombia, busca conocer la incidencia de la política agropecuaria en la producción de alimentos, para garantizar la seguridad alimentaria en la población rural de Puente Nacional - Santander en el periodo 2002 al 2010.

Para comenzar es necesario hacer unas apreciaciones sobre la situación del sector agropecuario en Colombia, que en los últimos años por los efectos propios de la economía de libre mercado y en parte el limitado accionar de los gobiernos entre otros, ha presentado serias dificultades en su desempeño. Particularmente para quienes nos referiremos como productores agropecuarios y/o agricultores; toda vez que sus posibilidades de producción se han venido disminuyendo. Condiciones como el alto costo de los insumos, la escasa financiación, la inexistencia de subsidios, la falta de asistencia técnica y los precios bajos de los productos en el mercado entre otros, han limitado el bienestar de la población rural en especial los pequeños productores, que sienten desprotegidas sus unidades productivas y sin oportunidad en el mercado. Esta situación pone dificulta la generación de ingresos y el acceso de sus familias a los alimentos.

Como consecuencia hay un efecto negativo global sobre la producción de alimentos de la canasta básica; pues el campo Colombiano en parte, está dejando de ser una oportunidad de crecimiento y en algunos casos ni siquiera un medio de supervivencia. El efecto directo es el riesgo la seguridad alimentaria familiar de la población rural y paulatinamente el incremento la pobreza en el campo.

Al respecto de la seguridad alimentaria, la Organización de las Naciones Unidas para la Agricultura y la Alimentación-FAO, y el Programa especial para la Seguridad Alimentaria ${ }^{1}$, señalan que, "el objetivo de la seguridad alimentaria es garantizar a todos los seres humanos el acceso físico y económico a los alimentos básicos que necesitan. Esta definición comprende cinco aspectos: la disponibilidad, el acceso, el consumo, el aprovechamiento biológico y calidad e inocuidad de los alimentos". De otra parte el concepto de seguridad alimentaria familiar, aceptada por el Comité de Seguridad Alimentaria Mundial, perfecciona la definición anterior de siguiente: siguiente "acceso material y económico a alimentos suficientes para todos los miembros del hogar, sin correr riesgos indebidos de perder dicho acceso", lo que introduce el concepto de vulnerabilidad.

Según Thomson A, Metz M. (1999), un país puede tener seguridad alimentaria a nivel nacional y al mismo tiempo un número considerable de hogares expuestos a la inseguridad alimentaria. En este caso, los problemas de seguridad alimentaria se identificarán en general por regiones o grupos socioeconómicos, y requerirán medidas de políticas sectoriales o selectivas. También puede haber inseguridad alimentaria nacional, en el sentido de que tal vez el país no puede producir o importar alimentos suficientes

\footnotetext{
${ }^{1}$ Los cinco ejes de la Seguridad Alimentaria Nacional son: La disponibilidad de alimentos, acceso a los alimentos, consumo de alimentos, aprovechamiento biológico de los alimentos y calidad e inocuidad de los alimentos. Política Nacional de Seguridad Alimentaria y Nutricional [PNSAN], 2007.
} 
para satisfacer la demanda del mercado. Los precios de los alimentos aumentarán y un número creciente de hogares quedará expuesto a la inseguridad alimentaria. En esta situación, es probable que los problemas de seguridad alimentaria se vinculen estrechamente con las cuestiones macroeconómicas y exijan la revisión de la política básica del gobierno.

En tal sentido, la investigación se centro en un grupo de hogares rurales y agricultores del Municipio de Puente Nacional (S), caracterizados por tener a una actividad económica basada en gran parte en la producción de bienes agrícolas tradicionales y vinculados a mercados poco dinámicos. Allí existen algunas acciones que el estado ha desarrollado, pero al parecer corresponden a situaciones coyunturales que no garantizan el fomento real de la producción de alimentos. Sin embargo a nivel central, existieron algunos planes y documentos Conpes, que instan al Ministerio de Agricultura y a sus entidades adscritas, a desarrollar acciones que incentivan la producción; disposiciones que atienden a la adecuación del sector agropecuario para el mercado internacional, estimulando el agro negocio y la participación de inversión privada de grandes capitales priorizando productos y regiones contenidas dentro de la agenda exportadora. [1].

Además de la situación expuesta que refiere una problemática latente, existe una justificación clara desde la evaluación del cumplimiento del estado colombiano en la formulación de la política pública.

La Constitución Política Colombiana en su Artículo 64 dice, "Es deber del Estado promover el acceso progresivo a la propiedad de la tierra de los trabajadores agrarios, en forma individual o asociativa, y a los servicios de educación, salud, vivienda, seguridad social, recreación, crédito, comunicaciones, comercialización de los productos, asistencia técnica y empresarial, con el fin de mejorar el ingreso y calidad de vida de los campesinos" Así mismo, es misión del ministerio de agricultura formular, coordinar y promover las políticas que promuevan el desarrollo competitivo, equitativo y sostenible de los procesos agropecuarios forestales, pesqueros y de desarrollo rural, con criterios de descentralización, concertación y participación, que contribuyan a mejorar el nivel y la calidad de vida de la población colombiana.

Además del mandato constitucional, la evaluación de la política agropecuaria adquiere importancia frente a grandes cambios de la economía. Los países en su proceso de transformación productiva, deberán regir esta transformación por objetivos que garanticen el crecimiento de la agricultura pero de la mano del desarrollo social y sin detrimento de los recursos naturales, consolidando las bases conceptuales y operativas que permitan diseñar instrumentos de políticas y mecanismos institucionales eficientes, así como concebir otros que permitan analizar y evaluar el impacto que las medidas de política tiene en la producción agrícola, la población rural y la base de capital natural.[2]

Por lo anterior, el presente trabajo de grado planteó la siguiente pregunta de investigación ¿Cuál ha sido la incidencia de la política agropecuaria en la producción de alimentos, para garantizar la seguridad alimentaria en el municipio de Puente Nacional durante el periodo 2002 al 2010? 
Por lo tanto; el objetivo de esta investigación es: "Evaluar la incidencia de la política agropecuaria en la producción de alimentos, para garantizar la seguridad alimentaria en la población rural del municipio de Puente Nacional (S), durante el periodo 2002 al 2010".

De forma específica fue necesario revisar la existencia o no de la política agropecuaria; su composición (por planes, programas y proyectos), para identificar la interdepencia con la Política de Seguridad Alimentaria. De igual manera, determinar las relaciones entre los requerimientos de la seguridad alimentaria y las acciones en materia de producción de alimentos. Lo anterior para llegar a establecer criterios, indicadores, parámetros de medición de los resultados en materia del apoyo a la producción de alimentos y la disponibilidad de los mismos, para que la población Rural del municipio pudiese tener acceso a los alimentos.

Para este fin la investigación planteó como hipótesis nula: "La política agropecuaria para la producción de alimentos no es suficiente para atender las necesidades de seguridad alimentaria de la población rural del municipio de Puente Nacional (S)". Y como hipótesis alternativa: "La política agropecuaria para la producción de los alimentos si es suficiente para atender las necesidades de seguridad alimentaria de la población rural del municipio de Puente Nacional (S)".

En cuanto a la a metodología de investigación aplicada, se hizo una investigación exploratoria - descriptiva no experimental; toda vez que se observaran y describen los fenómenos tal y como se dan en su contexto natural. En cuanto al tiempo, se hace un corte transversal al tratarse de la recolección de información en el periodo comprendido entre los años 2002 al 2010.

Se plantea entonces, un modelo econométrico con las variables que explican la producción, para identificar su comportamiento en la región en estudio. Luego, se establecen las relaciones causa-efecto, entre la variable dependiente o explicada "La producción de alimentos", y las variables independientes o explicativas, que son: "El valor de los incentivos, otras actividades que sustituyen la producción de alimentos, los subsidios recibidos, las deudas de los productores, el valor de los insumos, el margen de utilidad y la tenencia de la tierra.

Finalmente con los resultados del modelo, se analizó si las acciones de política sectorial para el fomento de la producción de alimentos en el municipio, fueron o no coherentes y suficientes con los objetivos y requerimientos de la seguridad alimentaria.

La investigación se desarrolló en 4 capítulos; Capitulo 1. Consideraciones Teóricas y Conceptuales, Capítulo 2. Análisis de las Política Agropecuaria y de Seguridad Alimentaria en Colombia, Capítulo 3. Aspectos Metodológicos y Desarrollo del Modelo y Capítulo 4. Análisis cuantitativo de la Incidencia de la política agropecuaria en la disponibilidad de alimentos, para garantizar la seguridad alimentaria. 


\section{Capítulo 1. Consideraciones Teóricas y Conceptuales.}

\subsection{Aspectos Teóricos}

A lo largo de la historia ha habido una manifiesta evolución del pensamiento en el campo del crecimiento económico y el desarrollo de la sociedad y, particularmente, con referencia a la agricultura. Ello se ha plasmado en diversas teorías económicas y sociales que deben interpretarse en el contexto en que fueron generadas. Estas teorías propician políticas económicas y promueven acciones sociales de diversa naturaleza, las que inciden en la sociedad y en los procesos económicos y, por lo tanto, en el desarrollo. La comprensión de las teorías y los marcos conceptuales sobre los cuales se han basado las diversas visiones acerca del crecimiento y el desarrollo, constituyen la base para la comprensión de los procesos de Desarrollo Rural orientados desde la Política Pública.

\subsubsection{Enfoques Teóricos sobre Agricultura}

La producción agrícola ha sido abordada por la literatura económica desde diferentes enfoques, entre otros: (i) el enfoque físico de los Fisiócratas; (ii) la visión pecuniaria de los clásicos como Adam Smith y David Ricardo; (iii) el análisis histórico de Karl Marx y (iv) la concepción empresarial de León Walrás y los neoclásicos; (v) las ideas macroeconómicas de Simón Kuznets y los institucionalistas. El interés teórico en la agricultura radica en que los recursos generados en esta actividad contribuyen a la generación de riqueza en toda la economía.

Thomas Robert Malthus (1820), incluye el factor demográfico como una variable adicional que determina no solo el comportamiento de la economía sino también el bienestar de la población, configurando interrelaciones con los sectores económicos, en especial con la agricultura a través de la producción de alimentos. Para el autor, mientras los alimentos se incrementan en progresión aritmética, la población se multiplica en 4 progresión geométrica, de esta manera la escasez de los alimentos tendería a limitar el crecimiento de la población y deprimiría su nivel de vida hasta conducirlo a la subsistencia.

Marx, entiende la agricultura como una estructura capitalista donde coexisten marcadas clases sociales: capitalista, obrero asalariado y terrateniente. Los primeros son los productores de mercancías, quienes organizan y dirigen la producción; los segundos, están privados de la posesión de la tierra, medios de producción y de la ganancia; por último, los terratenientes alquilan sus tierras a los capitalistas. El autor reivindica la propiedad de la tierra como base de la explotación de la clase obrera por el capital; el obrero es incapaz de poner todas las condiciones de producción y carece del derecho a participar en la renta de la tierra y la plusvalía extraída. La agricultura capitalista para Marx se da en un entorno donde hay usurpación de predios, acumulación de la propiedad, se incorpora el capital a la tierra y surge el trabajo agrícola asalariado. (Arango, 1983). 
En la propuesta neoclásica, la importancia de la agricultura se asume desde la empresa agrícola, regida por los mismos principios de las demás actividades económicas (comportamiento individual); autores como Laur en Suiza, Aeroboe y Brinkman en Alemania, Serpieri y Bandini en Italia, estrecharon relaciones entre ciencias económicas y economía agraria creando la escuela europea (Caldentey, 1996).

En Estados Unidos surge una visión de economía agraria empírica y pragmática que circunscribe sus estudios a temáticas específicas: economía de la producción, administración de fincas, mercadeo, economía de la tierra y política agrícola. Estos aportes se formalizaron con el trabajo de Heady (1952), quien aplica principios de teoría económica neoclásica a la agricultura donde se abordan problemas agrícolas individuales y colectivos en un plano normativo fundamentado en la maximización del beneficio.

El planteamiento neoclásico ha suscitado críticas respecto a su estructura teórica básica: irrealismo de sus supuestos, carácter estático del modelo e introducción fallida de elementos dinámicos, entre otros aspectos de discusión. Como respuesta a tales críticas, se han dado modificaciones al interior del mismo paradigma dando lugar a la teoría de la Organización industrial en los años cincuenta y a la Teoría de Juegos en los años ochenta; además han surgido propuestas heterodoxas de análisis macroeconómico como el neo institucionalismo o nueva economía institucional (Caldentey, 1996).

La importancia de la agricultura en el proceso de crecimiento económico fue también enfatizada por Johnston y Mellor (1961), al sostener que ella puede realizar cinco importantes contribuciones a la transformación estructural de la economía (proveer trabajo, capital, divisas y alimentos para el sector industrial así como servir de mercado para los bienes industriales) y señalar que las interrelaciones entre agricultura e industria poseían implicaciones significativas. Los aportes de estos autores se concretaron en estrategias diseñadas para incrementar la productividad y el producto agrícola a través de la introducción de tecnología agrícola.

A fin de lograr ese propósito, era imprescindible invertir en investigación agrícola, educación y extensión con el fin de elevar la baja productividad de la fuerza de trabajo agrícola, la tierra y otros recursos del mencionado sector. Los planteamientos de Johnston y Mellor fueron posteriormente ratificados por Nicholls (1968), quien otorgó relevancia significativa al sector agrícola al destacar la trascendencia del progreso agrícola como condición para lograr el desarrollo industrial, señalar la importancia estratégica de la agricultura como sector suministrador de trabajo y alimentos a precios que hagan más viable la acumulación, y propugnar la necesidad de lograr excedentes alimenticios como condición necesaria para alcanzar importantes niveles de desarrollo.

En esa misma línea de pensamiento, Schultz (1964) sostuvo que para transformar a los campesinos más pobres en un sector que contribuyera al crecimiento económico era necesario modernizarlos a través de la realización de inversiones requeridas, para poner a disposición de éstos Insumos industriales e inducirlos a su consumo. A fin de lograr este objetivo, era menester que esos agricultores dispusieran de nuevas Tecnologías y recibieran el suficiente entrenamiento o capacitación para poderlas utilizar; de esta forma Schultz coloca en el centro del debate los aspectos relacionados con el cambio 
tecnológico en la agricultura. De esta manera sus aportes condujeron a la creación y orientación de las actividades de renombrados centros de investigación como el CIMMYT, que tuvo indiscutibles repercusiones a través de la llamada «Revolución Verde».

En la década del 60 la CEPAL consideró que la salida al problema de la agricultura de América Latina no consistía simplemente en corregir la asignación de los recursos, ni la aplicación y mejoramiento de las oportunidades educativas, menos el fomento y desarrollo de las comunidades; el problema radicaba más bien en la presencia de desequilibrios sociales de profunda significación derivados de algunos factores como la alta concentración de la propiedad de la tierra, que impedía la total y eficiente utilización de éste y otros recursos productivos. Así, los límites impuestos al desarrollo agrícola estaban más relacionados con los factores de carácter estructural e institucional y menos con la falta de tecnología, capital, insumos e investigación. Tales planteamientos se derivaron de la atención que la CEPAL empezó a otorgar al denominado "crecimiento hacia adentro", vale decir, a la política de industrialización por sustitución de importaciones.

Más tarde, en los inicios de la década del 80, la CEPAL y la FAO (1981) realizaron un diagnóstico de la agricultura de los países de América Latina. A partir de este diagnóstico, formulan tres estrategias alternativas de transformación de la agricultura, a saber: a) modernización periférica, b) estrategia del desarrollo rural, y c) transformación social (FAO, 1981), conducentes todas ellas a la modernización agrícola, a través de cambios estructurales que condujeran a una regulación del acceso y utilización de recursos básicos para la producción agrícola, la organización económica de la producción, la organización económica e institucional de la comercialización, el procesamiento de los productos agrícolas, etc.

En los años 90 Bejarano (1998, p. 83-84), consideró que los problemas de la estructura agrícola tradicional, propios del pensamiento estructuralista de los años cincuenta, incluyen las categorías tenencia de la tierra, desarrollo tecnológico, crecimiento de la producción, empleo y problemas de pobreza; a finales de los noventa avances en el conocimiento y transformaciones en la realidad agrícola latinoamericana, han agregado otros elementos al análisis de esta problemática como: política macroeconómica, términos de intercambio, mercado internacional de productos agrícolas, papel de las empresas transnacionales y preocupaciones por la tecnología ,como elemento endógeno, por la seguridad alimentaria y por el uso de los recursos naturales.

En síntesis, se tienen dos grandes abordajes teóricos sobre la manera de analizar la cuestión agraria: la propuesta Marxista, y la neoclásica y neo institucionalista. Por una parte, desde el marxismo, la producción agrícola está inmersa en sistemas sociales, históricos, políticos y económicos que a través de la propiedad de la tierra, intervienen en la generación de riqueza y bienestar para la población, se denomina análisis de la estructura agraria. Por otra parte, desde los neoclásicos y neo institucionalistas, se entiende la agricultura como un sector que responde a la misma lógica de otros sectores, que busca la eficiencia y productividad a través de la maximización; donde desaparece la discusión sobre propiedad de la tierra y la lógica de mercado está presente en todos los 
factores del sector agrícola; esta visión se consolida a través del análisis de Sistemas Agroindustriales SAI.

Dicha coexistencia es explicada por Machado (2002) al afirmar que dentro de los países en desarrollo se presentan dos posibilidades: En los países en desarrollo de mayor ingreso, el núcleo dominante de los Sistemas Agroindustriales SAI, se concentra alrededor de las relaciones de la agroindustria con el sector financiero y comercial, mientras que la estructura agraria tradicional subsiste al interior del SAI como subordinada, aunque puede conservar su identidad, para luego ser transformada por el proceso de modernización inherente al SAI a partir de cambios tecnológicos, demográficos, patrones de consumo distintos, políticas de estado, avances en comunicaciones, entre otras; mientras que en los países menos desarrollados subsisten estructuras agrarias tradicionales que no han sido transformadas en sus relaciones fundamentales a nivel regional, aunque con una subordinación al SAI nacional.

La FAO (2008), estima que para poder atender la mayor demanda de alimentos, el mundo necesita incorporar 3,75 millones de nuevas hectáreas/año de aquí hasta el 2030. Por ello en los países en desarrollo, la agricultura siempre ha tomado un papel protagónico en los procesos económicos y sociales; prueba de ello, E.E.U.U. y Unión Europea utilizan el 97\% de sus tierras aptas para la Agricultura y buscan más allá de la seguridad, la soberanía alimentaria ${ }^{2}$.

\subsubsection{Enfoques Teóricos sobre Seguridad Alimentaria.}

Los asuntos de la seguridad alimentaria anudados a la producción agrícola, han sido materia de preocupación mundial con mayor énfasis en los últimos tiempos; sin embargo existe poca producción sobre el tema. Por ello a continuación, se adelanta una revisión de algunos enfoques teóricos y de investigaciones de las estructuras agrícolas, el problema del hambre en el mundo y la cuestión alimentaria, realizados por organismos internacionales.

El interés por la seguridad alimentaria se puede remontar a finales del siglo XVIII con el estudio de la población, "Malthus (1798, citado por Teodoro Ortiz; Kingsley Davis, 1951). "La población tiende a crecer en progresión geométrica, mientras que los alimentos sólo aumentan en progresión aritmética, por lo que llegará un día en que la población será mayor que los medios de subsistencia, de no emplear medios preventivos y represivos". La ley de Malthus predecía por tanto la ocurrencia en el futuro de un fenómeno llamado catástrofe malthusiana en el que los recursos alimentarios serían claramente insostenibles para mantener a la población mundial y sobrevendrían graves guerras y hambrunas que diezmarían a la humanidad.

\footnotetext{
${ }^{2}$ La Organización de las Naciones Unidas para la Agricultura y la Alimentación [FAO], Informe Estado de Inseguridad Alimentaria. 2008.
} 
Contrario al enfoque anterior, hubo quienes consideran que Malthus no acertó. Cole, G.D.H (1986), encontró lo siguiente: "La inmediata experiencia inglesa registrada durante el siglo XIX demostró que, al menos en su país, Malthus se equivocaba. A pesar de que Gran Bretaña aumentó considerablemente su población durante el siglo pasado, el gran incremento de las áreas cultivadas como el correlativo crecimiento de la productividad agrícola -consecuencia del mejoramiento de las técnicas agrícolas permitieron superar los problemas de subsistencia"(p.184 y ss).

En tiempos más cercanos, los organismos internacionales preocupados por los problemas del hambre y su relación con la agricultura, se ponen por primera vez sobre la mesa en la Declaración Universal de los Derechos Humanos de 1948, en la que se reconoció el derecho a los alimentos como un elemento fundamental de un nivel de vida adecuado, se da origen al concepto de seguridad alimentaria (Naciones Unidas, 1948).

Más adelante la problemática de la producción de alimentos y el hambre de la población mundial, empezaría a ser vista de manera interrelacionada. Es así como en la década del 50 en los aportes realizados por Davis y Golberg (principales representantes de la Universidad de Harvard en los Estados Unidos en el problema agroalimentario) ${ }^{3}$, los convirtió en precursores de la aplicación de las teorías de la organización industrial a la cadena agroalimentaria a través de un enfoque que se convino en denominar "análisis de subsector"4.

Los referidos autores estudiaron el "Agribusiness Commodity System", entendiendo por este término a todos los participantes involucrados en la producción, transformación y comercialización de un producto agrícola en particular. Para ellos, en términos concretos, el Agribusiness ${ }^{5}$ (que podría entenderse como agronegocio o complejo agrícola en el idioma español) o «cadena agroindustrial» comprende la producción de insumos (material genético, semillas, maquinaria, fertilizantes, pesticidas, etc.), la finca que consume tales insumos en la producción de cosechas o animales, la industria que transforma esos productos y, la distribución de los mismos. Además, el "Agribusiness" comprende todas las instituciones que intervienen y coordinan las etapas que siguen los productos hasta llegar al mercado (Golberg, 1968).

El planteamiento teórico de "la organización industrial", se puede afirmar que correspondió a Marion, Schrader y Ward (1986) al tomar como unidad de análisis el conjunto de la cadena agroalimentaria (desde la producción agrícola hasta el consumidor y sus respectivas interrelaciones), integrar a la misma las variables y los esquemas conceptuales relativos a la teoría de la organización industrial. Tal paradigma coloca su mayor énfasis en el funcionamiento de los mercados agroalimentarios, y otorga a los mecanismos de integración vertical, un papel preponderante para el funcionamiento de

3 Tales investigadores se nuclearon en uno de los más importantes grupos de trabajo sobre economía agroalimentaria en los Estados Unidos. Este grupo se fundó con el nombre de MC-117 y se propuso como objetivo aplicar las teorías de la Organización Industrial al Sistema Agroalimentario Estadounidense.

4 Tal análisis concentra su mayor atención en: a) los flujos de información que discurren en sentido vertical entre los distintos agentes ubicados en la cadena; b) en la permanente adaptación a las transformaciones estructurales; y c) en las repercusiones sobre el funcionamiento de los mercados.

${ }^{5}$ El Programa de Investigación acerca del tema del «agribusiness», principal aporte de esta escuela, fue creado en 1952. 
éstos en razón de que tal integración garantizaría un eficaz flujo de información entre los agentes ubicados en la cadena y evitaría las imperfecciones del mercado.

Los investigadores citados ratifican el hecho, ya observado por otros autores, de que las actividades agrarias (dentro del «agribusiness») asumen cada vez más un carácter residual en razón del incesante proceso de transferencia de funciones hacia el "exterior" del sector agrícola y, además, verificaron el hecho de que los productos agrarios se destinaban cada vez más a la agroindustria antes que al consumo directo.

Desde el punto de vista estrictamente empresarial (Golbergy Davis, 1957), una cabal comprensión del flujo de bienes intermedios y finales dentro de una cadena de productores agrícolas, acopiadores, transportistas, industrias procesadoras y comerciantes mayoristas y minoristas, así como la identificación de los agentes económicos que participan en cada una de las etapas de la cadena, constituía un aspecto imprescindible y determinante para que las empresas que estaban operando dentro de esa cadena pudieran tomar sus decisiones.

Las observaciones anteriormente referidas y otras más, les permitió asegurar que cualquier análisis relativo al sector agrícola no podía perder de vista esas constataciones $\mathrm{y}$, en consecuencia, el referido sector no podía ser tratado como si estuviera aislado del conjunto de la economía.

El investigador de Montpellier Francia, Malassis (1973), consideró que en las sociedades industrializadas el «Sistema Agroalimentario» comprende cuatro subsectores, a saber: el correspondiente a las empresas que abastecen a la agricultura de los respectivos servicios y medios de producción; el subsector agropecuario; el subsector de las industrias agrícolas de transformación y el subsector de la distribución de alimentos.

A sí mismo, se refiere a que la producción agroalimentaria, el sector agrícola cumple un papel esencial como productor de materias primas y constituye la base sobre la cual se conforma un aparato industrial y comercial encargado de transformar los productos agrícolas y de distribuir tanto las materias primas como los bienes finales agroalimentarios. A este respecto se puede adelantar que en la actualidad el funcionamiento del sector agroalimentario se sustenta sobre la preeminencia de los productos finales y de su correspondiente distribución y consumo. Considera que el "subconjunto agroalimentario" constituye parte de una formación económica y social determinada.

Posteriormente en 1974 en la Conferencia Mundial de la Alimentación, la primera definición de Seguridad Alimentaria se refiere a "la disponibilidad en todo momento de suficientes suministros mundiales de alimentos básicos" y el concepto evoluciona a seguridad alimentaria nacional SAN, centrada en la disponibilidad de suministros alimentarios suficientes a escala de un país.[4]

Luego, desde principios de los años 80, el concepto viene marcado por la seguridad alimentaria familiar SAF, centrada en el acceso a los alimentos por parte de las familias pobres, (Sen, 1981). "Las titularidades o derechos" al alimento constituyen las 
capacidades o recursos de una familia o individuo para acceder al mismo de forma legal, produciéndolo, comprándolo o percibiéndolo como donación del Estado o la comunidad. Vienen determinadas, por tanto, por el nivel de propiedades poseídas, las relaciones de intercambio en el mercado (niveles de precios y salarios, lo que se pueda comprar en función de lo que se posee) y el nivel de protección social existente. Concepto que es retomado por el Banco Mundial (1986:1) en su informe La Pobreza y el Hambre.

La Organización de las Naciones Unidas para la Agricultura y la Alimentación-FAO, El Programa Especial para la Seguridad Alimentaria, también se refiere a la seguridad alimentaria como: "la posibilidad potencial de las personas de adquirir una canasta suficiente de alimentos inocuos y de calidad para el consumo, mediante el uso de diferentes canales legales de acceso como el mercado y el autoconsumo, entre otros". Al respecto la (FAO, 1999), señala que un tercio de la humanidad principalmente proveniente de los países no desarrollados, pero también en bolsones de pobreza de muchos países con desarrollo alto, está bajo el índice de lo que se denomina "seguridad alimentaria".

En esta perspectiva, el Instituto Interamericano de Cooperación para la Agricultura, IICA $(2006)^{6}$. Señala que una persona está en una situación potencial de hambre o malnutrición por cualquiera de las siguientes causas: 1) Escasez de oferta de alimentos que componen la canasta básica, 2) Pérdida o disminución de las dotaciones de los hogares y de las personas como ingresos y/o de activos físicos y humanos, 3) Pérdida del poder adquisitivo ocasionado, entre otros factores, por alza en los precios de los alimentos, caída en los salarios y 4) Disminución de los precios de los bienes que producen las personas para su subsistencia que son determinados por el grado de vulnerabilidad socioeconómica.

\subsection{Autores que han contribuido con el desarrollo del problema.}

Las investigaciones sobre política agropecuaria y seguridad alimentaria han sido del interés de instituciones y teóricos de la economía en los últimos años, desde un enfoque u otro, lo que ha prevalecido es el interés por que los estados apropien los instrumentos de los que disponen para movilizar los agentes sociales y económicos para que las políticas públicas sean acertadas y efectivas.

\footnotetext{
${ }^{6}$ IICA (2006) Políticas agropecuarias, estrategias de desarrollo rural, seguridad alimentaria, pobreza rural y servicios de extensión agrícola - Instituto Interamericano de Cooperación para la Agricultura.
} 
Tabla No 1.2 Diversas Contribuciones Teóricas Recientes.

\begin{tabular}{|c|c|}
\hline Autor & Caracterización de la problemática \\
\hline $\begin{array}{l}\text { Barkin D, } \\
\text { y Suárez } \\
\text { B (1982), }\end{array}$ & $\begin{array}{l}\text { Sostiene que "las agriculturas nacionales tienden a estar determinadas no por factores } \\
\text { nacionales, sino por el patrón internacional de homogeneización de la producción y } \\
\text { consumo que restringe la autonomía de los Estados nacionales para impulsar y proteger } \\
\text { a las agriculturas domésticas; generándose en consecuencia un declive de la } \\
\text { autosuficiencia alimentaria". Encontraron que ello se traduce en un proceso de } \\
\text { homogeneización de los patrones de producción y consumo generando una nueva } \\
\text { división internacional del trabajo que transforma a los países del sur en importadores de } \\
\text { alimentos básicos. }\end{array}$ \\
\hline $\begin{array}{l}\text { Arroyo et } \\
\text { al., } \\
\text { (1985), }\end{array}$ & $\begin{array}{l}\text { Al estudiar la seguridad alimentaria de América Latina y el Caribe (ALC), en primer } \\
\text { lugar, señalan que en la mayoría de los países de ALC, la dependencia externa del sector } \\
\text { alimentario se detecta una tendencia a la disminución del superávit de la balanza } \\
\text { comercial agroalimentaria en muchos países. Señala, igualmente, que los países andinos } \\
\text { se han convertido en importadores netos de alimentos de consumo masivo y que se da } \\
\text { una situación de elevada dependencia cerealera en Brasil, México y Centroamérica. }\end{array}$ \\
\hline $\begin{array}{l}\text { Sen } \\
(19\end{array}$ & $\begin{array}{l}\text { En breve, argumenta que "la capacidad de una persona para obtener suficientes } \\
\text { alimentos guarda relación directa con el conjunto de derechos de ésta persona respecto a } \\
\text { los medios que hacen posible obtener alimentos vía producción propia o comprada en el } \\
\text { mercado (acceso a medios de producción, comercio, trabajo asalariado u otra)." Desde } \\
\text { esta perspectiva, el acceso a la tierra y el tipo de acceso (renta o propiedad por ejemplo) } \\
\text { es fundamental ya que incide directamente en la capacidad de las personas en obtener } \\
\text { alimentos. }\end{array}$ \\
\hline & $\begin{array}{l}\text { Plantean que "La capacidad de la región se ha visto comprometida produciéndose un } \\
\text { declive en la autosuficiencia alimentaria, que transformaría a los países latinoamericanos } \\
\text { en importadores netos de alimentos básicos. La existencia de un proceso de } \\
\text { relocalización industrial entre el norte y el sur que impulsa el desarrollo agroindustrial en } \\
\text { el sur bajo la égida de las Empresa Transnacionales (ETN)". }\end{array}$ \\
\hline $\begin{array}{l}\operatorname{Max} \\
(199\end{array}$ & $\begin{array}{l}\text { Señala, "la seguridad alimentaria se logrará cuando los pobres y vulnerables, en } \\
\text { particular las mujeres y los niños y niñas y las personas que viven en las áreas } \\
\text { marginales, tengan acceso seguro a la comida que quieran". Esto es, para algunos } \\
\text { autores, el umbral que determina la Seguridad Alimentaria Familiar - SAF, no sería } \\
\text { tanto un nivel científicamente prefijado de ingresos o de calorías consumidas, sino más } \\
\text { bien el nivel o calidad de alimentación que las personas perciban como suficiente. Esto } \\
\text { plantea el difícil reto de establecer nuevos indicadores que reflejen las percepciones de } \\
\text { las personas (p. 22). }\end{array}$ \\
\hline $\begin{array}{l}\text { Alamgir } \\
\text { y Arora, } \\
(1991: 7- \\
8),\end{array}$ & $\begin{array}{l}\text { El objetivo de las políticas de seguridad alimentaria debe consistir en garantizar un } \\
\text { abastecimiento de alimentos per cápita suficiente y regular en el tiempo, a través de: a) } \\
\text { el incremento de la producción agrícola nacional, que algunos propugnaron que debía } \\
\text { perseguir una autosuficiencia alimentaria nacional, y que dio lugar a procesos como la } \\
\text { revolución verde; b) la importación de alimentos, creando las infraestructuras portuarias } \\
\text { y las reservas de divisas necesarias para ello; c) la creación de reservas alimentarias que } \\
\text { permitan cubrir escaseces temporales hasta que lleguen la cosecha, las importaciones o } \\
\text { la ayuda internacional }\end{array}$ \\
\hline $\begin{array}{l}\text { Maxwell } \\
\text { y Smith } \\
(1992: 8),\end{array}$ & $\begin{array}{l}\text { Encontraron que tanto esa definición como las otras muchas existentes sobre la } \\
\text { Seguridad Alimentaria Familiar - SAF, coinciden en que la característica clave de la } \\
\text { SAF es el acceso seguro en todo momento a una comida suficiente. Por tanto, podemos } \\
\text { decir que la SAF se asienta implícitamente sobre cuatro conceptos básicos: La } \\
\text { suficiencia de comida, el acceso al alimento, la seguridad y el tiempo. }\end{array}$ \\
\hline
\end{tabular}




\begin{tabular}{|c|c|}
\hline Autor & Caracterización de la problemática \\
\hline $\begin{array}{l}\text { Thomson } \\
\text { A, Metz } \\
\text { M. } \\
\text { (1999), }\end{array}$ & $\begin{array}{l}\text { Los conceptos de autosuficiencia alimentaria y seguridad alimentaria se diferencian en } \\
\text { dos cuestiones fundamentales: Para la autosuficiencia alimentaria, la producción } \\
\text { nacional es la única fuente de suministro, mientras que para la seguridad alimentaria, las } \\
\text { importaciones comerciales y la ayuda alimentaria constituyen posibles fuentes de } \\
\text { suministro de productos básicos, e introduce elementos de estabilidad de los suministros } \\
\text { y acceso a los alimentos por la población. Los teóricos de la economía han sostenido } \\
\text { discusiones encarnizadas sobre este asunto, pero, desde un punto de vista pragmático, } \\
\text { gran parte depende de la situación específica del país. Nadie sugeriría que Singapur u } \\
\text { Hong Kong deben fijarse como objetivo prioritario el logro de la autosuficiencia } \\
\text { alimentaria. Por otro lado, el Banco Mundial, entre otras organizaciones, ha reconocido } \\
\text { que la India ha logrado reducir notablemente la inseguridad alimentaria mediante el } \\
\text { fomento de la producción interna de alimentos. }\end{array}$ \\
\hline $\begin{array}{l}\text { Machado. } \\
\text { (2002), }\end{array}$ & $\begin{array}{l}\text { En su libro "De la estructura agraria al sistema agroindustrial" Las políticas agrícolas en } \\
\text { el mundo se pueden clasificar en cinco grandes grupos: el primero corresponde a los } \\
\text { países que no tienen una política agrícola, según su propia opinión, como Argentina, } \\
\text { Australia y Nueva Zelanda. Estas naciones pertenecen al Grupo Cairns, en el que } \\
\text { prevalece la política macroeconómica y no se aboga por políticas sectoriales. El segundo } \\
\text { grupo lo componen Estados Unidos y la Unión Europea, con políticas a largo plazo para } \\
\text { la agricultura, proteccionismo e importantes ayudas para este sector. El tercer grupo lo } \\
\text { constituyen países que tienen leyes con orientación hacia la agricultura, como Francia. } \\
\text { El cuarto grupo lo conforman países con leyes rectoras para la agricultura como Japón y } \\
\text { Corea, que no reglamentan aspectos específicos pero le dan un norte a la política. El } \\
\text { quinto grupo está conformado por países en vía de desarrollo, donde se hacen intentos de } \\
\text { aplicar políticas agrícolas de corte coyuntural, buscando una política activa que tiene } \\
\text { grandes contradicciones con las políticas macroeconómicas. Son países donde no se ha } \\
\text { podido llegar aún a una visión a largo plazo del Estado sobre la agricultura, como } \\
\text { Colombia, los países del Grupo Andino, de Centroamérica y de África. }\end{array}$ \\
\hline $\begin{array}{l}\text { Díaz } \\
\text { Bonilla, } \\
\text { E., L. } \\
\text { Reca, } \\
\text { Carlos } \\
\text { Espinal y } \\
\text { V. } \\
\text { Piñeiro } \\
\text { (2003), }\end{array}$ & $\begin{array}{l}\text { Un estudio patrocinado por el Instituto Interamericano de Cooperación para la } \\
\text { Agricultura - IICA orientado a evaluar los efectos de la apertura comercial sobre el } \\
\text { sector agropecuario de los países de América Latina y el Caribe (ALC), revela que la } \\
\text { reforma mencionada impulsó una mayor integración del sector agropecuario en el } \\
\text { entorno internacional, lo cual se tradujo en un incremento de los coeficientes de } \\
\text { importación y exportación. En consecuencia, se produjo un aumento de las } \\
\text { importaciones de origen agropecuario, debido no sólo a la apertura sino también a otros } \\
\text { factores como precios internacionales más bajos, una mayor apreciación de los tipos de } \\
\text { cambio y la reasunción del crecimiento económico en la primera mitad de los años } 90 \text {. } \\
\text { Pero al mismo tiempo se produjo un mayor crecimiento de las exportaciones de origen } \\
\text { agropecuario. }\end{array}$ \\
\hline $\begin{array}{l}\text { (Díaz } \\
\text { Bonilla et } \\
\text { al., 2003), }\end{array}$ & $\begin{array}{l}\text { Al evaluar los efectos de la apertura comercial en la situación de autosuficiencia o dependencia } \\
\text { externa de productos básicos como los cereales, encontramos que Argentina y Brasil mantienen } \\
\text { una dependencia de nivel bajo y moderado como en el período previo a la apertura. En cambio, } \\
\text { México y Colombia incrementan su dependencia para sumarse a los países que ya en el período } \\
\text { pasado presentaban un nivel crítico de dependencia. En ese sentido la situación posterior a la } \\
\text { apertura se caracteriza por la existencia de dos grupos de países por un lado los grandes } \\
\text { agroexportadores como Brasil y Argentina con elevadas ventajas comparativas en la } \\
\text { producción de materias primas agrícolas, en los cuales se observa una baja o moderada } \\
\text { dependencia externa que en el caso argentino es prácticamente nula. Otro grupo de países, } \\
\text { como Chile, Colombia, México y Venezuela, presentan una dependencia externa que se ubica } \\
\text { en niveles críticos, lo que revela la carencia de ventajas comparativas en la producción de este } \\
\text { tipo de rubros. }\end{array}$ \\
\hline
\end{tabular}




\begin{tabular}{|c|c|}
\hline Autor & Caracterización de la problemática \\
\hline $\begin{array}{l}\text { Rubio } \\
\text { (2004), }\end{array}$ & $\begin{array}{l}\text { Analiza el impacto de la globalización en el campo mexicano desarrollando una } \\
\text { argumentación que en términos generales se identifica con las tesis de los autores } \\
\text { mencionados. Concluye que la apertura comercial desarrollada en el contexto del } \\
\text { Tratado de Libre Comercio (TLC) ha profundizado la presencia de las Empresas } \\
\text { Transnacionales (ETN) en los principales cultivos, impulsando el proceso de } \\
\text { sustitución de la producción nacional por la importación, lo cual ha generado una } \\
\text { presión de los precios a la baja y pérdida de mercados para los productores agrícolas. } \\
\text { Ello ha derivado en una situación de crisis permanente del campo mexicano. }\end{array}$ \\
\hline $\begin{array}{l}\text { Echeverri } \\
\text { R. (IICA), } \\
2005 \\
\text { "Enfoques } \\
\text { del } \\
\text { Desarrollo } \\
\text { Rural" }\end{array}$ & $\begin{array}{l}\text { Por tal razón, en una estrategia para el fortalecimiento de la política agropecuaria con } \\
\text { miras a garantizar la seguridad alimentaria debe quedar claro que, hay que actuar a } \\
\text { nivel de las políticas macroeconómicas y que también se necesita tener políticas } \\
\text { específicas para apoyar la producción de alimentos, que deben basarse en diagnósticos } \\
\text { concretos en las regiones, las actividades a que se dedican y las estrategias de } \\
\text { subsistencia que emplean. }\end{array}$ \\
\hline $\begin{array}{l}\text { Machado } \\
\text { (2004, } \\
2008)\end{array}$ & $\begin{array}{l}\text { Expone un listado de problemas por resolver, entre los cuales se encuentran el alto grado } \\
\text { de concentración de la propiedad y la fragmentación antieconómica, el uso ineficiente de } \\
\text { suelos, altos índices de pobreza rural, institucionalidad rural inconsistente, destrucción } \\
\text { de los recursos naturales y escasa participación de los pobladores rurales en los sistemas } \\
\text { de decisión. }\end{array}$ \\
\hline $\begin{array}{l}\text { IICA } \\
(2006) \\
\text { Políticas } \\
\text { agropecu } \\
\text { arias, } \\
\text { estrategia } \\
\text { s de } \\
\text { desarrollo } \\
\text { rural, } \\
\text { seguridad } \\
\text { alimentar } \\
\text { ia, pobreza } \\
\text { pobra y } \\
\text { rural servicios } \\
\text { de } \\
\text { extensión } \\
\text { agrícola. }\end{array}$ & $\begin{array}{l}\text { La política Agropecuaria hace parte del desarrollo rural, visión planteada por el Estado, } \\
\text { en representación de la sociedad. Sin embargo, en una sociedad que opera bajo un } \\
\text { sistema democrático con economía de mercado, como en la mayoría de nuestros países, } \\
\text { la tarea de alcanzar esa visión, no es competencia directa del Estado, que tiene más bien } \\
\text { el papel de influir en las voluntades de los actores sociales para que, a través de estos, se } \\
\text { avance en el camino hacia esa sociedad deseada. } \\
\text { Además, son estos últimos los que cuentan con las capacidades para alcanzarla, } \\
\text { situación que se ejemplifica en los niveles de inversión pública agrícola de nuestros } \\
\text { países, ya que aún en países de altísima inversión pública en el sector agropecuario, } \\
\text { como es el caso de México, ésta equivale únicamente a un } 12 \% \text { de la inversión total, y } \\
\text { en Colombia a menos de un } 1 \% \text {; el resto es aportado por el sector privado: los agentes } \\
\text { económicos de la agricultura, sean ricos o pobres, ya sea en tierra, trabajo, crédito, etc. }\end{array}$ \\
\hline $\begin{array}{l}\text { (Banco } \\
\text { Mundial } \\
\text { WDR } \\
\text { 2008), }\end{array}$ & $\begin{array}{l}\text { El abandono a la agricultura mediana y pequeña ha sido progresivo. La reducción de } \\
\text { inversión pública en agricultura en los países en desarrollo ha sido imparable en los } \\
\text { últimos } 30 \text { años, la inversión pública en agricultura en los países, cuya economía se } \\
\text { basan fundamentalmente en ese sector, no alcanza el } 4 \% \text { del total del gasto. Esta cifra se } \\
\text { aleja mucho del } 10 \% \text { que invertían en promedio en } 1980 \text { aquellos países que, } \\
\text { comparativamente, lograron mejores niveles de desarrollo La consecuencia inmediata de } \\
\text { tal abandono es el dramático incremento de la dependencia de los países en desarrollo de } \\
\text { los mercados internacionales alimentarios y, por lo tanto, de su mayor vulnerabilidad a la } \\
\text { fluctuación de los precios internacionales. } \\
\text { De esta manera, en los últimos } 30 \text { años, los } 49 \text { países más empobrecidos del mundo } \\
\text { pasaron de ser exportadores a importadores netos de alimentos (IEH, 2008). }\end{array}$ \\
\hline
\end{tabular}




\begin{tabular}{|c|c|}
\hline Autor & Caracterización de la problemática \\
\hline $\begin{array}{l}\text { Fajardo } \\
\text { (2009), }\end{array}$ & $\begin{array}{l}\text { Los problemas las medidas de apertura comercial, que han contribuido a la disminución } \\
\text { de la producción, la debilidad de la investigación y transferencia de tecnologías y la } \\
\text { adquisición de tierras con fines ilícitos. } \\
\text { La experiencia andina de integración, en el Acuerdo de Cartagena se consagra } \\
\text { exclusivamente a programas para impulsar el desarrollo agropecuario y agroindustrial } \\
\text { conjunto y alcanzar un mayor grado de seguridad alimentaria subregional. Ellos hacen } \\
\text { referencia de manera explícita a la implementación de programas comunes y acciones } \\
\text { conjuntas en ámbitos tales, como sanidad, desarrollo tecnológico y conservación de } \\
\text { recursos naturales. Pero, la consecución de estos propósitos debería ser logrado por } \\
\text { intermedio de las agencias nacionales existentes. Luego, el acuerdo constitutivo no se } \\
\text { propuso a constituir una política agropecuaria común propiamente. A lo largo del } \\
\text { proceso, los productos agrícolas se fueron incorporando al programa de liberalización } \\
\text { comercial y al arancel externo mínimo común, si bien con plazos más largos, destinados } \\
\text { a reducir los costos de ajuste frente a la competencia externa. }\end{array}$ \\
\hline $\begin{array}{l}\text { Medina J, } \\
\text { (2011). }\end{array}$ & $\begin{array}{l}\text { Entre los factores que explican el abandono del sector agrícola muchos tratados de comercio } \\
\text { han sido perniciosos para el sector agropecuario. Se ha generado competencia entre las } \\
\text { cosechas para producir alimentos y combustible; Además se está produciendo el acaparamiento } \\
\text { de tierras en países en desarrollo por parte de grandes inversores, unas } 30 \text { multinacionales } \\
\text { controlan la producción y el comercio agrícola internacional. } \\
\text { Las políticas agropecuarias no deberían fundamentarse exclusivamente en parámetros de } \\
\text { productividad, sino incorporar el enfoque de soberanía alimentaria y de respeto del medio } \\
\text { ambiente que permita a los pueblos ejercer su derecho a definir sus propias estrategias } \\
\text { sostenibles de producción, distribución y consumo de alimentos y fomente el carácter } \\
\text { multifuncional de la agricultura. }\end{array}$ \\
\hline
\end{tabular}

Fuente: Elaboración Propia

Después de revisar diversos enfoques teóricos e investigaciones realizadas a nivel mundial y nacional; Comienzo retomando la tesis de Machado C. Absalón. (2002), en su libro "De la estructura agraria al sistema agroindustrial", donde expresa que - Colombia pertenece a un grupo de países en vía de desarrollo donde se hacen intentos de aplicar políticas agrícolas de corte coyuntural, buscando una política activa que tiene grandes contradicciones con las políticas macroeconómicas. Son países donde no se ha podido llegar aún a una visión a largo plazo del Estado sobre la agricultura, como Colombia, los países del Grupo Andino, de Centroamérica y de África-.

Continúo anudando la tesis de Echeverri P. Rafael. (IICA), 2005 "Enfoques del Desarrollo Rural" donde señala que, en una estrategia para el fortalecimiento de la política agropecuaria con miras a garantizar la seguridad alimentaria debe quedar claro que, hay que actuar a nivel de las políticas macroeconómicas y que también se necesita tener políticas específicas para apoyar la producción de alimentos, que deben basarse en diagnósticos concretos en las regiones, las actividades a que se dedican y las estrategias de subsistencia que emplean. En ese sentido a pesar de que las políticas macroeconómicas inciden de manera significativa en los precios de los alimentos, en los términos de intercambio rural-urbano y en el poder de compra; si la políticas macroeconómicas impactan negativamente a los sistemas agroalimentarios, las políticas agroalimentarias, por más adecuadas que sean, no lograrán corregir los efectos negativos de las políticas macroeconómicas. 
Lo anterior implica que el Estado, en la formulación de las políticas públicas, debe tratar de lograr efectos directos en las decisiones de comportamiento de los agentes sociales y agentes económicos, recurriendo para esto a los distintos instrumentos con que cuenta, cómo el liderazgo político, la potestad de regular, la capacidad de crear instituciones, la capacidad de hacer inversiones en bienes públicos, e inclusive intervenir en la economía.

Finalizo considerando que "La agricultura y por consiguiente la producción de alimentos, significa al interior de las familias rurales un camino para salir de la pobreza, en realidad, muchas veces el único de que disponen, es la fuente principal de ingresos y derechos, que da la posibilidad de alcanzar una alimentación adecuada y sostenible." Por ello, Colombia necesita con urgencia una Política agropecuaria con visión de desarrollo Rural y en particular que responda a la seguridad alimentaria tanto de pobladores rurales como urbanos. 


\section{Capítulo 2. Análisis de las Política Agropecuaria y de Seguridad Alimentaria en Colombia.}

\subsection{Comparativo entre las Políticas de Países Latinoamericanos.}

Según el banco mundial, para el $70 \%$ de los pobres del mundo que viven en zonas rurales, la agricultura es la principal fuente de ingresos y de trabajo. Pero el agotamiento y la degradación de la tierra y del agua afectan gravemente la capacidad de cultivar alimentos y otros productos necesarios para sustentar los medios de vida en estas zonas y satisfacer las necesidades de la población urbana. Los datos presentados contienen medidas de los insumos, productos y productividad agrícola compiladas por la Organización de las Naciones Unidas para la Agricultura y la Alimentación (FAO).

Tabla No. 1.1 La Política Agropecuaria en algunos Países Latinoamericanos 2002 al 2010

\begin{tabular}{|c|c|c|c|c|}
\hline B & na & Chile & bia & ico \\
\hline $\begin{array}{l}\text { BI } \\
\text { en el } \\
\text { en } \\
\% \text { ) para } \\
\text { ctividad } \\
\text { pales } \\
\text { esde } \\
53 \% \text {. }\end{array}$ & $\begin{array}{l}\text { opecuar } \\
\text { t el PBI } \\
\text { onal en } \\
\text { entina } \\
(11 \%) \\
\text { el año }\end{array}$ & $\begin{array}{l}\text { Chile } \\
\text { s } \\
\text { ia }\end{array}$ & año & $\begin{array}{l}\text { cimien } \\
\text { anual } \\
\text { PIB } \\
\text { ila } \\
\text { re } 0 \text { y } \\
\text {. }\end{array}$ \\
\hline $\begin{array}{l}\text { - Las políticas } \\
\text { agrícolas y agrarias } \\
\text { que contemplan las } \\
\text { reivindicaciones de } \\
\text { los agricultores } \\
\text { familiares por crédito } \\
\text { y acceso a la tierra. } \\
\text { - En los años } \\
90 \text { se profundizo en } \\
\text { proceso de apertura } \\
\text { comercial, fue un } \\
\text { proceso gradual. } \\
\text { - En 1996 los } \\
\text { subsidios al sector } \\
\text { cayeron a la quinta } \\
\text { parte de lo que eran } \\
\text { en 1986 (Pereira, } \\
\text { 2003), y el sector } \\
\text { creció de manera } \\
\text { importante. } \\
\text { - La noción } \\
\text { de agricultura } \\
\text { familiar se afirmó en } \\
\text { Brasil como una } \\
\text { categoría política en } \\
\text { oposición a otras } \\
\text { nociones igualmente } \\
\text { poderosas, como la } \\
\text { de agro negocio. }\end{array}$ & $\begin{array}{l}\text { - Fue al } \\
\text { inicio de } \\
\text { los años } \\
2000 \quad \\
\text { cuando } \\
\text { comenzó a } \\
\text { generalizar } \\
\text { se el } \\
\text { término: } \\
\text { agricultura } \\
\text { familiar. } \\
\text { - La } \\
\text { agricultura } \\
\text { familiar, } \\
\text { está } \\
\text { adquiriend } \\
\text { o un uso } \\
\text { amplio y } \\
\text { difundido, } \\
\text { adoptado } \\
\text { desde el } \\
\text { ámbito de } \\
\text { las políticas } \\
\text { públicas y } \\
\text { desde } \\
\text { muchas de } \\
\text { las } \\
\text { organizacio } \\
\end{array}$ & 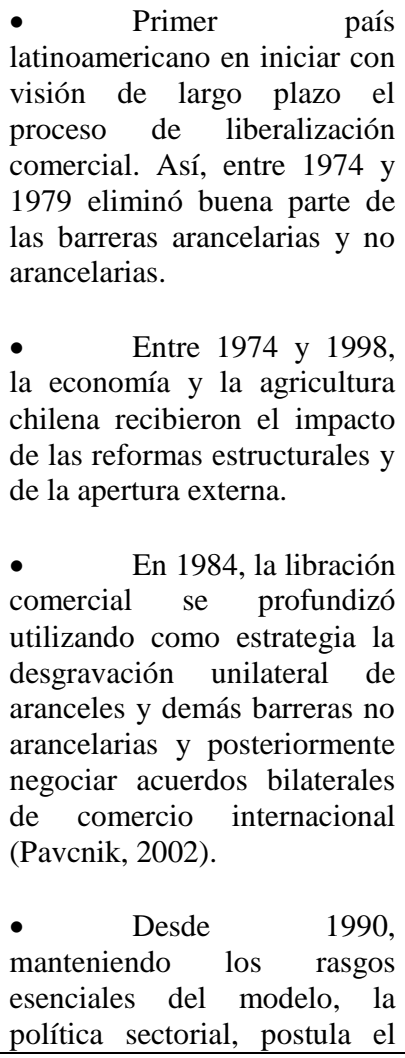 & 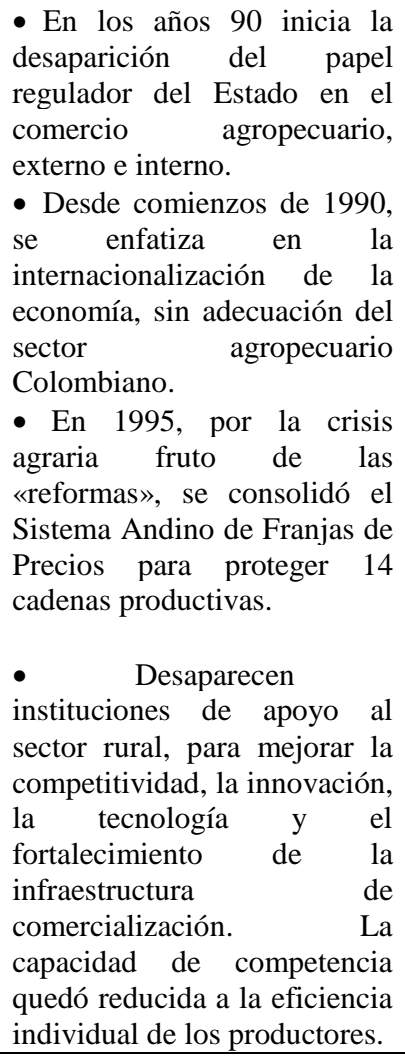 & $\begin{array}{l}\text { • E } \\
\text { n los años } \\
80, \quad \text { se } \\
\text { inicia la } \\
\text { apertura } \\
\text { comercial } \\
\text { se cuando } \\
\text { incorporó } \\
\text { de manera } \\
\text { unilateral } \\
\text { al GATT. } \\
\text { - } \\
\text { n 1993 } \\
\text { entró en } \\
\text { vigor el } \\
\text { NAFTA, } \\
\text { el tratado } \\
\text { de libre } \\
\text { comercio } \\
\text { de } \\
\text { México } \\
\text { con los } \\
\text { Estados } \\
\text { Unidos y } \\
\text { Canadá. }\end{array}$ \\
\hline
\end{tabular}




\begin{tabular}{|c|c|c|c|c|}
\hline 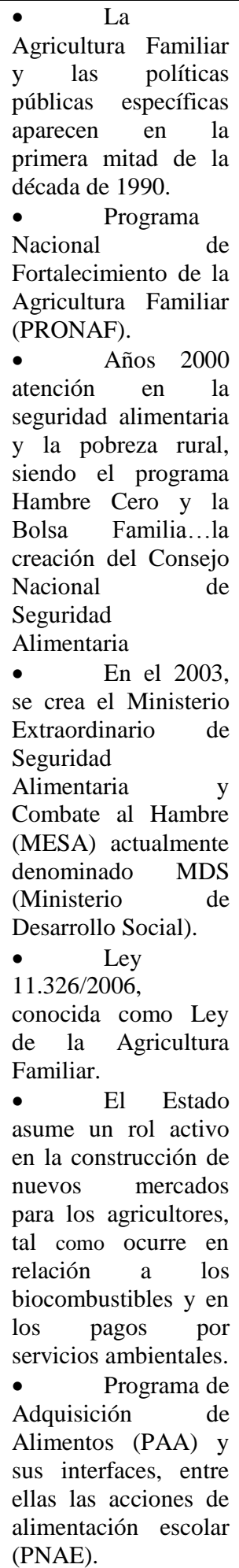 & $\begin{array}{l}\text { nes } \\
\text { representati } \\
\text { vas de este } \\
\text { sector } \\
\text { social. } \\
\text { - Como } \\
\text { señala } \\
\text { Soverna et } \\
\text { al (2009: 1) } \\
\text { "la } \\
\text { instalación } \\
\text { de la } \\
\text { problemáti } \\
\text { ca de la } \\
\text { agricultura } \\
\text { familiar } \\
\text { (AF) en el } \\
\text { país llega } \\
\text { de la mano } \\
\text { del } \\
\text { MERCOS } \\
\text { UR"; más } \\
\text { precisamen } \\
\text { te por por } \\
\text { influencia } \\
\text { de Brasil } \\
\text { (Manzanal } \\
\text { y anzé } \\
\text { González, } \\
\text { 2010).29 }\end{array}$ & 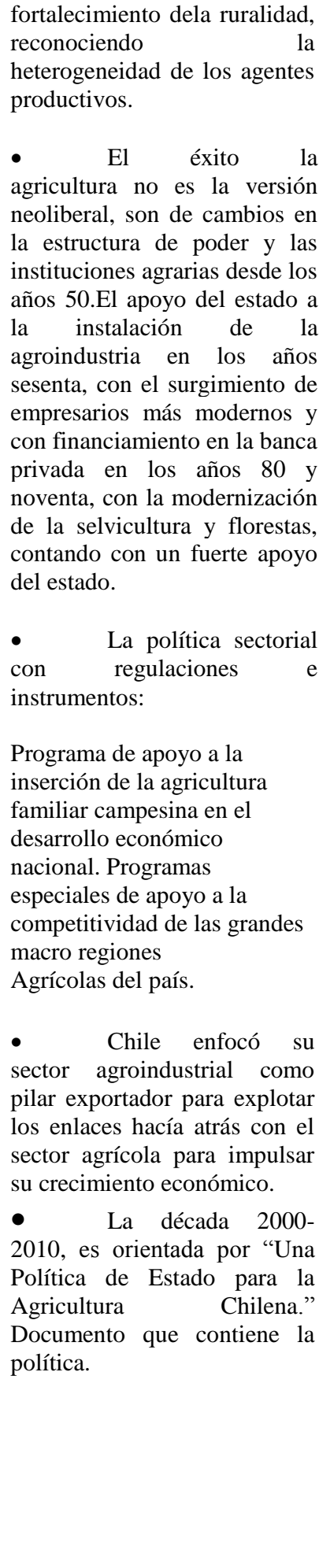 & 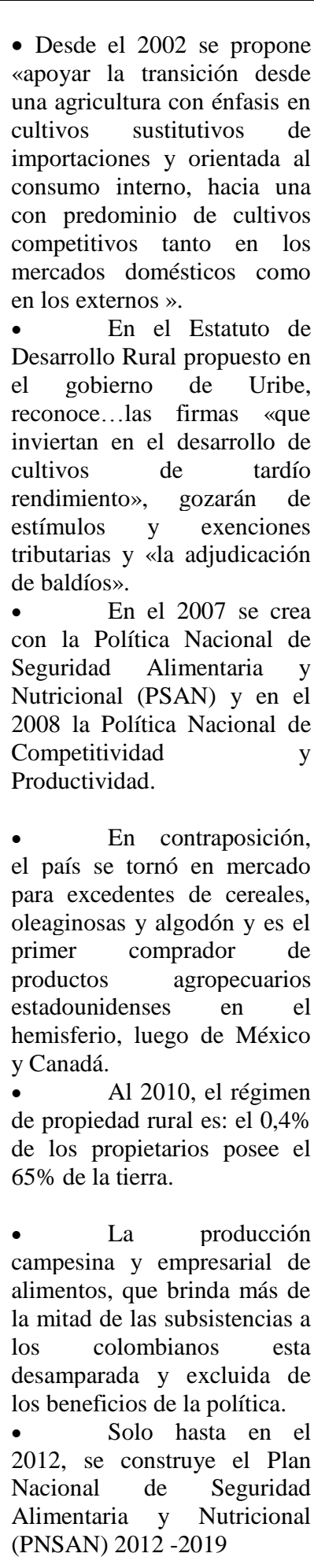 & $\begin{array}{l}\text { - } \\
1 \text { impacto } \\
\text { de corto } \\
\text { plazo de } \\
\text { este } \\
\text { acuerdo } \\
\text { comercial } \\
\text { fue } \\
\text { limitado } \\
\text { pues al } \\
\text { momento } \\
\text { de entrar } \\
\text { al GATT, } \\
\text { México } \\
\text { ya había } \\
\text { eliminado } \\
\text { buena } \\
\text { parte de } \\
\text { las } \\
\text { barreras } \\
\text { arancelari } \\
\text { as y para- } \\
\text { arancelari } \\
\text { as. }\end{array}$ \\
\hline
\end{tabular}

Fuente: Elaboración Propia. 
Del análisis comparativo se pueden mencionar los siguientes aspectos:

1. Es evidente que durante los periodos comprendidos entre el año 2002 al 2006 y el siguiente 2006 al 2010, no existió una política clara, independiente, expresa y escrita para el sector agropecuario. Por el contrario las acciones que se desarrollaron estaban contenidas dentro de otras políticas; prueba de ello fue la política de cohesión social, en la que se contemplaba herramientas como: la revolución educativa, la promoción y expansión de la seguridad social, el impulso de la economía solidaria, el manejo social de los recursos públicos, el manejo social del campo, la calidad de vida urbana y el país de propietarios.

2. En Colombia no se aprovecho el auge del mercado internacional, porque tampoco existió una política comercial del sector, ni consideración suficiente sobre el cómo y para que se debe intervenir en el sector agropecuario. En tal sentido, el desempeño económico y social del sector, mostro la carencia de una capacidad nacional fuerte para generar nuevas opciones que impacten en el bienestar del agro.

3. Es claro cómo otros países han integrado la dinámica del sector agropecuario fuertemente con el resto de la economía y con una política pública contundente, a largo plazo y con instrumentos que mejoran efectivamente la productividad, incluyendo tanto a empresarios, como campesinos y pobladores rurales.

4. Desde el punto de vista de la seguridad alimentaria, en Colombia, tal ausencia de política de desarrollo agropecuario, conllevo a que desde la perspectiva o dimensión de los medios económicos, la población no contara con una adecuada oferta del grupo de alimentos de la canasta básica; contrario al mandato de la Política Nacional de Seguridad Alimentaria y Nutricional en lo referente a la disponibilidad de alimentos.

5. El Estado representado por el Ministerio de Agricultura y Desarrollo Rural y sus entidades adscritas y vinculadas, no privilegiaron la producción del grupo de alimentos prioritarios para la seguridad alimentaria, particularmente, a través de la inclusión de estos productos, con condiciones especiales en los instrumentos sectoriales pertinentes en aumento de la productividad de los alimentos.

\subsection{Planes Nacionales de desarrollo}

En el programa de gobierno 2002-2006”, p.75, el candidato Álvaro Uribe Vélez, asegura "en el 2010 nuestra Patria tendrá cerca de 50 millones de habitantes con alta dependencia del campo para su seguridad alimentaria y empleo. El desafío es construir un sector rural competitivo, equitativo y sostenible".

Esta retrospectiva, comienza indicando que a diferencia de otros países, en Colombia, no existió una política pública agropecuaria que propendiera por el desarrollo económico y social de campo, durante los dos periodos de gobierno comprendidos entre el 2002 al 2010; Pese a ello, se mencionan algunas de las acciones realizadas; que por el contrario, trajeron como consecuencia el mal desempeño que el sector vive actualmente. 
El presidente Álvaro Uribe en su plan de desarrollo "Hacia un Estado Comunitario" (2002-2006), con el ministerio de agricultura en cabeza de su ministro Carlos Gustavo Cano Sanz, impulsaron una recomposición de las instituciones públicas agrarias. Desde el año 2002 propuso «apoyar la transición desde una agricultura con énfasis en cultivos sustitutivos de importaciones y orientada al consumo interno, hacia una con predominio de cultivos competitivos tanto en los mercados domésticos como en los externos» al igual que adoptar medidas para incrementar las inversiones en el campo, aumentar los ingresos de los agricultores y desarrollar sectores agropecuarios de clase mundial. Para ello el documento Conpes 3316 de 2004, relacionado con un préstamo del Banco Mundial para apoyar a la Transición de la Agricultura y el Medio Rural, reiteró la necesidad de «fortalecer las instituciones e instrumentos de política para responder a los retos y aprovechar las oportunidades que supone la integración comercial». [5].

Es así como este gobierno construyo la agenda Visión Colombia 2019 II centenario Aprovechar las potencialidades del campo, el Plan Nacional de Protección a la Producción Agropecuaria 2003-2006, diseñado e implantado por el Ministerio de Agricultura y Desarrollo Rural en conjunto con el Instituto Colombiano Agropecuario ICA. Parte estas acciones previstas por el Gobierno Nacional para "promover la productividad y competitividad, reducir la desigualdad en el campo y preparar al sector agropecuario para enfrentar el reto de la internacionalización de la economía", lo constituye el programa Agro Ingreso Seguro-AIS.

En abril del 2007, el Congreso de la República aprobó la Ley 1133 de 2007 mediante la cual se crea e implementa el programa "Agro, Ingreso Seguro-AIS". El Programa fue diseñado e implantado por el entonces ministro de Agricultura de Colombia, Andrés Felipe Arias bajo la presidencia de Álvaro Uribe, el cual estaba "destinado a proteger los ingresos de los productores que resulten afectados, ante las distorsiones derivadas de los mercados externos y a mejorar la competitividad de todo el sector agropecuario nacional, con ocasión de la internacionalización de la economía".

En materia de seguridad alimentaria, siguiendo el mandato de la Cumbre del Milenio de las Naciones Unidas realizada en septiembre de 2000, donde los líderes del mundo convinieron en establecer objetivos y metas factibles, con plazos definidos, para combatir la pobreza, el hambre, las enfermedades, el analfabetismo, la degradación del ambiente y la discriminación contra la mujer. Objetivos y metas, que constituyen la esencia del programa mundial, se denominan Objetivos de Desarrollo del Milenio ODM, los cuales tienen un periodo de cumplimento de 15 años (2000 -2015). Colombia entonces, mediante el documento Conpes Social 91 de 2005 "Metas y estrategias de Colombia para el logro de los Objetivos de Desarrollo del Milenio - 2015" el estado se comprometió en el objetivo 1 a: I ) Reducir la desnutrición global en los niños menores de cinco años, el indicador pasará de $7 \%$ en 2005 a 3\% en 2015 y II) Mejorar el indicador de consumo de energía mínima; en el año 2000, el porcentaje de personas sub nutridas era del orden del 13\%, se espera que en el año 2015 este porcentaje se encuentre alrededor del 7,5\%. [6]

En el segundo gobierno de Álvaro Uribe, en su plan de desarrollo "Estado Comunitario desarrollo para todos" (2006-2010), que conserva la misma tendencia de su gobierno 
anterior, el Ministerio de Agricultura y Desarrollo Rural en cabeza de Andrés Felipe Arias Leiva, formuló la política agropecuaria de "Transición de la Agricultura" apoyada en los programas misionales denominados empresarización de actividades agropecuarias, acceso a mercados, apoyos económicos - financiamiento y oportunidades para la equidad rural. En ella se establece que la seguridad alimentaria se garantiza a través de la orientación de la agricultura hacia productos de alto valor agregado que le permitan a la población emplearse en sectores que aunque no se pueden consumir como alimentos, pero tienen alta generación de empleo y de ingresos (tabaco, palma de aceite, flores, etc.), y el flujo de comercio garantiza la oferta de alimentos.[7]

Según el Plan Nacional de Desarrollo 2006-2010, "Hay un vínculo entre la seguridad y la cohesión social. La seguridad provee condiciones para la inversión, y esta permite que se alcancen objetivos sociales. La seguridad democrática es, por lo tanto, un medio para la erradicación de la pobreza."

Según el expresidente Álvaro Uribe Vélez, la cohesión social sería alcanzada mediante la reducción de la pobreza, la cual debería ser una consecuencia del crecimiento económico, sin embargo los mecanismos de inclusión social en los que hizo énfasis el gobierno, se referían a la ejecución de programas de transferencias de dinero como el de Familias en Acción, Familias Guarda bosques y Mujeres Ahorradoras en Acción, articulados en la Red Juntos. Estos mecanismos, son propios de una política asistencialista, no coinciden con el concepto de la CEPAL, precisado en los siguientes términos: La cohesión social se refiere tanto a la eficacia de los mecanismos instituidos de inclusión social como a los comportamientos y valoraciones de los sujetos que forman parte de la sociedad. ${ }^{7}$

Los mecanismos incluyen, entre otros, el empleo, los sistemas educacionales, la titularidad de derechos y las políticas de fomento de la equidad, el bienestar y la protección social. Los comportamientos y valoraciones de los sujetos abarcan ámbitos tan diversos como la confianza en las instituciones, el capital social, el sentido de pertenencia y solidaridad, la aceptación de normas de convivencia y la disposición a participar en espacios de deliberación en proyectos colectivos.

En Colombia los indicadores propuestos por la CEPAL arrojaron resultados precarios, en efecto el desempleo según el DANE se mantuvo en el 2010 por encima de 11,8\%, levemente inferior al $12,0 \%$ registrado en $2009 .^{8}$

En Materia de Seguridad Alimentaria, a inicios del año 2010, el documento Conpes 113, crea la Política Nacional de Seguridad Alimentaria y Nutricional (PSAN, 2007), inicialmente corresponde a perspectiva de la seguridad alimentaria Nacional-SAN, centrada en la disponibilidad de suministros alimentarios suficientes a escala de un país. La PSAN "establece como ejes y determinantes de la seguridad alimentaria y nutricional

\footnotetext{
${ }^{7}$ Ver CEPAL. “Cohesión social: inclusión y sentido de pertenencia en América Latina y el Caribe”. Primer Capítulo:

"Los Alcances de la Cohesión Social". Documento electrónico.

${ }^{8}$ Comparar Centro De Investigación y Educación Popular CINEP/programa por la paz. Informe Especial Agosto 2010.

2010. Documento electrónico.
} 
la disponibilidad, el acceso, el consumo, el aprovechamiento biológico y la calidad e inocuidad de los alimentos.

Tabla 2.2. Ejes de la seguridad alimentaria y nutricional, sus dimensiones y determinantes según la política de Seguridad Alimentaria y Nutricional.

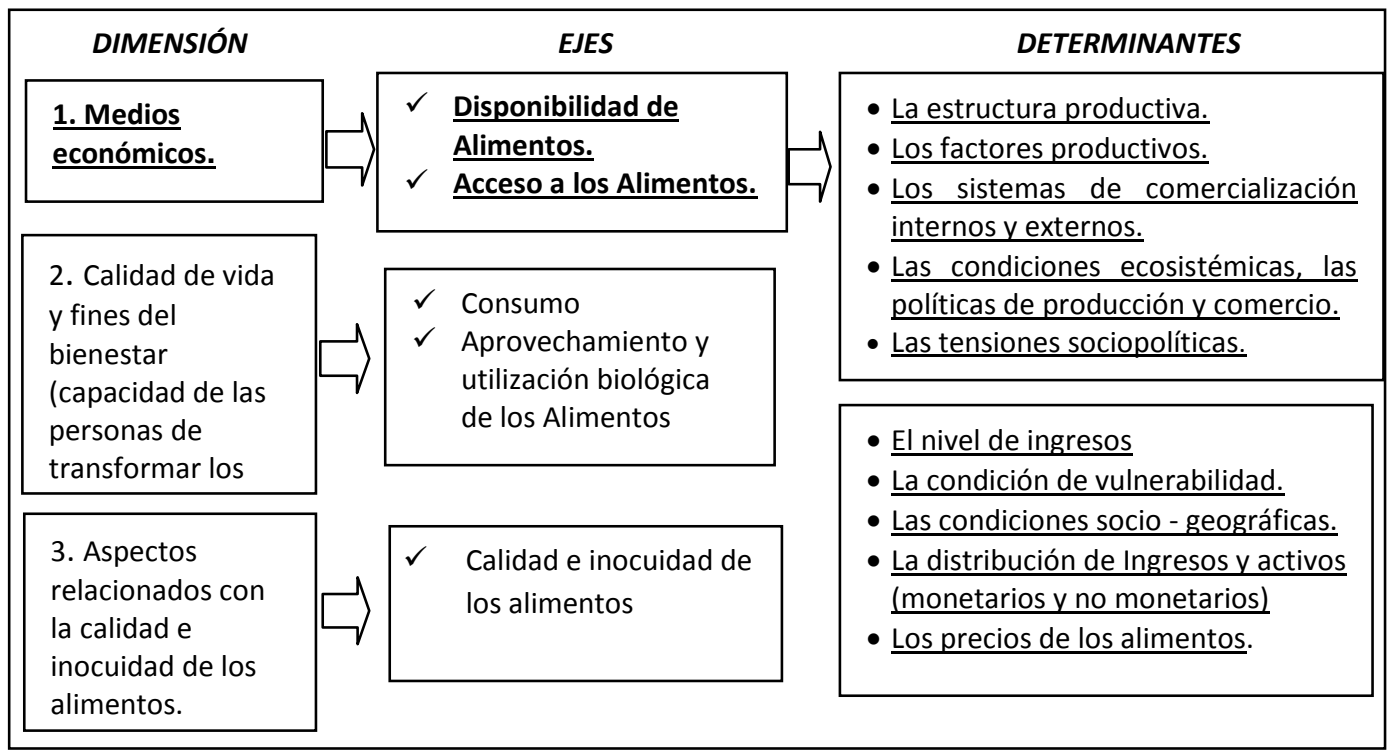

Fuente: Tomado del Conpes Social 113 de 2008.

Dentro de la anterior política, considerando el eje que nos ocupa en esta investigación "La disponibilidad de alimentos", lo define como: La cantidad de alimentos con que se cuenta en los ámbitos nacional, regional y local de forma continua y oportuna, para satisfacer la demanda de los habitantes de un país. Está relacionada con el suministro suficiente de éstos frente a los requerimientos alimentarios de la población y depende fundamentalmente de la producción y la importación. ${ }^{9}$

La misma Política Nacional de Seguridad Alimentaria y Nutricional (PSAN, 2007), señala que: "Los factores que determinan la disponibilidad de alimentos en Colombia" son: la estructura productiva, los factores productivos, los sistemas de comercialización internos y externos, las condiciones ecosistémicas, las políticas de producción y comercio y las tensiones sociopolíticas.

En la dimensión de los medios económico, el Acceso a los alimentos es otro eje a considerar en esta investigación, la política lo define como: "La cantidad de alimentos a los cuales puede acceder una familia, una comunidad o un país. Está relacionado con la posibilidad que tienen las personas de alcanzar una alimentación adecuada y sostenible".

Son determinantes del acceso a los alimentos: El nivel de ingresos, la condición de vulnerabilidad, las condiciones socio - geográficas, la distribución de Ingresos y activos (monetarios y no monetarios) y los precios de los alimentos. Sin embargo, existen otros

\footnotetext{
${ }^{9}$ El Documento Conpes 113, crea la Política Nacional de Seguridad Alimentaria y Nutricional (PSAN, 2007).
} 
aspectos poco investigados que también son fundamentales para garantizar el acceso a los alimentos como: la calidad del empleo, las desigualdades regionales en el Producto Interno Bruto (PIB), gastos en alimentación de la población, efectos de las políticas públicas en la regulación de los precios al consumidor y determinantes sociales para el acceso a los alimentos, entre otros.

En el año 2010, se inició la creación del Observatorio de Seguridad Alimentaria y Nutricional de Colombia, quien tendrá en cuenta las siguientes acciones adoptadas por la FAO. [3]

1. Intervenciones para aumentar el acceso de los agricultores en pequeña escala a los insumos; para valorar la implementación (como semillas, fertilizantes, forrajes y mejorar las prácticas agrícolas (como la ordenación del agua y el suelo y la reducción de las pérdidas posteriores a la cosecha).

2. Apoyo técnico y normativo.

3. Medidas relativas al acceso de los pequeños productores a los mercados.

4. Una respuesta estratégica para paliar las consecuencias del aumento de los precios a corto, medio y largo plazo, mediante una mayor inversión sostenible en la agricultura.

Como programa derivado de dicha política, la Agencia presidencial para la Acción Social y la Cooperación Internacional, crea el programa Red de Seguridad Alimentaria ReSA: fortalecimiento de las bases de la seguridad alimentaria en el sector rural; el objetivo principal fue el potenciar la cultura de la Producción para el autoconsumo en hogares rurales. Éste Programa hasta el año 2010, ejecutó un total de 418 proyectos, distribuidos en los 32 departamentos del país, y benefició a un total de 865,461 familias que corresponden a 4,137,736 participantes. La inversión total en estos proyectos fué de 248,365 millones de pesos. ${ }^{10}$

Otra medida que puede considerarse como derivada de la anterior política, es documento Conpes 3527 de 2008, con el que se crea la Política Nacional de Competitividad y Productividad. Allí se refiere a la Competitividad en el sector agropecuario a partir de las siguientes líneas de acción: 1) Mejorar la productividad y la eficiencia en los sistemas de producción agropecuaria, 2) Mejorar el acceso real de la producción agropecuaria a los mercados internacionales, 3) Propender por la estabilidad del ingreso de los productores y el incremento de las inversiones en el campo, 4) Sectores de clase mundial en el sector agropecuario. Pese a estas medidas y tal como lo indican las estadísticas, ¿Qué es lo que ha generado el mal desempeño del sector agropecuario y que no se vea el bienestar en las regiones. ${ }^{11}$

\subsection{Características de las acciones desarrolladas para el sector agropecuario.}

Aquí se recoge la aplicación de las disposiciones y la legislación implementada para el campo colombiano durante los dos gobierno 2002- 2006 y 2006 -2010:

\footnotetext{
${ }^{10}$ Ver Estudio de Consultoría: Actualización y Conceptualización del Modelo de Intervención Red de Seguridad Alimentaria. FAO -FEDESARROLLO, Agosto de 2010.

${ }^{11}$ La política Comercial en el sector agrícola Colombiano. Fedesarrollo cuaderno No.38.
} 


\subsubsection{La Empresarización del campo en manos de los grandes capitales:}

$\checkmark \quad$ Desapareció de la política agraria del país el tema de la reforma agraria, para implementar el Desarrollo rural comienza por eliminar el 21 de mayo del año 2003 con los decretos 1290 el DRI (Fondo de Cofinanciación para la Inversión Rural), 1291 el INPA (Instituto Nacional de Pesca y Agricultura), 1292 el INCORA (Instituto Colombiano para la Reforma Agraria), para la población campesina, la liquidación del Incora significó el fin de las posibilidades de acceso a la tierra y la renuncia del Estado a democratizar la propiedad a través de la reforma de la estructura de tenencia de la tierra. Todas ellas, instituciones que de alguna manera prestaban un servicio a los campesinos. En sustitución crea con el decreto 1300 el INCODER (Instituto Colombiano para el Desarrollo Rural). ${ }^{12}$

$\checkmark \quad$ El decreto ley 812 del 26 de junio del 2003 que dictamina su plan "hacia un estado comunitario" y el plan de desarrollo 2006 - 2010, que propone adelantar en el congreso la ley de aguas, ley de paramos, ley forestal, y la reforma al Código minero, cuyo principal objetivo para estas nuevas reglamentaciones es acondicionar las leyes para los tratados de libre comercio TLC y buscar el beneficio para el capital transnacional.

$\checkmark \quad$ Propone ante el congreso la ley 1152 de 2007 que rige el Estatuto de Desarrollo Rural, siendo aprobado por el congreso, tumbado luego por la Corte Constitucional por no haberse cumplido con la consulta previa a las comunidades indígenas y negras como lo establece la constitución nacional, privilegia los proyectos empresariales, se ajusta al TLC firmado con los Estado Unidos, Canadá y la Unión Europea, no establece como prioritario la producción de alimentos, posibilita la legalización de las tierras arrebatadas a los campesinos de forma violenta a nombre de los usurpadores, pierde vigencia lo ganado en la constitución de 1991 para los indígenas, afrocolombianos y las zonas de reserva campesina.

$\checkmark \quad$ El caso Carimagua cuando el ministro de agricultura Andrés Felipe Arias pretendía entregar un terrero de 17.000 hectáreas en el departamento del Meta a un grupo de empresarios para el cultivo de palma aceitera, negándose a entregarlo como había sido previsto a 60 familias desarraigadas por el conflicto armado diciendo que "los pobres somos inviables para producir".

$\checkmark \quad$ No obstante, se continuó encaminando los recursos públicos a producción de monocultivos, los agronegocios y exportaciones beneficiando los grandes capitales nacionales e internacionales. "Creo que la otra Ley es la Ley Agro Ingreso Seguro: una

\footnotetext{
${ }^{12}$ Entidad oficial del orden nacional, adscrito al Ministerio de Agricultura y Desarrollo Rural, con personería jurídica, patrimonio propio y autonomía administrativa y financiera. Su sede principal y domicilio está en la ciudad de Bogotá y hace presencia en los 31 departamentos de Colombia a través de sus Direcciones Territoriales, El Instituto tiene como objetivo fundamental ejecutar la política agropecuaria y desarrollo rural, facilitar el acceso a los factores productivos, fortalecer las entidades territoriales y sus comunidades y propiciar la articulación de las acciones institucionales el medio rural, bajo principios de competitividad, equidad, sostenibilidad, multifuncionalidad y descentralización, para contribuir a mejorar la calidad de vida de los pobladores rurales y al desarrollo socioeconómico del país.
} 
gran concertación con el sector agropecuario, a raíz de la suscripción del acuerdo con los Estados Unidos. Y hay que defender el instrumento". 13

$\checkmark$ Con la Ley 113 del 9 de abril de 2007 se crea el programa Agro, Ingreso Seguro AIS, una gran concertación con el sector agropecuario, a raíz de la suscripción del acuerdo con los Estados Unidos ${ }^{14}$. Sin embargo, la Procuraduría General de la Nación, encontró irregularidades en la ejecución del programa relacionados con contratación sin los debidos estudios, irregularidades en los métodos de contratación, actos de corrupción, beneficios indebidos a algunas familias terratenientes, falta de supervisión de los programas, detrimento del erario y aumento indebido de los recursos destinados al programa.

$\checkmark$ Lo que han visto los pequeños campesinos con este proyecto es la desigualdad total, cuando en la caracterización de pequeño productor: es aquel productor cuyos activos totales para el año 2010 no superen los $\$ 55^{\prime} 900.550$ incluidos los del cónyuge y el monto máximo de crédito para este pequeño campesino es de 39'130.385 millones, para la Mujer rural cabeza de familia de bajos ingresos cuyos activos totales para el año 2010 no superen $\$ 39^{\prime} 130.385$. Mediano productor es aquel cuyos activos totales según balance comercial sean $\$ 5^{\prime} 150.000 .000$ para el año 2010 y el Gran productor es toda persona natural o jurídica cuyos activos totales, según balance comercial sea superior a $\$ 5 ’ 150.000 .000$ para el año 2010.

Hasta aquí el Gobierno vendió la idea a todos los productores agropecuarios, que el norte estaba en las exportaciones y los biocombustibles.

\subsubsection{Las restricciones para los pequeños productores de alimentos:}

$\checkmark$ Los decretos 2838 y 616 de 2006, impiden la comercialización masiva de la leche para hervir, es decir, la que se produce en nuestros campos a pequeña escala. Dejando la comercialización de la leche exclusivamente a las grandes pasteurizadoras como Alpina, Nestlé y Friesland, Parmalat, Danone Yoplait y las Nacionales, Colanta, Alquería y Coolecheras-Siledco.

$\checkmark$ La resolución 779 de 2006, regula las medidas de producción de la panela y obliga la instalación de los trapiches con las medidas sanitarias requeridas para poder comercializar, esta adecuación puede llegar a costar hasta 300 millones de pesos. La estrategia es clara, no hay capacidad para el pequeño productor, nos ofrecen la alianza

\footnotetext{
${ }^{13}$ Palabras Álvaro Uribe, al clausurar el Foro Internacional sobre Agricultura Controlada - Mayo 6 de 2010.

14 Tiene como finalidad mejorar la competitividad del sector agropecuario nacional y proteger los ingresos de los productores que resulten afectados ante las distorsiones derivadas de los mercados externos. Promover la productividad y competitividad, Reducir la desigualdad en el campo y preparar al sector agropecuario para enfrentar el reto de la internacionalización de la economía, Propender por el ordenamiento productivo del territorio y la empresarización del campo, en concordancia con la agenda interna de productividad y competitividad, la apuesta exportadora del Ministerio de Agricultura Desarrollo Rural (MADR), y en coordinación con las instituciones del orden territorial.
} 
estratégica con quien puede cubrir los costos y ésta deja de ser producción de alimento para ser producción de etanol. También para tener el monopolio de la producción de panela y comercializarla a precios altos afectando enormemente la alimentación de los colombianos.

$\checkmark$ La resolución 4287 de 21 de noviembre de 2007 del INVIMA establece normas que junto con la resolución 000957 del ICA de 2 de abril de 2008, con las normas de bioseguridad restringen la producción de carne de pollo gallinas y huevos del pequeño productor, y exige la autorización para las plantas de crianza y sacrificio de estos animales favoreciendo el monopolio de las grandes plantas de gallinas ponedoras y pollos de sacrificio, también a los productores de alimentos para pollos de la multinacional PURINA y la nacional RAZA. La meta es desaparecer las gallinas campesinas.

$\checkmark$ El decreto 1500 de 4 de Mayo de 2007 crea el sistema de inspección, vigilancia y control de la carne, productos cárnicos comestibles y derivados cárnicos destinados para el consumo humano, limitando el sacrificio en los municipios y favoreciendo la importación de productos cárnicos, para esto crean frigoríficos regionales quienes los dueños son los grandes ganaderos quienes cuentan con infraestructura para el transporte de ganado a los centros de sacrificio.

$\checkmark$ Colombia tiene una frontera agrícola de 50.910.793 hectáreas, de las cuales para la para la actividad Pecuaria se utiliza un $77 \%$, de los cuales sembradas en pastos un $81 \%$ y sembradas en malezas y rastrojos el 19\%; el otro $14 \%$ se encuentra en bosques naturales el $95 \%$ y en bosques plantados el $5 \%$ y solo el $7 \%$ se usa para la producción Agrícola del cual el 39\% en cultivos transitorios y el 59\% en cultivos permanentes, el $2 \%$ está en descanso y en otros el $2 \%$. El sector agropecuario contribuye con el $7.5 \%$ del PIB nacional. ${ }^{15}$

$\checkmark$ Entre el año 2003 y 2009 la Red de Seguridad Alimentaria Resa el programa llego a 30 departamentos del país y 832 municipios y 1.697.036 unidades de Familia, fueron beneficiarias de estos proyectos; pese a estos resultados se considera un programa insuficiente y para cubrir las necesidad en esta materia. ${ }^{16}$

\subsubsection{Alimentos para los carros no para los humanos.}

$\checkmark$ En el año 2009 se cultivaron 1.059.000 hectáreas cultivos de ciclo corto, 1.724.725 de cultivos de ciclo largo, se considera que 6.5 millones de hectáreas son aptas y se destinarán para "reforestarlas" con cultivos que sean materia prima para agro combustibles (palma, yuca, caña, cacao, eucalipto, pino entre otros). Caso concreto es el de la palma africana para nosotros palma aceitera, en el año 2003 existían 206.801 hectáreas sembradas, en el año 2009 existen 360.537 hectáreas sembradas, lo que

\footnotetext{
${ }^{15}$ Ver Sociedad de Agricultores de Colombia SAC - Perspectivas del Sector Agropecuario Colombiano.

${ }^{16}$ Ver Modelo de Intervención ReSA: En pos de la superación del hambre en las zonas rurales, Fedesarrollo - Acción Social 2007
} 
representa un $42.6 \%$ en aumento del área sembrada; con ventas de aceite de palma de 570.174 toneladas solo la industria del agrodisel compro 153.496 toneladas. $^{17}$

$\checkmark$ La caña para la producción de azúcar y alcohol carburante en el año 2002 se produjeron 2.528.765 toneladas, (para ese año en Colombia no había producción de alcohol carburante), Para el año 2009 se produjeron 2.598.496 toneladas de azúcar, y una producción de 324.563 litros para alcohol carburante. ${ }^{18}$

$\checkmark$ Entramos a la nociva moda de producir alimentos transgénicos, se han sembrado 35.700 hectáreas de maíz transgénico, en 10 departamentos del país, auspiciado por la asociación de biotecnología vegetal agrícola AGRO BIO. Se incentiva la investigación y la producción de transgénicos en papa, yuca, arroz, Pasto, maíz, girasol, remolacha, algodón, claveles.

$\checkmark$ En la Encuesta Nacional de la Situación Nutricional, ENSIN 2005, se identificaron algunos determinantes que afectan el consumo de alimentos como la desigualdad en la ingesta promedio de energía según nivel del SISBEN $^{19}$ y zona geográfica, deficiencia en el consumo de proteínas por grupos de edad y por regiones, alto consumo de grasa saturada y bajo de frutas y verduras, la alta prevalencia de deficiencia bioquímica de vitamina A y $\mathrm{C}$, y el bajo promedio de lactancia materna exclusiva.

$\checkmark \mathrm{El}$ auge de la revolución verde y de otras tecnologías, también puede tuvo efectos en la producción y cultura alimentaria al generar dependencia a los insumos y semillas importadas, cuyos precios se afectan por los precios del petróleo y contribuyen al desestimulo de la producción autóctona.

\subsubsection{Cereales y leguminosas importadas y no producidas por nosotros.}

El Arroz cuya producción para el año 2002 fue de 2.063.030 toneladas, y la importación de 169.950 toneladas, en el año 2009 la producción fue de 2.379.848, y la importación de 329.589 toneladas significa esta que en 7 años solo aumenta la producción en un $13.3 \%$ y las importaciones crecen un $48.44 \%$ En el año 2008 importamos: maíz 3.306.823 toneladas, sorgo 141.685 toneladas, Cebada 284.777 toneladas, Avena 12.310 toneladas, Frijol 20.111 toneladas, Arveja 32.697 toneladas, Garbanzo 12.865 toneladas, Lenteja 56.061 toneladas, Trigo 1.369.391 toneladas, lo que significa que en el año 2008 importamos 5.310.009 toneladas de cereales y leguminosas básicas para la alimentación, y que en Colombia por su diversidad de climas y la bondad de sus tierras podríamos cultivar, estos datos sin contar las importaciones de carne, leche, verduras. ${ }^{20}$

\footnotetext{
${ }^{17}$ Ver Fedepalma Estadística de Producción.

${ }^{18}$ Balance Sector Azucarero Colombiano 2000-2010 Asocaña.

${ }^{19}$ SISBEN - Sistema de salud en Colombia hace parte del Sistema de Seguridad social de Colombia regulado por el gobierno nacional, por intermedio del Ministerio de la Salud y Protección Social y del Ministerio de Trabajo.

${ }^{20}$ Fenalce, DIAN -Legiscomex.
} 
Ganado para el año 2008 se calcula la existencia de 23.500 .000 cabezas de las cuales se sacrificaron 4.054.485 para el consumo y la exportación. Se produjeron 6.450 millones de litros de leche. ${ }^{21}$

\subsubsection{Los tratados de libre comercio.}

$\checkmark$ Firma los TLC con estados unidos firmado el 27 de febrero del 2006 por los dos gobiernos, aprobado por el congreso colombiano de mayoría Uribista, sin que aun sea aprobado por el congreso de los estados unidos, que su componente afecta al campo colombiano porque entrega nuestra soberanía alimentaria, biodiversidad, agua, conocimiento ancestral, patrimonios genéticos, propiedad intelectual.

$\checkmark \quad$ La firma del Tratado de Libre Comercio (TLC) con Europa firmado el 19 de mayo del 2010, en Madrid España queda a la espera de la aprobación por el Parlamento Europeo, cuyo componente afecta a más de 400.000 familias lecheras en el país quienes no pueden competir debido a los subsidios que allí reciben los ganaderos, se permitirá la entrada a los productos agrícolas que también están subsidiados entraran libremente.

Firma el TLC con Canadá el 21 de noviembre del 2008, también debe ser ratificado por el congreso canadiense, será beneficioso para las multinacionales mineras canadienses. Ninguno de los tres tratados contiene cláusulas en la defensa de la producción en Colombia.

\subsubsection{La pobreza no retrocede y crece en nuestros campos}

$\checkmark$ La pobreza en Colombia según el DANE en el 2009 es del 45.5\%, lo que significa unos 21 millones de colombianos somos pobres y el 16.4\%, unos 7.6 millones viven la pobreza absoluta, de los cuales en el campo la pobreza sube al $54.3 \%$ y la pobreza extrema es del $29.1 \%$ el analfabetismo en zonas rurales es del $14,8 \%$, frente al promedio nacional que es del $6,9 \% .^{22}$

$\checkmark$ En el acceso a la educación han estudiado la primaria incompleta el 33\%, la primaria completa el $27 \%$, secundaria incompleta el $15 \%$, secundaria completa el $7 \%$ y la educación más avanzada solo el 3\%, el acceso a la energía eléctrica cobija un $89.4 \%$, al acueducto accede el 58.3\%, al servicio de alcantarillado se llega al $14.9 \%$, el servicio de gas el $3.4 \%$, y al servicio de telefonía celular accede el $70.8 \%{ }^{23}$

$\checkmark$ En el tema de la salud, no hay política de prevención ni tratamiento, existe el sisben que aunque tiene una alta cobertura de inscritos no presta óptimamente el servicio y al igual que para todo el pueblo colombiano, accede a la salud quien tiene dinero para pagarla.

\footnotetext{
${ }^{21}$ Corporación Colombia Internacional CCI- Ministerio de Agricultura y Desarrollo Rural MADR- Encuesta Nacional Agropecuaria 2008.

${ }^{22}$ Encuesta de calidad de vida 2008 Departamento Administrativo Nacional de Estadística [DANE].

${ }^{23}$ DANE Sistema de Información Ganadero SIGA - FEDEGAN.
} 


\subsection{Aspectos Macroeconómicos de la Producción de Alimentos.}

Una parte importante de la producción se destina al mercado internacional, el sector agropecuario y agroindustrial es hoy en día el tercer renglón más importante en las ventas de productos al exterior, después de los sectores minero-energético e industrial, con el $20 \%$ del total de exportaciones del país. A pesar de lo anterior, el potencial agro exportador está desaprovechado, teniendo en cuenta la disponibilidad de recursos naturales y diversidad climática de Colombia. Como resultado, el sector agropecuario crece, emplea, produce y exporta por debajo de su potencial.

Gráfica 2.4.1. Comportamiento del PIB Agropecuario entre el 2001 y el 2012.
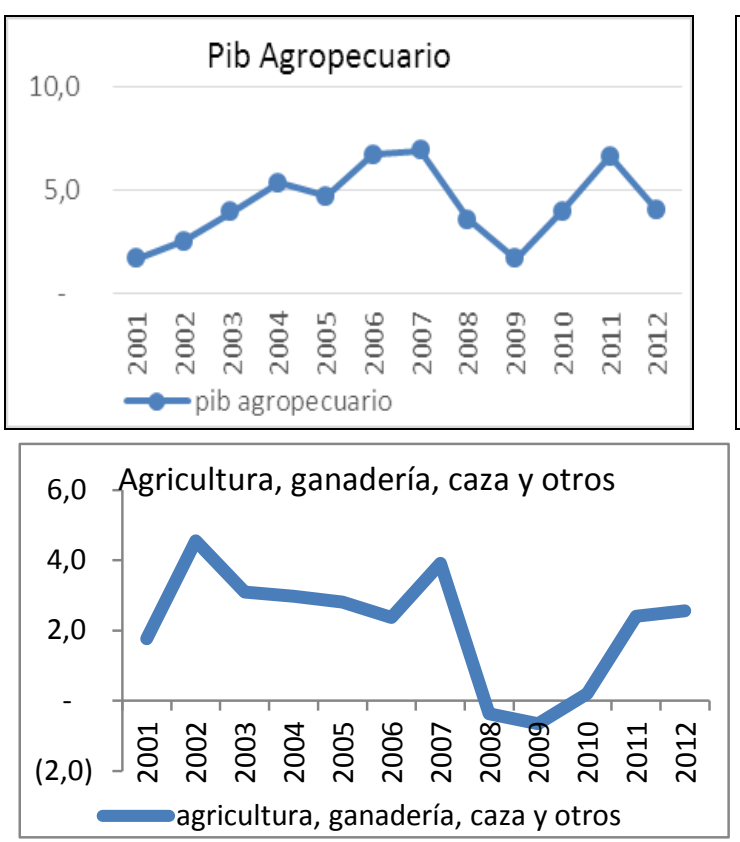
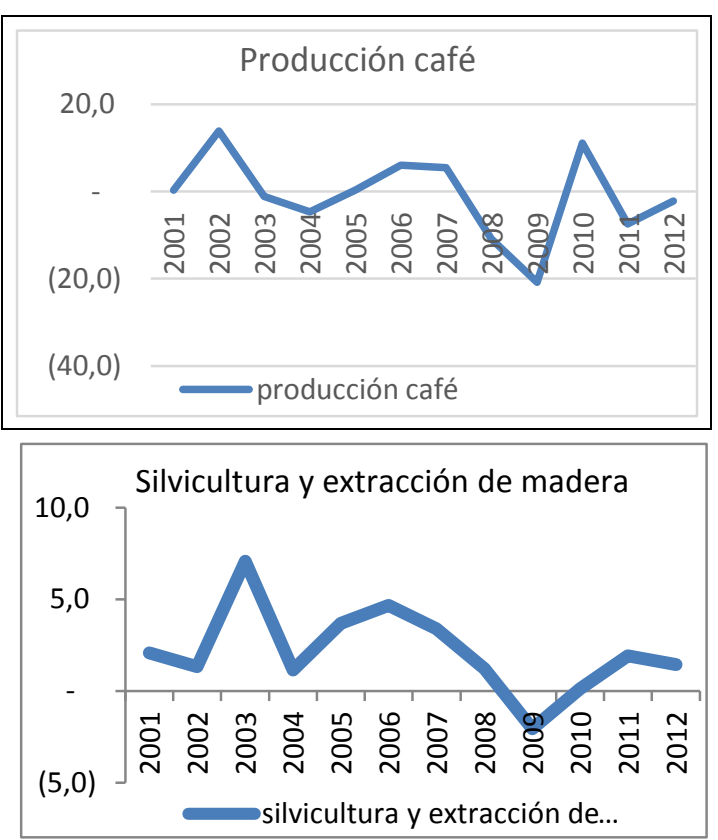

Fuente: SAC, 2014

Gráfica 2.4.2 Comportamiento de la Balanza Comercial total agropecuaria y agroindustrial.

\begin{tabular}{|c|c|c|c|}
\hline \multirow{2}{*}{\multicolumn{2}{|c|}{$\begin{array}{c}\text { Balanza comercial total agropecuaria y } \\
\text { agroindustrial sin café }\end{array}$}} & \multirow{2}{*}{\multicolumn{2}{|c|}{$\begin{array}{c}\text { Balanza comercial total agropecuaria } \\
\text { y agroindustrial con café }\end{array}$}} \\
\hline & & & \\
\hline 1.500 .000 & & 2.500 .000 & \\
\hline $\begin{array}{r}1.000 .00 \\
500.00\end{array}$ & & 2.000 .000 & \\
\hline & & 1.000 .000 & \\
\hline-500.000 & 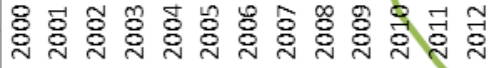 & 500.000 & \\
\hline-1.000 .000 & & & 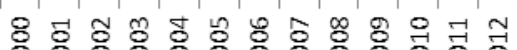 \\
\hline — TOT & & — Tот & AL AGROPECUARIA Y AGROINDUSTRIAL CON... \\
\hline
\end{tabular}


Fuente: SAC, 2014

Hoy se cultivan en Colombia alrededor de 5 millones de hectáreas y se producen cerca de 30 millones de toneladas de alimentos y materias primas, de las cuales $85 \%$ corresponden a productos agrícolas como alimentos y las oleaginosas para la producción industrial; en este caso, pese a existir una vocación agrícola en los suelos del 21,5\% tan solo el 4,9 es destinado a ello. El restante $15 \%$ corresponde a productos pecuarios que paradójicamente, pese a existir una vocación pecuaria del $21,1 \%$ de los suelos, se ha sobrepasado hasta llegar a ocupar el 39.2\% del total de suelo. Esto muestra que tanto los suelos con vocación agrícola y con vocación de protección o zonas de reserva, se han venido ocupando por actividades pecuarias principalmente la ganadería.

Gráfica 2.4.3 Comportamiento de la producción de alimentos frente a otros cultivos.
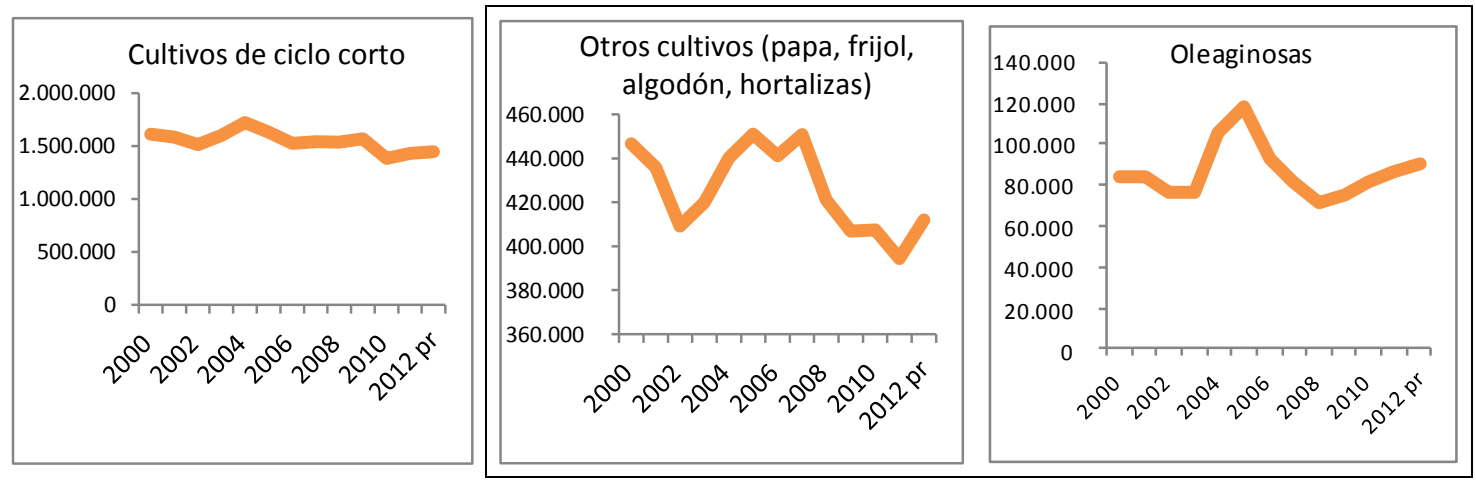

Fuente: SAC, 2014

Hoy se cultivan en Colombia alrededor de 5 millones de hectáreas y se producen cerca de 30 millones de toneladas de alimentos y materias primas, de las cuales $85 \%$ corresponden a productos agrícolas y el restante $15 \%$ a productos pecuarios.

Gráfica 2.4.4 Potencial para la producción agropecuaria en Colombia.

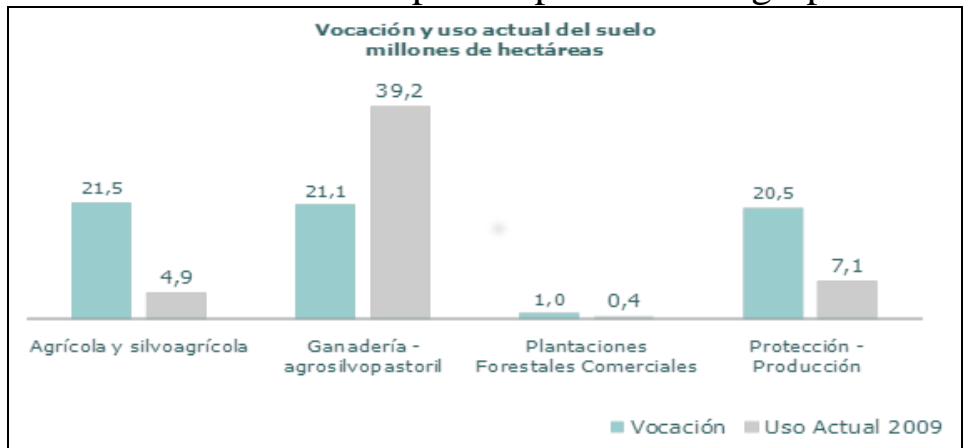

Fuente: IGAC - Elaboró: SAC Departamento de Estudios Agroeconómicos

Las gráficas anteriores reflejan el comportamiento desordenado del sector frente a la disponibilidad de los recursos naturales. En consecuencia durante el periodo 2002 al 2010 
a nivel nacional, esta problemática anudada a la falta de preparación del campo para la internacionalización con llevó cuatro grandes secuelas.

a. La primera fue la pérdida de la soberanía alimentaria y poner en riesgo la seguridad alimentaria, como consecuencia de las importaciones anuales de cerca de diez millones de toneladas de alimentos básicos y productos del agro.

b. La segunda, el aumento de la concentración de la tierra, el $0,4 \%$ de los propietarios que tiene más de 500 hectáreas, controlan $65 \%$ de la tierra, mientras $85 \%$, con menos de 20 hectáreas, posee sólo el 9\%.

c. La tercera, fue el arrinconamiento de la economía campesina, con menor participación en la producción y en el área de siembra, y reducida a unos pocos renglones.

d. La cuarta, el envilecimiento y la explotación del empleo rural, cuya remuneración en el $66 \%$ de los casos es inferior al salario mínimo, incluso los asalariados de las grandes plantaciones. $^{24}$

\subsection{Características Sociodemográficas de la Población Rural.}

Existen serias falencias en los diagnósticos oficiales sobre el campo colombiano, debido a que la información tiene una desactualización de 43 años, desde la última vez que se realizó el Censo Agropecuario. Por lo tanto, la información sobre la situación del campo está dispersa, es incompleta y desactualizada. Sin embrago, a partir de los datos disponibles, a continuación se presentará un panorama sobre la situación de la población rural en el país.

Según proyecciones del censo de población realizado en 2005, Colombia tenía en 2009 42'888,594 habitantes, de los cuales 31'886,602 (74,3\%) habitan en las cabeceras municipales o distritales y 11'001,990 $(25,7 \%)$ en el sector rural.

Sin embargo, el Informe de Desarrollo Humano de 2011 dedicado a la situación rural ha encontrado que el campo y su población tienen un peso más significativo en la realidad nacional de lo que indican las cifras oficiales. Los hallazgos de dicho estudio indican que el 75,5\% de los municipios del país son rurales; en donde habita el 31,6\% de la población y cubren el 94,4\% de la superficie total del país. En 2005 la pobreza rural en Colombia alcanzaba un $68 \%$ mientras que la urbana era del $42 \%$, lo que equivalía a ocho millones de personas pobres en el campo, y el $28 \%$ vivía en Condiciones de indigencia (3,2 millones de personas), situación que ha empeorado. En 2008, el gobierno reconocía que la pobreza rural representaba el 36,5\% de la pobreza nacional y el 49,2\% de la indigencia total, y que el ingreso per cápita del campo apenas representa el 30,5\% del ingreso per cápita urbano.

El gobierno del presidente Alvaro Uribe Vélez, que comprendió dos períodos de cuatro años, atribuyó la situación de la población rural descrita anteriormente a "la baja productividad y por ende los bajos ingresos, y no necesariamente la falta de empleo". Otra causa de la pobreza rural es la violencia, porque, según lo observado del gobierno del Alvaro Uribe Vélez, dicha violencia desincentivó la inversión en el campo y habría desviado la atención de los instrumentos y recursos de la política e institucionalidad para

\footnotetext{
${ }^{24}$ Ver La política Agraria de Santos Fase superior del "Modelo Malayo" Colonialista. Documento Electrónico.
} 
atender los efectos de sobre las víctimas del desplazamiento forzado y del terrorismo, en detrimento de los campesinos, principal objetivo de las instituciones de desarrollo rural del sector. [8]

\subsection{Análisis del Entorno local}

En el caso de Puente Nacional - Santander cuya vocación primordial es agropecuaria, el total del área es de 315 Kilómetros cuadrados, el área rural que corresponde a 25.320 hectáreas, ubicadas a una altura de 1.757 metros sobre el nivel del mar, que son dedicadas a cultivos de caña panelera, maíz, café, plátano, mora, cacao, guayaba, fríjol, yuca y papa. También a actividades pecuarias como la ganadería, avicultura y piscicultura y un gran parte del suelo es de conservación o reserva pese a que la presencia de actividades pecuarias ha incidido en la ampliación de la frontera agrícola. Éste municipio tiene una población de 14.538 habitantes de los cuales 8.925 en el sector rural y 5.328 en la cabecera municipal según datos del censo (Departamento Nacional de Estadística [DANE], 2005).

La estructura de la propiedad rural de éste Municipio, indica claramente una situación minifundista en todo el territorio, pues de 25.320 hectáreas que tiene el Municipio, el $75.5 \%$ de los predios tienen menos de 5 hectáreas, lo cual muestra que es una región caracterizada por pequeños productores; el Municipio cuenta con 6.165 predios de los cuales el $76 \%$ es explotado por los propietarios, el 15\% en arriendo, el 8\% en aparcería. El 91,5\% de las viviendas rurales ocupadas, tienen actividad agropecuaria así: Agrícola el $59,8 \%$, pecuaria $96,6 \%$, piscícola $4,8 \%$. La mayoría de las viviendas tiene simultáneamente 2 o 3 tipos de actividades. [9]

En materia de resultados de la política sectorial, pese a que el municipio cuenta con amplia disponibilidad de tierras con vocación agrícola, oferta de recursos naturales: agua y biodiversidad y condiciones climáticas tropicales que permiten la producción de alimentos durante todo el año, hoy en día son escasas las experiencias que muestren resultados de éxito en la producción de alimentos mediante economías de gran o pequeña escala, que se ha visto reemplazada también por actividades como la ganadería, al igual que ocurre en el territorio nacional. 


\section{Capítulo 3. Aspectos Metodológicos y Desarrollo del Modelo.}

\subsection{Tipo de Investigación.}

Se realizó una investigación exploratoria - descriptiva - no experimental ${ }^{25}$; toda vez que fue necesario observar, y describir los fenómenos tal y como se dan en su contexto natural; en cuanto al tiempo, se hace corte transversal al tratarse de la recolección de información en el periodo comprendido entre los años 2002 al 2010. De la misma manera, buscando establecer las relaciones causa-efecto, se estudió la manifestación de un fenómeno aquí denominado variable dependiente, que es "La producción de alimentos de la canasta básica alimentaria", para identificar retrospectivamente sus antecedentes o causas; aquí denominadas variables independientes, que son: "El valor de los incentivos, otras actividades que sustituyen la producción de alimentos, los subsidios recibidos, las deudas de los productores, el valor de los insumos, el margen de utilidad y la tenencia de la tierra.

Se construyeron entonces los siguientes Indicadores de eficacia que permiten evaluar en concreto aspectos que dejan ver como incidió la política agropecuaria o sus las acciones en los habitantes rurales. Con ellos se elaboró una encuesta y durante un mes de trabajo de campo se recogió la información.

Tabla No 3.1.1: Indicadores de eficacia para evaluar la política agropecuaria en el municipio de Puente Nacional, (S).

\begin{tabular}{|c|c|}
\hline Variable & Indicador \\
\hline \multirow{2}{*}{$\begin{array}{l}\text { 1.Incentivos } \\
\text { Institucionales }\end{array}$} & $\begin{array}{l}\text { Programas del ministerio de agricultura, comité de cafeteros, Umata, Fedegán, corpoica y otros } \\
\text { organismos para incentivar la producción de alimentos. }\end{array}$ \\
\hline & $\begin{array}{l}\text { Formas de incentivos recibidos Asistencia técnica, semillas, pie de cría, herramienta y equipo, } \\
\text { insumos, riego, dinero entre otros. }\end{array}$ \\
\hline \multirow{2}{*}{$\begin{array}{l}\text { 2.Tenencia de } \\
\text { la tierra }\end{array}$} & $\begin{array}{l}\text { Predios que son propiedad del productor frente al total de los predios. } \\
\text { Finca propia, arrendada, en aparcería, custodia u otros }\end{array}$ \\
\hline & Tamaño de las fincas menos de 2 hectáreas en adelante hasta más de 40 has. \\
\hline \multirow{3}{*}{$\begin{array}{l}\text { 3. Sistemas de } \\
\text { producción }\end{array}$} & Tipos de Sistemas de producción de alimentos establecidos, ganadería, especies menores, cultivos. \\
\hline & Área destinada a la producción de alimentos sin ganadería, menos de 1 hectárea. \\
\hline & Sustitutos de la producción de alimentos abandono, ganadería, turismo, biocombustibles, otras. \\
\hline \multirow[t]{2}{*}{$\begin{array}{l}\text { 4. Inventario } \\
\text { de producción }\end{array}$} & $\begin{array}{l}\text { Clasificación de los alimentos producidos según la canasta básica alimentaria. Tubérculos, cárnicos, } \\
\text { frutas, verduras, cereales, lácteos, etc. }\end{array}$ \\
\hline & Cantidad de alimentos para el autoconsumo y para la venta. \\
\hline \multirow{4}{*}{$\begin{array}{l}\text { 5.Acceso a } \\
\text { mercados } \\
\text { Eficiencia } \\
\text { económica }\end{array}$} & Lugares de venta de los alimentos, en el municipio, Bogotá, Bucaramanga, Tunja, Barbosa, otros. \\
\hline & Ingresos por ventas de alimentos menos de $\$ 200.000$ hasta más de $\$ 1.000 .000$. \\
\hline & Costos por sistema de producción de alimentos menos de $\$ 200.000$ hasta más de $\$ 1.000 .000$. \\
\hline & Margen de utilidad para el productor, negativa hasta el 30 y $40 \%$. \\
\hline \multirow{3}{*}{$\begin{array}{c}6 . \\
\text { Financiación }\end{array}$} & Recursos de crédito, recursos propios, de familiares o subsidios para financiar la producción. \\
\hline & Subsidios del estado recibidos para financiar la producción instituciones, programa, monto y destino. \\
\hline & $\begin{array}{l}\text { Tipología de deudas de los productores Finagro y/o libre inversión para capital de trabajo, inversión, } \\
\text { compra de cartera, }\end{array}$ \\
\hline \multirow[b]{2}{*}{$\begin{array}{l}\text { 7.Asistencia } \\
\text { técnica }\end{array}$} & Frecuencia de la técnica recibida en la finca mensual, trimestral, semestral, anual entre otras. \\
\hline & $\begin{array}{l}\text { Prestador de la Asistencia técnica recibida para los sistemas de producción de alimentos, comité de } \\
\text { cafeteros, Umata, Fedegán, Corpoica, Alcaldía, entre otros. }\end{array}$ \\
\hline
\end{tabular}

Fuente: Elaboración propia

\footnotetext{
${ }^{25}$ Hernández Sampieri, Roberto, "La investigación es Descriptiva"
} 


\subsubsection{Metodología.}

El universo, es decir los sujetos de estudio y mencionados al momento de enunciar el problema y establecer el objetivo, fueron los 8.925 habitantes del municipio de Puente Nacional - Santander ${ }^{26}$; que corresponden al total de las familias por comunidades y unidades territoriales. Para la muestra, se aplica el tipo de muestreo probabilístico, con el fin de asegurar la representatividad de la muestra extraída y el método de muestreo es aleatorio por conglomerados, donde se toma como marco muestral cada una de las 32 veredas del municipio y se extrae una muestra proporcional al número de habitantes por vereda. [10]

Tabla No 3.1.2.Cálculo del tamaño de la muestra para población finita.

\begin{tabular}{|l|}
\hline Dónde: \\
$\boldsymbol{n}=\frac{\boldsymbol{Z}^{2} \boldsymbol{\sigma}^{\mathbf{2}} \boldsymbol{N}}{\boldsymbol{e}^{\mathbf{2}}(\boldsymbol{N}-\mathbf{1})+\boldsymbol{Z}^{\mathbf{2}} \boldsymbol{\sigma}^{\mathbf{2}}}$ \\
$\mathrm{n}=$ Tamaño de la muestra. $=?=368$ \\
$\mathrm{~N}=$ Tamaño de la población. $=8.925$ \\
$\sigma=$ Desviación estándar de la población = valor constante de $0,5$. \\
$\mathrm{Z}=$ Niveles de confianza en una distribución normal, $95 \%$ de confianza = equivale a $1,96$. \\
$\mathrm{e}=$ Límite aceptable de error maestral que es $=0,05$
\end{tabular}

Fuente: Hernandez Sampierı y Pilar Bautısta, Metodologia de la investigacion cientitica (19y8).

El tamaño de la muestra fue de 368 habitantes rurales que son productores agropecuarios y que su actividad se encuentra en diferentes zonas geográficas, es decir en las 32 veredas que conforman el municipio de Puente Nacional (S).

Tabla No. 3.1.3. Cálculo de la Muestra. Muestreo Probabilístico - Aleatorio por conglomerados.

\begin{tabular}{|c|c|c|c|c|c|c|c|}
\hline No. & Vereda & No. Habitantes & Muestras & No. & Vereda & No. Habitantes & Muestras \\
\hline 1 & Alto Cantano & 385 & 18 & 17 & Medios & 137 & 7 \\
\hline 2 & Alto Capilla & 303 & 13 & 18 & Los Robles & 294 & 10 \\
\hline 3 & $\begin{array}{c}\text { Alto } \\
\text { Guamito }\end{array}$ & 363 & 16 & 19 & Sandimas & 311 & 15 \\
\hline 4 & Alto Semisa & 288 & 12 & 20 & Montes & 229 & 9 \\
\hline 5 & $\begin{array}{c}\text { Bajo } \\
\text { Cantano }\end{array}$ & 276 & 9 & 21 & Petaqueros & 305 & 11 \\
\hline 6 & Kilómetro 4 & 161 & 7 & 22 & Rio Suarez & 307 & 12 \\
\hline 7 & $\begin{array}{c}\text { Bajo } \\
\text { Guamito }\end{array}$ & 246 & 12 & 23 & Rincón & 332 & 13 \\
\hline 8 & Bajo Semisa & 311 & 10 & 24 & Corinto & 234 & 9 \\
\hline 9 & Cantano & 326 & 11 & 25 & Culebrilla & 196 & 8 \\
\hline 10 & Capilla & 271 & 9 & 26 & Providencia & 147 & 6 \\
\hline 11 & Guamito & 341 & 15 & 27 & Peña Blanca & 287 & 12 \\
\hline 12 & Semisa & 289 & 12 & 28 & $\begin{array}{c}\text { Quebrada } \\
\text { Negra }\end{array}$ & 213 & 9 \\
\hline 13 & La cuchilla & 294 & 12 & 29 & Urumal & 325 & 15 \\
\hline 14 & Iroba & 291 & 12 & 30 & Popoa Norte & 275 & 10 \\
\hline 15 & Delicias & 403 & 18 & 31 & Popoa Sur & 328 & 15 \\
\hline 16 & Jarantiva & 322 & 13 & 32 & $\begin{array}{c}\text { Alto } \\
\text { Sandimas } \\
\end{array}$ & 135 & 8 \\
\hline
\end{tabular}

Fuente: Elaboración propia

\footnotetext{
${ }^{26}$ Censo Poblacional Departamento Nacional de Estadística [DANE], 2005
} 


\subsection{Procedimiento de Recolección de Información}

En esta investigación, se tuvo en cuenta los dos tipos de fuentes de información. Las fuentes primarias conformadas por los habitantes encuestados, las personas entrevistadas o sondeadas, los documentos originales, las fichas de observación y demás apuntes de investigación. Información que fue recopilada durante un mes de trabajo de campo en el sector urbano y rural del municipio; en este periodo se dispuso de un equipo de veinte encuestadores y dos Instructores de investigación del Servicio Nacional de Aprendizaje SENA.

Se consultaron fuentes secundarias como: Las bases de datos de la Alcaldía Municipal, Ministerio de Agricultura y sus dependencias, base de datos comerciales, estudios hechos por CORPOICA, SENA, Comité de Cafeteros, se consultaron en bibliotecas: libros, diarios, revistas, publicaciones y resúmenes que contienen información relacionada al objetivo del estudio.

\subsubsection{Métodos e instrumentos de recolección de información}

Los métodos para recolección de datos utilizados fueron la encuesta y la observación sistemática; para su aplicación se utilizaron dos técnicas de recolección, la primera técnica es la encuesta, para la recolección de la información primaria, mediante un cuestionario previamente elaborado con 22 preguntas, a través del cual se pudo conocer la opinión o valoración de los sujetos de estudio (productores agropecuarios) frente a las variables estudiadas. El cuestionario, utilizado como instrumento de recolección, está diseñado con preguntas específicas, cerradas, en las que se incluyen preguntas de opción múltiple con selección simple o selección múltiple. ${ }^{27}$

La segunda técnica fue la observación científica de campo, con percepción sistemática y dirigida a captar los aspectos más significativos de los objetos, hechos, realidades sociales y personas en el contexto donde se desarrollan normalmente (sector agropecuario del municipio de Puente Nacional) para confirmar o constatar la información obtenida. Se utilizó como instrumento: la ficha de observación y diario de campo para el registro de la información apoyado de igual manera en medios audiovisuales. ${ }^{28}$

\subsection{El análisis de datos.}

En esta fase esencial de la investigación, se hizo la revisión de los cuestionarios para identificar y descartar si hubo errores en el diligenciamiento. Posterior a ello se procedió a la codificación y tabulación de la encuesta; calificación y tabulación de los datos.

Se hizo la tabulación de la información mediante tablas de resumen de resultados, con ello se graficaron los resultados de cada pregunta y se presentan los hallazgos frente a las variables e indicadores en estudio, como lo indica la presentación de los resultados.

\footnotetext{
${ }^{27}$ Ver Anexo 1 Cuestionario de encuesta.

${ }^{28}$ Ver Anexo 2 Cuadernillo de observación.
} 
Posteriormente, se hace una categorización de los datos en términos de los resultados de la investigación, que dio origen a las bases de datos más adelante requeridas para el análisis cuantitativo del modelo. En la tabla 3.3.1 la cantidad de observaciones y encuestas recogidas con información de las variables en estudio son agrupadas bajo dos categorías establecidas en el manual de servicios de Finagro, en donde es considerado mediano productor, toda persona natural o jurídica cuyos activos totales sean inferiores o iguales a $5.000 \mathrm{smlmv}$, es decir $\$ 2.947500 .000$ y pequeño productor, toda persona cuyos activos totales no superen $\$ 85^{\prime} 477.500$ para el año 2013.

La primera categoría corresponde al tamaño de los productores, en ella se agrupa la información de los productores medianos ${ }^{29}$ y productores pequeños ${ }^{30}$. La segunda categoría corresponde a la tenencia de la tierra; en ella se agrupa la información de los productores que son propietarios de la tierra ${ }^{31}$ y los que la tienen en arrendamiento. ${ }^{32}$

Tabla No. 3.3.1 Análisis de datos

\begin{tabular}{|c|c|c|c|c|}
\cline { 2 - 5 } \multicolumn{1}{c|}{} & \multicolumn{2}{c|}{$1^{\text {a }}$. Categoría. Tamaño de los } & \multicolumn{2}{c|}{$2^{\text {a }}$. Categoría. Tenencia de la Tierra } \\
\hline \multirow{2}{c|}{$\begin{array}{c}\text { Numero de } \\
\text { Observaciones }\end{array}$} & Medianos & Pequeños & Tierra propia & Tierra arrendada \\
\cline { 2 - 6 } & 92 & 245 & 202 & 135 \\
\hline Total analizado & \multicolumn{2}{|c|}{337} & \multicolumn{2}{c|}{337} \\
\hline
\end{tabular}

Fuente: Elaboración propia

\subsection{Los Resultados de la investigación:}

\subsubsection{Incentivos Institucionales}

El $62,4 \%$ de los encuestados no se beneficiaron de ningún programa del ministerio de agricultura u otros organismos para incentivar la producción de alimentos y del 37,6\% que si se beneficiaron, lo que más recibieron fue asistencia técnica.

Gráfica 3.4.1.1Entidades que otorgaron incentivos. Gráfica 3.4.1.2 Incentivos recibidos.
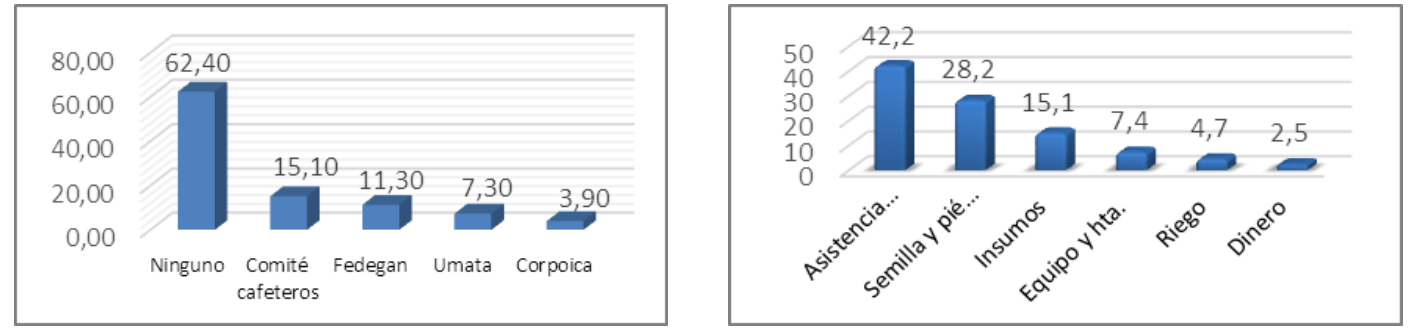

Fuente: Elaboración propia

\footnotetext{
${ }^{29}$ Ver Anexo 3. Productores agropecuarios organizados por tamaño en medianos.

${ }^{30}$ Ver Anexo 4. Productores agropecuarios organizados por tamaño en pequeños.

${ }^{31}$ Ver Anexo 5. Productores agropecuarios organizados según la tenencia de la tierra- Propia.

${ }^{32}$ Ver Anexo 6. Productores agropecuarios organizados según la tenencia de la tierra- Arrendada.
} 


\subsubsection{Tenencia de la tierra}

El 40,5\% de las fincas de los predios poseen entre 2 y 10 hectáreas, seguido por el 23,6\% que poseen menos de 2 hectáreas y solo el 4,2\% de los predios son de más de 40 hectáreas. En cuanto a la propiedad, el $61 \%$ de los predios don propios y $29 \%$ corresponde a predios arrendados.

Gráfica 3.4.2.1 Tenencia de la tierra

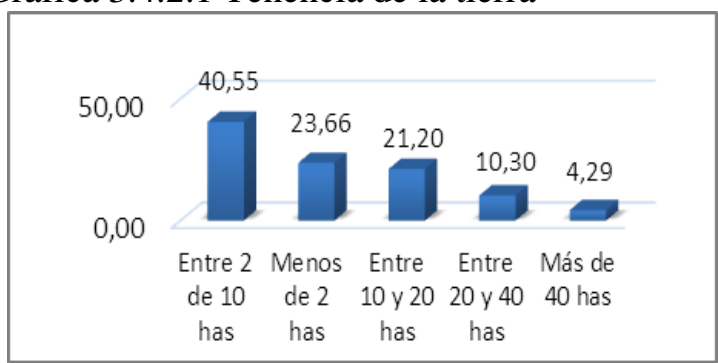

Fuente: Elaboración propia
Gráfica 3.4.2.2 Propiedad de la Tierra

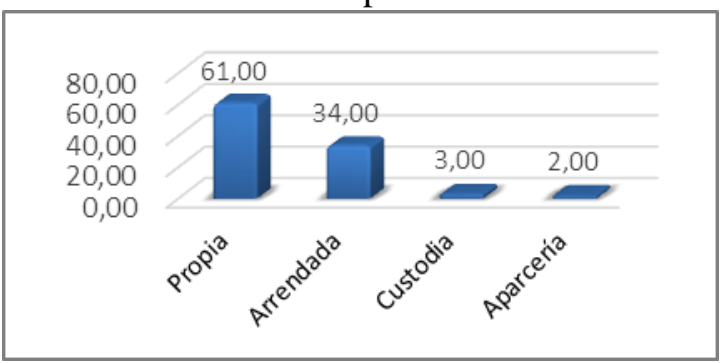

\subsubsection{Sistemas de producción de alimentos}

Del área apta para la agricultura el 38,5\% está destinada a la ganadería, el 23,8 a las especies menores, el $22,4 \%$ a cultivos de alimentos y el $10,20 \%$ a otras actividades.

Gráfica 3.4.3.1Sistemas de Producción

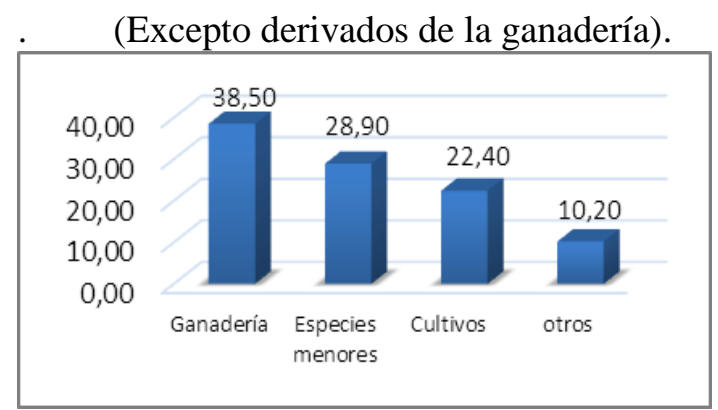

Fuente: Elaboración propia
Gráfica 3.4.3.2 Área destinada a producir alimentos

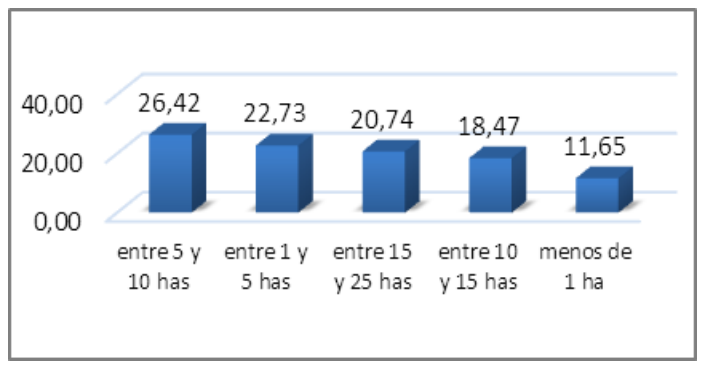

De los sistemas de tenencia de la tierra el área destinada para la producción de alimentos sin contar la ganadería y sus derivados, que más predomina con un $26,42 \%$ es: entre 5 y 10 hectáreas, seguida por un $22,73 \%$ entre 1 y 5 y el área que menos predomina con un $11,65 \%$ es menos de 1 hectárea.

Gráfica 3.4.3.2 Actividades sustitutas de la producción de alimentos.

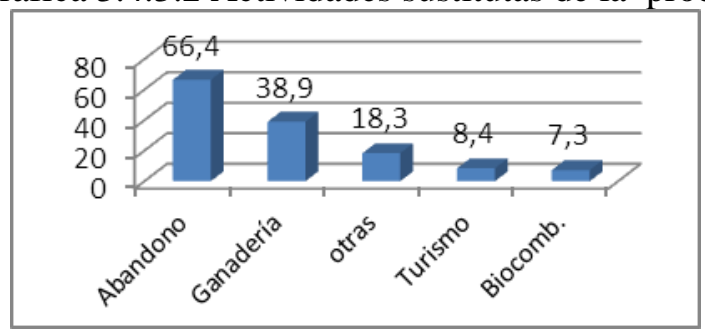

Fuente: Elaboración propia 
Con relación a las actividades que están sustituyendo la producción de alimentos se encuentra que $66,4 \%$ indica que ha abandonado pero no se ha dedicado a otra, seguido por el $38,9 \%$ de ganadería, el $18,3 \%$ por otras actividades y el $8,3 \%$ turismo y el 7,3\% biocombustibles.

\subsubsection{Inventario de Producción}

Del $100 \%$ de los alimentos que se producen, el $71 \%$ corresponde a los tubérculos, seguido del 14,8\% de frutas, los lácteos corresponden al 11,8\% y los cárnicos al 5,2\%.

Gráfica 3.4.4.1 Producción de alimentos

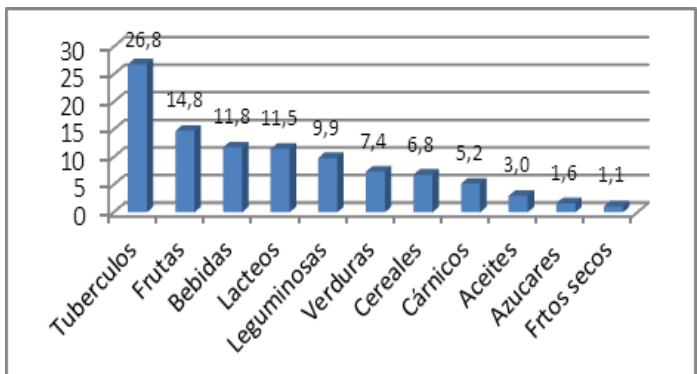

Fuente: Elaboración propia
Gráfica 3.4.4.1 Destinación de los Alimentos

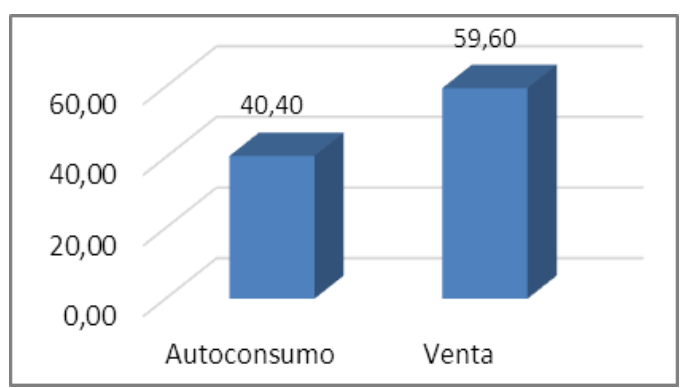

Del $100 \%$ de los alimentos producidos, el 40,4\% son destinados para el auto consumo de las familias y el 59,6\% es destinado para la venta. La cantidad para el autoconsumo aumenta en la medida que el área destinada para la producción es más pequeña y viceversa.

\subsubsection{Acceso a mercados y eficiencia económica.}

Gráfica 3.4.5.1 Mercado de alimentos

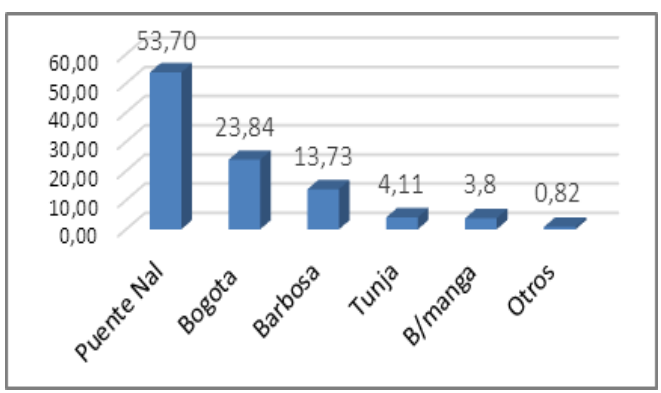

Gráfica. 3.4.5.2Ingresos por la venta/ mes

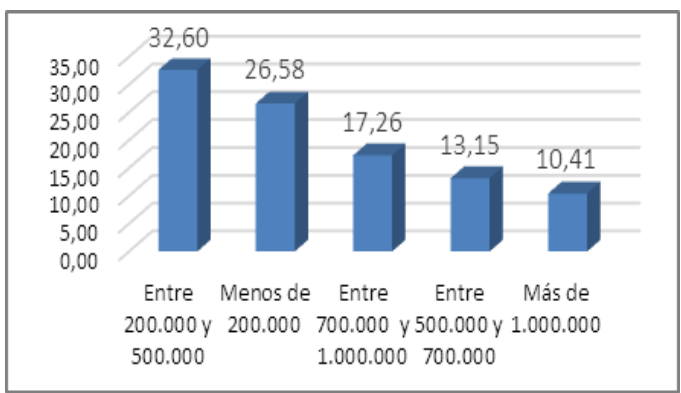

En cuanto al mercado donde se venden los alimentos producidos en Puente Nacional, el $53,7 \%$ de la producción es vendida en el mismo municipio, seguido del 23,8\% en Bogotá y el $13,73 \%$ en Barbosa que es un municipio cercano y el lugar donde menos se vende es Bucaramanga por estar lejos. 
Los ingresos mensuales generados por la venta de alimentos, para el 32,60\% de los productores esta entre $\$ 200.000$ y $\$ 500.000$, seguido por el $26,58 \%$ que son menos de $\$ 200.000$ y tan solo el 10, 41\% los ingresos equivalen a más de \$1’000.000.

Gráfica 3.4.5.3 Costos de producción de Gráfica 3.4.5.4 Margen de utilidad en la

Alimentos al Mes

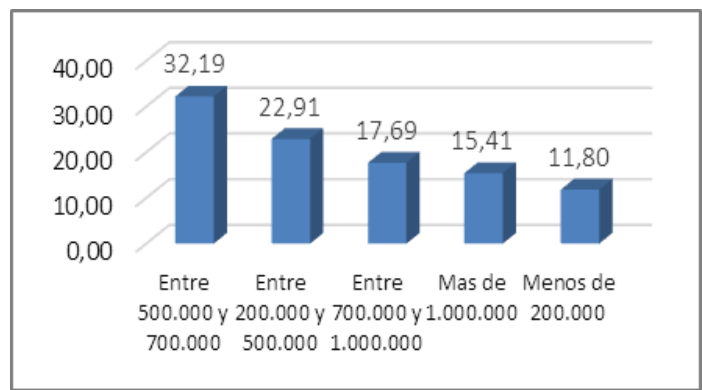

Fuente: Elaboración propia producción de alimentos

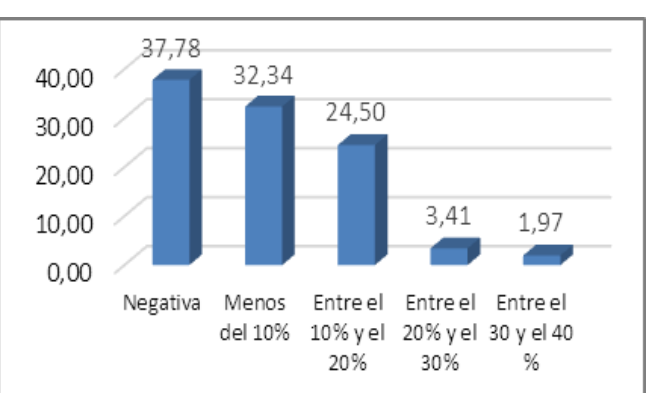

Los costos de la producción mensuales, para un 32,19\% representan entre $\$ 500.000$ y $\$ 700.000$, seguido por el $22,91 \%$ a quienes les representa entre $\$ 200.000$ y $\$ 500.000$ y para el $11,80 \%$ de los productores, el costo representa menos de $\$ 200.000$.

Frente al margen de utilidad en la producción de alimentos el 37,78\% de los productores tienen utilidad negativa, seguido por el $32,34 \%$ que tienen un margen utilidad menor del $10 \%$, el $24,5 \%$ está entre el $10 \%$ y $20 \%$, el $3,41 \%$ está entre el $20 \%$ y $30 \%$ y solo el $1,97 \%$ manifiesta tener un margen de utilidad entre el $30 \%$ y $40 \%$

\subsubsection{Financiación}

Gráfica 3.4.6.1 Financiación de la producción Gráfica 3.4.6.2 Tipos de Crédito
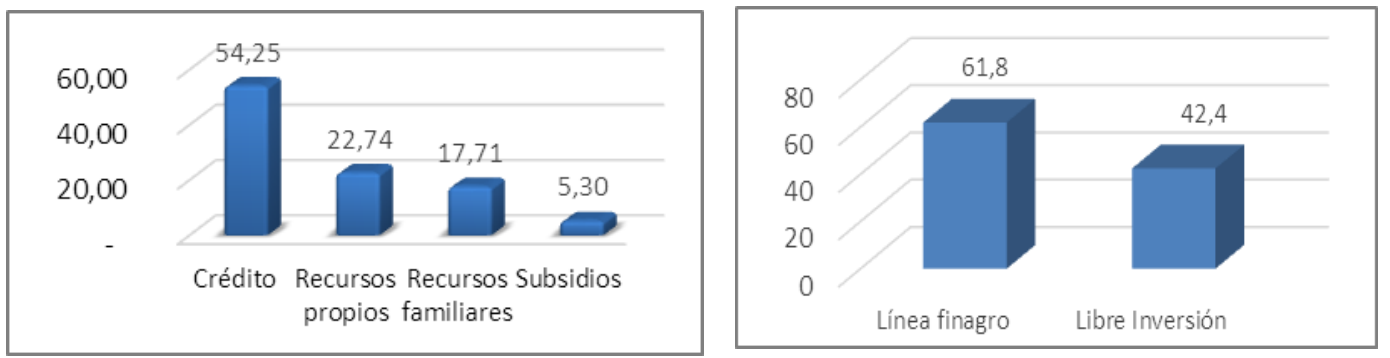

El 54,2\% de los productores financia sus sistemas de producción con recursos de crédito, el 22,7 con recursos propios y el $22,74 \%$ con recursos propios, tan solo el 5,3\% financiaron sus sistemas de producción con subsidios provenientes del comité de cafeteros. El tipo de crédito pactado corresponde al línea finagro el $68.8 \%$ y a libre inversión el 42,4\%. 

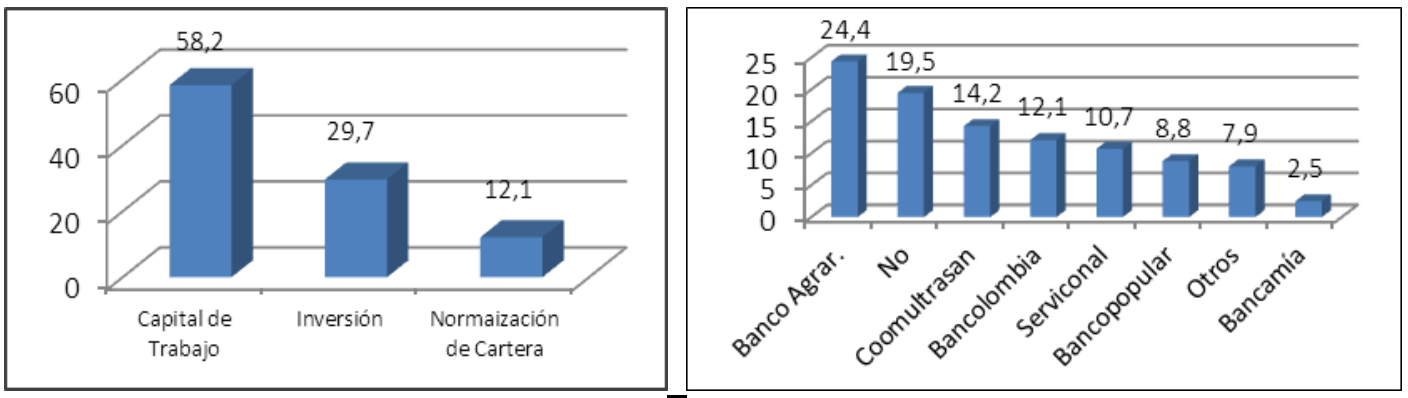

Fuente: Elaboración propia

Frente al tipo de servicio adquirido con el crédito, el 58,2\% de los productores lo adquirió para capital de trabajo, el $29,7 \%$ para inversión y el 12,1\% solicito el crédito para normalización de cartera.

En cuanto a las deudas de los productores, el $19,5 \%$ no tienen ninguna deuda y el $80,5 \%$ reporta tener alguna deuda. Respecto a los acreedores de los productores, el 24,4\% le debe al banco agrario, seguido por el 14,25\% le deben a coomultrasan, el 7,9\% tiene deudas con otras personas y el resto está repartido en diversas entidades financieras privadas.

\subsubsection{Asistencia Técnica}

Gráfica 3.4.7.1Frecuencia de la Asistencia Técnica Gráfica 3.4.7.2 Prestador de Asistencia Técnica
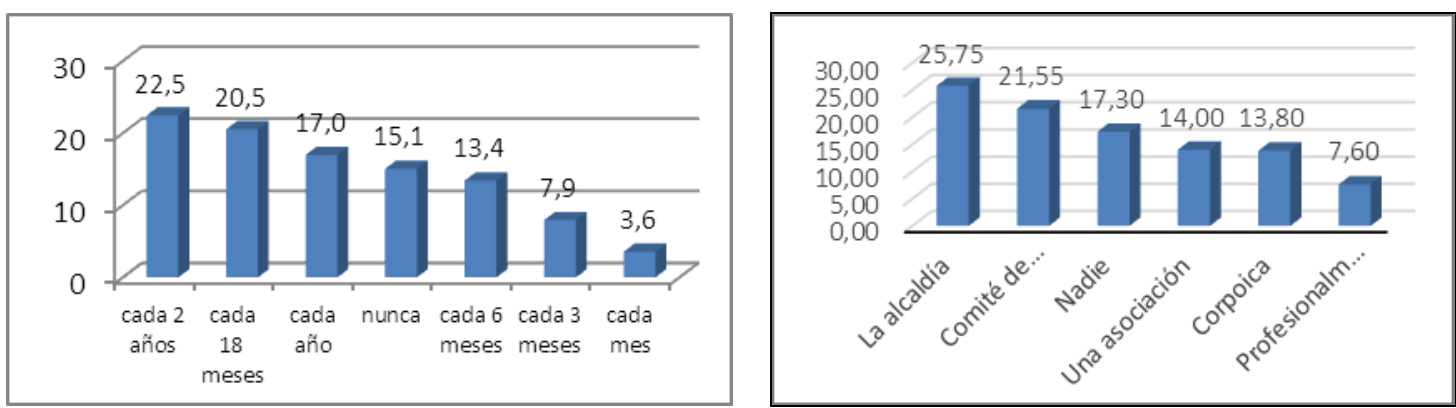

Fuente: Elaboración propia

La asistencia técnica que reciben los productores es cada dos años para el 22,5\%, seguido de cada 18 meses para el $20,5 \%$, el $15,1 \%$ nunca la ha recibido y tan solo el $3,6 \%$ recibe asistencia técnica cada mes.

En cuanto a quien presta la asistencia técnica, el 25,75\% manifiesta que ha sido la alcaldía municipal, seguida por el 21,55\% el comité de cafeteros, al 17,30\% nadie le ha prestado asistencia técnica y al 7,6\% se la presta un profesional particular. 
La encuesta permitió conocer de fuentes primarias, cómo vivieron los productores agropecuarios del municipio la producción de alimentos, todos los aspectos que en ella intervinieron y como la relacionaron con la seguridad alimentaria tanto para sus familias como para la población en general durante el periodo en estudio. 


\section{Capítulo 4. Análisis cuantitativo de la Incidencia de la política agropecuaria en la disponibilidad de alimentos, para garantizar la seguridad alimentaria.}

Con este capítulo, se espera que haya coherencia entre la producción de alimentos, la seguridad alimentaria y la política pública como determinante en este fenómeno económico.

\subsection{Modelo econométrico}

Considerando que un modelo econométrico es un "conjunto de ecuaciones concebidas para proporcionar una explicación cuantitativa del comportamiento de las variables económicas" [Christ (1968), pág. 344]. En ese sentido, se hizo el análisis de lo que constituye el valor de la producción de alimentos para los productores; es decir la composición del PIB como valor de la producción desde la oferta.

Tabla No. 4.1 Composición del PIB de la Oferta de Alimentos.

\begin{tabular}{|c|l|}
\hline \multirow{2}{*}{$\begin{array}{c}\text { El PIB, Valor de la Producción desde } \\
\text { la Oferta. }\end{array}$} & Salarios \\
\cline { 2 - 2 } & Impuestos - Subsidios \\
\cline { 2 - 2 } & Utilidad Neta (Margen de utilidad) \\
\cline { 2 - 2 } & Valor agregado (Insumos, asistencia técnica) \\
\hline
\end{tabular}

Fuente: Elaboración propia

Teniendo en cuenta la tabla 4.1, los datos económicos correspondientes a cada variable, son consolidados como datos de panel, consistente en la observación de múltiples fenómenos en una muestra de individuos, datos que fueron tomados en determinado tiempo mediante una encuesta, tabulados y analizados.

Posteriormente para trabajar el modelo econométrico, con estos datos se construyen las bases de datos y con ello, se aplicó una regresión lineal con el fin de modelar la relación entre la variable dependiente o endógena $Y$ que es: (El valor de la producción de alimentos) y las variables independientes, explicativas o exógenas $X_{i}$ que son: (El valor de los incentivos, otras actividades que sustituyen la producción de alimentos, los subsidios recibidos, las deudas de los productores, el valor de los insumos, el margen de utilidad y la tenencia de la tierra).

Tabla No. 4.2 Variables en estudio

\begin{tabular}{|c|l|}
\hline Variable dependiente $\mathbf{Y}$ & \multicolumn{1}{|c|}{ Variables independientes $\mathbf{X}_{\mathbf{i}}$} \\
\hline \multirow{4}{*}{$\begin{array}{c}\text { El valor de la } \\
\text { producción de } \\
\text { alimentos }\end{array}$} & El valor de los incentivos \\
\cline { 2 - 2 } & Otras actividades que sustituyen la producción de alimentos \\
\cline { 2 - 2 } & El valor de los subsidios recibidos \\
\cline { 2 - 2 } & El valor de las deudas de los productores \\
\cline { 2 - 2 } & El valor de los insumos \\
\cline { 2 - 2 } & El margen de utilidad \\
\cline { 2 - 2 } & La tenencia de la tierra \\
\hline
\end{tabular}

Fuente: Elaboración propia 
Es así como se plantea la ecuación teóricamente:

$$
\begin{aligned}
& Y_{i}=f\left(X_{i} \ldots\right) \quad Y_{i}=\beta_{o}+\beta_{i} X_{i p}+\mathcal{E}_{\mathrm{i}} \\
& Y_{i}=\beta_{o}+\beta_{1} X_{1}+\beta_{2} X_{2}+\beta_{3} X_{3}+\beta_{4} X_{4}+\beta_{4} X_{4}+\beta_{5} X_{5}+\beta_{6} X_{6}+\beta_{7} X_{7}+\mathcal{E}_{\mathrm{i}}
\end{aligned}
$$

Con el modelo se busca comprobar la hipótesis nula planteada en la investigación: "La política agropecuaria en materia de disponibilidad de los alimentos, no es suficiente para atender las necesidades de seguridad alimentaria de la población rural del municipio de Puente Nacional Santander"; Para ello se considera entonces, que los estimadores de los parámetros o coeficientes de las variables explicativas:

$\left(\beta_{o}+\beta_{1} X_{1}+\beta_{2} X_{2}+\beta_{3} X_{3}+\beta_{4} X_{4}+\beta_{4} X_{4}+\beta_{5} X_{5}+\beta_{6} X_{6}+\beta_{7} X_{7}\right)$, sean estadísticamente significativos y que el error estimado $\left(\mathcal{E}_{\mathrm{i}}\right)$ no sea estadísticamente significativo; es decir, que los valores de la probabilidad $(\mathrm{P})$ resulten ser menores a $\alpha=0.05$, entonces son estadísticamente significativos, a un nivel del 5\% de significancia, o 95\% de intervalo de confianza.

\subsection{Lo esperado del Modelo}

En este capítulo se considera la producción de alimentos un eje fundamental de la política agropecuaria, se espera que la variable dependiente Y que como es: El valor de la producción de alimentos desde la oferta a precios corrientes, esté explicado por el comportamiento de las variables independientes $X_{i}$ que son: el valor de los incentivos, las otras actividades que sustituyen la producción de alimentos, el valor de los subsidios recibidos, el valor de las deudas, el valor de los insumos, el margen de utilidad y la tenencia de la tierra.

\section{Para que la Política Agropecuaria, incida positivamente en la Producción de Alimentos, se espera que las variables se relacionen de la siguiente manera:}

1. El valor de la producción desde la oferta depende de los incentivos otorgados por la política pública: entre más alto sea el valor de los incentivos que reciben los productores, más bajo es el valor de la producción desde la oferta, un nivel alto de incentivos públicos, con lleva a que los productores tengan que pagar menos para obtener su producción y de esta manera pueda ofrecer sus productos a precios bajos en el mercado.

2. El valor de la producción desde la oferta, depende de otras actividades que sustituyen la producción de alimentos: entre más bajo sea la sustitución de la producción de alimentos por otras actividades, el valor de la producción desde la oferta disminuye, porque es más tierra destinada a los alimentos y los costos disminuirían para el productor y de la misma forma los productos llegan al mercado con precios más accesibles al consumidor.

3. El valor de la producción desde la oferta, depende del valor de los subsidios recibidos: entre más alto sea el valor de los subsidios que el productor recibe, el valor de la producción desde la oferta disminuye, lo que indica que el productor obtiene una producción más barata y ofrecerá unos productos con precios competitivos. 
4. El valor de la producción desde la oferta depende del valor de las deudas de los productores: entre más bajo sea el valor de las deudas o las tasas de interés, más bajo será el valor de la producción desde la oferta por la disminución del costo financiero y esto se refleja en términos de precios de los productos en el mercado.

5. El valor de la producción desde la oferta, depende del valor de los insumos: entre más bajo sea el valor de los insumos, más bajo es será el costo de producción, por tanto el valor de la producción desde la oferta y con ello los precios de los alimentos en el mercado.

6. El valor de la producción desde la oferta depende del margen de utilidad: si el margen de utilidad es alto, indica que la producción se ha obtenido a un costo bajo y por tanto el valor de la producción desde la oferta es bajo y los precios son competitivos en el mercado.

7. El valor de la producción depende de la tenencia de tierra: entre más cantidad de tierra se disponga para la producción, se espera que sea más bajo el costo de producción y el valor de producción desde la oferta disminuye con el mismo efecto sobre los precios.

\section{Para que la Producción de Alimentos incida positivamente en la Seguridad Alimentaria, se espera que las variables se comporten de la siguiente manera:}

1. Las variables explicativas deben incidir positivamente en el valor de la producción desde la oferta como se indica en los anteriores párrafos, es decir, deben generar una disminución en el valor de la producción desde la oferta, para que los precios fijados por los productores a los alimentos sean competitivos en el mercado. De este modo, se da la posibilidad a los consumidores que optan por elegir una canasta de alimentos con precios más bajos, para que accedan a los alimentos. Por otra parte una estructura de precios basada en un costo bajo, le facilita a los alimentos nacionales el competir con los alimentos importados.

2. Al tener una disminución en el valor de la producción desde la oferta, facilita que el productor maximice sus beneficios y la producción de alimentos se convierta en una actividad económica rentable y sostenida, sin tener que sustituirla por otra para buscar el sustento. Dicha sostenibilidad garantizaría una oferta permanente de alimentos.

3. Una disminución en el valor de la producción, hace que los sistemas de producción de alimentos sean permanentemente, fuente de abastecimiento de alimentos para el autoconsumo de los productores y sus familias.

4. La disminución del valor de la producción desde la oferta, facilita las condiciones del mercado en términos de precios. Por ello la producción de alimentos debe ser un generador de ingresos para acceder a otros bienes de la canasta básica alimentaria que la finca no produce y satisfacer otras necesidades de los productores y sus familias. 
En este cuadro de salida del programa econométrico Stata, se aprecia en primer lugar que existe una regresión lineal significativa a nivel global por el valor de $F=0.0000$, en segundo lugar, las variables: valor de los insumos y valor de los incentivos son estadísticamente significativas $\leq 0,05$ para los medianos productores de alimentos.

El Coeficiente de Determinación $\left(\mathrm{R}^{2}\right)$ : de acuerdo con los resultados, el valor de los incentivos y el valor de los insumos explican la variación del valor de la producción en un $46,8 \%$.

El Coeficiente de Correlación (r), de acuerdo con los resultados el grado de asociación y el grado de dependencia lineal entre el valor de los insumos, el valor de los incentivos y el valor de la producción es del 0,45.

Entonces al 95\% de confianza en Medianos Productores de Alimentos se encuentra que:

- Un aumento en una unidad en el valor de los incentivos, disminuye el valor de la producción desde la oferta a precios corrientes en - 0,1784786. Es decir, cuando aumenta el valor de los incentivos, el valor de la producción desde la oferta se hace más bajo. Esto explicado porque el productor mediano no debe incurrir en el pago del incentivo, ya que es otorgado por alguna institución. Cuando el productor mediano se va al mercado, el valor de la producción, se ve compensado por el precio, toda vez que al tener un valor de la producción bajo, puede fijar precios bajos y competir con el precio de los alimentos importados; condición que es favorable para el productor.

- Un aumento en una unidad en el valor de los insumos, aumenta el valor de la producción desde la oferta a precios corrientes en 0,635438. Es decir, cuando los insumos aumentan de precio, el valor de la producción aumenta desde la oferta. Esto hace que el productor mediano tenga una expectativa de precio alto y cuando va al mercado el valor de la producción no se ve compensado por los precios relativos bajos máxime frente a los precios de los alimentos importados; condición que es desfavorable para el productor.

\subsubsection{Regresión Lineal Múltiple Pequeños Productores de Alimentos.}

Tabla 4.3.2 Resultados del Modelo de Regresión en Pequeños Productores de Alimentos.

- regress logpequeñproducción logpincentivos logpinsumos UTILIPORPEQUEÑOS

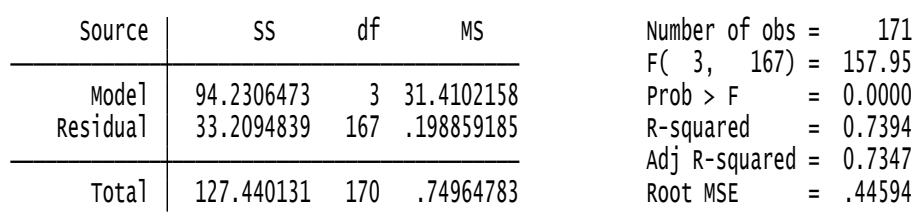

\begin{tabular}{r|rrrrrr}
\hline logpequeñp n & Coef. & Std. Err. & $\mathrm{t}$ & $\mathrm{p}>|\mathrm{t}|$ & & [95\% Conf. Interval] \\
\hline logpincent s & .082545 & .0261756 & 3.15 & 0.002 & .0308673 & .1342227 \\
logpinsumos & .7449936 & .0379522 & 19.63 & 0.000 & .6700657 & .8199214 \\
UTILIPORPE $S$ & .0117404 & .0023085 & 5.09 & 0.000 & .0071828 & .016298 \\
_cons & 3.145654 & .56641 & 5.55 & 0.000 & 2.027407 & 4.263901 \\
\hline
\end{tabular}


En este cuadro de salida del programa econométrico Stata, se aprecia en primer lugar que existe una regresión lineal significativa a nivel global por el valor de $\mathrm{F}=0.0000$, en segundo lugar, que las variables: el valor de los incentivos, el valor de los insumos y la utilidad en porcentaje, son estadísticamente significativos $\leq 0,05$ para los pequeños productores de alimentos.

El Coeficiente de Determinación $\left(\mathrm{R}^{2}\right)$ de acuerdo con los resultados, el valor de los incentivos, el valor de los insumos y la utilidad en porcentaje, explican la variación del valor de la producción en un 73,9\%.

El Coeficiente de Correlación (r) de acuerdo con los resultados, el grado de asociación y el grado de dependencia lineal entre el valor de los incentivos, el valor de los incentivos, el valor de los insumos, la utilidad en porcentaje y el valor de la producción es de: 0,73.

Entonces, al 95\% de confianza en Pequeños Productores de Alimentos se encuentra que:

- Un aumento en una unidad en el valor de los incentivos, aumenta el valor de la producción desde la oferta a precios corrientes en 0,082545. Es decir, cuando aumenta el valor de los incentivos el valor de la producción aumenta desde la oferta; en este caso particular, contrario a lo que sucede con el productor mediano, el valor de los incentivos recibidos no es significativo para llegar a la disminución del valor de la producción. Esto indica como el productor pequeño si debe incurrir en el pago de los incentivos suficientes como la asistencia técnica de los cultivos, ya que no es otorgado por alguna institución; condición que es desfavorable para el productor.

- Un aumento en una unidad en el valor de los insumos, aumenta el valor de la producción desde la oferta a precios corrientes en 0,7449936. Es decir, cuando los insumos aumentan de precio, el valor de la producción aumenta desde la oferta. Cuando el productor pequeño se va al mercado, el valor de la producción, no se ve compensado por el precio, toda vez que tiene que bajar los precios frente a los precios de los alimentos importados; condición que es desfavorable para el productor.

- Por cada unidad adicional en el margen de utilidad, el valor de la producción aumenta desde la oferta a precios corrientes en 0,0117404. Es decir, esta relación casi inelástica explica que cuando se espera que el margen de utilidad aumente el valor de la producción aumentará desde la oferta; sin embargo cuando se lleva la producción al mercado, el valor de la misma no se ve compensado por el precio, toda vez que el productor tiene que bajar los precios frente a los precios de los alimento frente a la competencia y por consiguiente se pierde el margen de utilidad; condición que es desfavorable para el productor. 


\subsubsection{Regresión Lineal Múltiple Productores de Alimentos con Tierra Propia.}

Tabla 4.3.3 Resultados del Modelo de Regresión en Productores de Alimentos con Tierra Propia.

\begin{tabular}{|c|c|c|c|c|c|}
\hline Source & SS & $d f$ & MS & \multirow{4}{*}{\multicolumn{2}{|c|}{$\begin{array}{l}\text { Number of obs } \\
F(4, \quad 172) \\
\text { Prob }>F \\
\text { R-squared } \\
\text { Adj R-squared } \\
\text { Root MSE }\end{array}$}} \\
\hline Model & $\begin{array}{l}76.9927276 \\
5\end{array}$ & \multirow{2}{*}{\multicolumn{2}{|c|}{$\begin{array}{rr}4 & 19.2481819 \\
172 & .307197491\end{array}$}} & & \\
\hline & J & & & & \\
\hline Total & 129.830696 & \multicolumn{2}{|l|}{176} & & \\
\hline LOGPPOD & Coef. & Std. Err. & $t$ & $P>|t|$ & [95\% Conf. \\
\hline SUBSIDIOS & -.1985541 & .0869836 & -2.28 & 0.024 & .3702468 \\
\hline logdeu & . 1301028 & . 0416361 & 3.12 & 0.002 & \\
\hline loginsumos & .5684226 & .05353999 & 10.62 & 0.000 & .4627428 \\
\hline UTILIDADPO & .0167 & .003025 & 5.52 & 0.000 & .010 \\
\hline _cons & 4.890021 & .74912 & 6.53 & 0.000 & 3.411369 \\
\hline
\end{tabular}

En este cuadro de salida del programa econométrico Stata, se aprecia en primer lugar que existe una regresión lineal significativa a nivel global por el valor de $\mathrm{F}=0.0000$, en segundo lugar, que las variables: subsidios recibidos, el valor de las deudas, el valor de los insumos y la utilidad en porcentaje, son estadísticamente significativos $\leq 0,05$ para los productores de alimentos con tierra propia.

El Coeficiente de Determinación $\left(\mathrm{R}^{2}\right)$, de acuerdo con los resultados, el valor de las deudas, subsidios recibidos, el valor de los insumos y la utilidad en porcentaje, explican la variación del valor de la producción en un 59,3\%.

El Coeficiente de Correlación (r), de acuerdo con los resultados, el grado de asociación y el grado de dependencia lineal entre el valor de las deudas, los subsidios recibidos, el valor de los insumos, la utilidad en porcentaje y el valor de la producción es de: 0,58.

Entonces, al 95\% de confianza en Productores de Alimentos con Tierra Propia se encuentra:

- Un aumento en una unidad en valor de los subsidios, disminuye el valor de la producción -0,1985541. Es decir, cuando aumenta el valor de los subsidios, el valor de la producción se hace más bajo desde la oferta; esto debido a que el productor con tierra propia, no debe incurrir en el pago de asuntos que son subsidiados, ya que son otorgado por alguna institución; condición que es favorable para el productor. 
- Un aumento en una unidad en valor de las deudas, aumenta el valor de la producción desde la oferta a precios corrientes en 0,1301028; Es decir, cuando aumenta el valor de las deudas, el valor de la producción se hace más alto desde la oferta; esto indica que el productor con tierra propia, debe incurrir en deudas que generan el pago de cuotas pactadas a tasa de interés altas, por los recursos obtenidos para financiar su producción y esto eleva el valor de la producción. Cuando el productor se va al mercado, el valor de la producción, no se ve compensado por el precio de los alimentos, toda vez que tiene que bajar los precios frente a los precios de los alimentos importados; condición que es desfavorable para el productor.

- Un aumento en una unidad en el valor de los insumos, aumenta el valor de la producción desde la oferta a precios corrientes en 0,5684226. Es decir, cuando los insumos aumentan de precio, el valor de la producción aumenta desde la oferta. Cuando el productor con tierra propia se va al mercado, el valor de la producción elevado, genera un expectativa de precio alto, sin embargo se tiene que bajar los precios frente a los precios de la competencia, principalmente los importados; condición que es desfavorable para el productor.

- Por cada unidad adicional en el margen de utilidad, el valor de la producción aumenta desde la oferta a precios corrientes en 0,0167. Es decir, esta relación casi inelástica explica que cuando el productor espera que el margen de utilidad aumente, el valor de la producción aumentará desde la oferta; sin embargo cuando se lleva la producción al mercado, el valor de la misma no se ve compensado por el precio, toda vez que el productor tiene que bajar los precios frente a los precios de los competidores por consiguiente se pierde el margen de utilidad; condición que es desfavorable para el productor.

\subsubsection{Regresión Lineal Múltiple Productores de Alimentos con Tierra Arrendada.}

Tabla 4.3.4 Resultados del Modelo de Regresión en Productores de Alimentos con Tierra Arrendada.

. regress logproduccionarriendo OTRASACTIVIDARRIENDO logdeudaarriendo loginsumosarrien UTILIDADARRIENDO

\begin{tabular}{|c|c|c|c|c|c|}
\hline Source & SS & $d f$ & MS & Number of obs & \\
\hline Model & 63.6497256 & 4 & 15.9124314 & Prob $>\mathrm{F}$ & $=0.0000$ \\
\hline Residual & 33.5319687 & 111 & .302089808 & R-squared & $=0.6550$ \\
\hline Total & 97.1816942 & 115 & .845058211 & Root MSE & $\begin{array}{l}=.042 \mathrm{~J} \\
=.54963\end{array}$ \\
\hline
\end{tabular}

\begin{tabular}{r|rrrrrr}
\hline logproducc 0 & Coef. & Std. Err. & $\mathrm{t}$ & $\mathrm{P}>|\mathrm{t}|$ & [95\% Conf. Interval] \\
\hline OTRASACTIV 0 & .2196942 & .1028631 & 2.14 & 0.035 & .0158641 & .4235243 \\
logdeudaar 0 & .1397015 & .0480127 & 2.91 & 0.004 & .0445612 & .2348419 \\
loginsumos n & .5827654 & .0594353 & 9.81 & 0.000 & .4649904 & .7005404 \\
UTILIDADAR 0 & .0131392 & .0031124 & 4.22 & 0.000 & .0069717 & .0193066 \\
_cons & 4.395809 & .8397993 & 5.23 & 0.000 & 2.731691 & 6.059927
\end{tabular}


En este cuadro de salida del programa econométrico Stata, se aprecia en primer lugar que existe una regresión lineal significativa a nivel global por el valor de $\mathrm{F}=0.0000$, en segundo lugar, que las variables: la sustitución de la producción de alimentos por otras actividades, el valor de las deudas, el valor de los insumos y la utilidad en porcentajes, son estadísticamente significativos $\leq 0,05$ para productores de alimentos con tierra arrendada.

El Coeficiente de Determinación $\left(\mathrm{R}^{2}\right)$, de acuerdo con los resultados, la sustitución de la producción de alimentos por otras actividades, el valor de las deudas, el valor de los insumos y la utilidad en porcentajes explican la variación del valor de la producción en un $65,5 \%$.

El Coeficiente de Correlación (r), de acuerdo con los resultados, el grado de asociación y el grado de dependencia lineal entre la sustitución de la producción de alimentos por otras actividades, el valor de las deudas, el valor de los insumos, la utilidad en porcentajes y el valor de la producción es de: 0,64.

Entonces, al 95\% de confianza en Productores de Alimentos con Tierra Arrendada se encuentra que:

- Por cada unidad adicional en la sustitución de la producción de alimentos por otras actividades, el valor de la producción aumenta desde la oferta a precios corrientes en 0,2196952. Es decir, cuando el productor con tierra arrendada aumenta el desarrollo de otras actividades que sustituyen la producción de alimentos, está disminuyendo su producción de alimentos y con ello agotando las ventajas en términos de reducción de costos que tenía, pues ahora la escala de producción no aumenta sino que disminuye, incrementando aún más el valor de la producción el valor de la producción de alimentos desde la oferta, condición que es desfavorable para el productor.

- Un aumento en una unidad en el valor de las deudas, aumenta el valor de la producción desde la oferta a precios corrientes en 0,1397015. Es decir, cuando aumenta el valor de las deudas, el valor de la producción se hace más alto, esto explicado porque el productor con tierra arrendada, incurre en deudas que generan el pago de cuotas e intereses altos por los recursos obtenidos para financiar su producción y esto eleva el valor de la producción. Cuando el productor se va al mercado, el valor de la producción, no se ve compensado por el precio, condición que es desfavorable para el productor.

- Un aumento en una unidad en el valor de los insumos, aumenta el valor de la producción desde la oferta a precios corrientes en 0,5827654, Es decir, cuando los insumos aumentan de precio, el valor de la producción aumenta desde la oferta. Cuando el productor con tierra arrendada se va al mercado, el valor de la producción, no es cubierto por el precio relativo del mercado que es bajo, teniendo que vender sus alimentos en una condición que es desfavorable.

- Por cada unidad adicional en el margen de utilidad, el valor de la producción aumenta desde la oferta a precios corrientes en 0,0131392. Es decir, esta relación casi inelástica 
explica que cuando el productor espera que el margen de utilidad aumente, el valor de la producción aumentará desde la oferta; sin embargo cuando se lleva la producción al mercado para venderla debe bajar los precios frente a los precios de los alimentos importados y de la competencia; entonces, se pierde el margen de utilidad, condición que es desfavorable para el productor.

\subsection{Validación de la hipótesis.}

La investigación planteó como hipótesis nula: $H_{O}$ "La política agropecuaria no es suficiente en materia de producción de alimentos, para atender las necesidades de seguridad alimentaria de la población rural del municipio de Puente Nacional (S)". Planteó como hipótesis alternativa: $H_{1}$ "La política agropecuaria si es suficiente en materia de producción de los alimentos, para atender las necesidades de seguridad alimentaria de la población rural del municipio de Puente Nacional (S)”.

La validación de la hipótesis se hace a la luz de los resultados arrojados por el estudio descriptivo - cualitativo, en donde se recogió y se validó información de fuentes primarias, que fue analizada para presentar los primeros hallazgos importantes y posteriormente con dicha información primaria plantear un modelo econométrico, en el que las pruebas, resultados y análisis cuantitativo, ratifican los primeros hallazgos.

En primer lugar, pese a que todas las variables independientes que fueron estudiadas están relacionadas con la variable dependiente; se encuentra que unas variables presentaron más significancia estadística que otras. En segundo lugar, existen variables que de forma general explican el fenómeno en todas las categorías de análisis, pero también existen variables que son explicativas o representativas de una categoría en particular. $^{33}$

En tal sentido se encuentra, que el municipio de Puente Nacional - Santander continua produciendo alimentos de manera general tanto "productores medianos y pequeños como productores con tierra propia y arrendada", pero presentan grandes limitantes o inconvenientes como el elevado precio de los insumos, seguido del insuficiente valor recibido como incentivos de instituciones públicas, y el deficiente margen de utilidad.

De manera particular se encuentra que tanto en "productores con tierra propia y con tierra arrendada" las deudas aumentan en la medida que se produce más y quienes producen con tierra arrendada han reemplazado la producción de alimentos por otras actividades más atractivas y para quienes producen con tierra propia los subsidios son claramente insuficientes.

\footnotetext{
${ }^{33}$ Categorías de análisis: La primera categoría corresponde al tamaño de los productores, en ella se agrupa la información de los productores medianos y productores pequeños según Finagro. La segunda categoría corresponde a la tenencia de la tierra; en ella se agrupa la información de los productores que son propietarios de la tierra y los que la tienen en arrendamiento.
} 
Estos hallazgos indican la insuficiencia de la política agropecuaria frente a la producción de alimentos y por consiguiente, advierten el riesgo que corre la seguridad alimentaria en esta población.

En consecuencia esta investigación acepta la hipótesis nula: $H_{O}$ "La política agropecuaria no es suficiente en materia de producción de alimentos, para atender las necesidades de seguridad alimentaria de la población rural del municipio de Puente Nacional (S)".

\subsection{Incidencia de la política agropecuaria en la producción de alimentos para la seguridad alimentaria.}

Los resultados de esta investigación muestran varios puntos de análisis sobre la forma como incide la política agropecuaria en la producción de alimentos y a sí mismo la producción de alimentos en la seguridad alimentaria. En la siguiente tabla se resume la interpretación de los resultados del modelo planteado.

Tabla 4.5.1 "Incidencia en el aumento o disminución del valor de la producción por efecto de las variables independientes."

\begin{tabular}{|c|l|c|}
\hline $\begin{array}{c}\text { Tipo de productor } \\
\text { de Alimentos. }\end{array}$ & $\begin{array}{c}\text { Afectación Positiva. } \\
\text { (Disminución del Valor de la } \\
\text { Producción desde la oferta a } \\
\text { precios corrientes) }\end{array}$ & $\begin{array}{c}\text { Afectación Negativa. } \\
\text { (Aumento del Valor de la } \\
\text { Producción desde la oferta a precios } \\
\text { corrientes) }\end{array}$ \\
\hline Medianos & El Valor de los Incentivos & El Valor de los Insumos \\
\hline \multirow{2}{*}{ Pequeños } & - & El Valor de los Incentivos \\
\cline { 2 - 3 } & - & El Valor de los Insumos \\
\cline { 2 - 3 } & - & El Margen de Utilidad en Porcentaje \\
\hline \multirow{3}{*}{ Con tierra propia } & El Valor de los Subsidios & El Valor de las Deudas \\
\cline { 2 - 3 } & - & El Valor de los Insumos \\
\cline { 2 - 3 } & - & El Margen de Utilidad en Porcentaje \\
\hline \multirow{3}{*}{ Con tierra arrendada } & - & La Sustitución por Otras actividades \\
\cline { 2 - 3 } & - & El Valor de las Deudas \\
\cline { 2 - 3 } & - & El Valor de los Insumos \\
\cline { 2 - 3 } & - & El Margen de Utilidad en Porcentaje \\
\hline
\end{tabular}

Fuente: Elaboración Propia.

En la tabla 4.5.1 se aprecia claramente como las variables explicativas se comportan en su mayoría a favor del aumento en el valor de la producción desde la oferta, generando una afectación negativa para el productor.

\subsubsection{El Valor de la producción de alimentos y el valor de los insumos.}

El valor de la producción de alimentos desde la oferta, esta explicado en primer orden por el valor de los insumos, que para todos los productores tanto productores medianos como pequeños, productores con tierra propia y arrendada, tiene el nivel de significancia más elevado dentro de todas las variables estudiadas. Indicando en todos los casos que un 
aumento en una unidad en el valor de los insumos, aumenta el valor de la producción de alimentos desde la oferta. Esto porque que el costo de los insumos es determinante en el costo de la producción de los alimentos y un aumento de los mismos genera una condición desfavorable para el productor.

\subsubsection{El Valor de la producción de alimentos y el valor de los incentivos.}

El valor de la producción de alimentos desde la oferta, está explicado por el valor de los incentivos que únicamente para los productores medianos un aumento en una unidad en los incentivos genera una disminución del valor de la producción desde la oferta. En el caso de los productores pequeños el comportamiento es opuesto, un aumento en una unidad en los incentivos genera un aumento del valor de la producción. Lo anterior indica que en el caso en que el productor recibe algún tipo de incentivo de una institución pública, su producción se hace menos costosa, pero cuando no recibe el incentivo, entonces ocurre lo contrario y es cuando se genera el aumento del valor de la producción desde la oferta.

\subsubsection{El Valor de la producción de alimentos y margen de utilidad.}

El valor de la producción de alimentos desde la oferta, esta explicado por el margen de utilidad, que para los productores pequeños, como para los productores con tierra propia y arrendada, tiene un nivel de significancia alto, indicando en todos los casos que un aumento en una unidad en el margen de utilidad, aumenta el valor de la producción de alimentos desde la oferta. Toda vez que el productor espera genera una utilidad de ésta actividad; sin embargo, como el productor tiene una estructura de costos alta, entonces aumentar el margen de utilidad genera aumentos en el valor de la producción desde la oferta. Si existiera el caso contrario, es decir una estructura de costos baja, no daría lugar a que un aumento en el margen de utilidad aumentar el valor de la producción, sino que permanecería constante y los precios en el mercado no se afectarían.

\subsubsection{EI Valor de la producción de alimentos y el valor de las deudas.}

El valor de la producción de alimentos desde la oferta, esta explicado por el valor de las deudas, que para los productores con tierra propia y tierra arrendada, tiene un nivel de significancia alto, indicando en todos los casos que un aumento en una unidad en el valor de las deudas, aumenta el valor de la producción de alimentos desde la oferta, porque en la medida que el productor asume deudas provenientes de créditos pactados a tasas de interés altas, son más altos los pagos que debe hacer y encuentra que esto encarece aún más su producción; situación que es desfavorable. 


\subsubsection{EI Valor de la producción de alimentos y la sustitución por otras actividades.}

El valor de la producción de alimentos esta explicado por la sustitución de la producción de alimentos por otras actividades, que para los productores con tierra arrendada, tiene un nivel de significancia alto, indicando que en este caso un aumento en una unidad en la sustitución por otra actividad, aumenta el valor de la producción de alimentos desde la oferta.

Lo anterior indica que cuando crece la atracción del productor por desarrollar cualquier actividad económica que sustituya o reemplace la producción de alimentos, está agotando las ventajas en términos de reducción de costos de producción de alimentos a gran escala, por consiguiente, él tendrá un incremento en el valor de la producción de alimentos de su finca y un efecto de incremento sobre el valor de la producción total de los alimentos.

\subsubsection{EI Valor de la producción de alimentos y el valor de los subsidios.}

El valor de la producción de alimentos desde la oferta, esta explicado por el valor de los subsidios, que para los productores con tierra propia, tiene un nivel de significancia alto, indicando que en este caso un aumento en una unidad en los subsidios, genera una disminución en el valor de la producción de alimentos desde la oferta. Toda vez que el productor no debe incurrir en algunos costos de su producción que son subsidiados; sin embargo cuando ocurre el caso contrario, la ausencia de los subsidios encarece la producción desde la oferta; es decir aumenta el valor.

\subsubsection{El Valor de la producción de alimentos y la tenencia de tierra.}

El valor de la producción de alimentos desde la oferta, esta explicado por la forma de tenencia de la tierra, que para los productores con tierra propia y con tierra arrendada, esta explicado de manera conjunta por el valor de las deudas, el valor de los insumos y el margen de utilidad y de manera individual para los productores con tierra arrenda por la sustitución de la producción por otras actividades; Indicando así que en las dos formas de tenencia de tierra, un aumento en una unidad de estas variables, genera un aumento en el valor de la producción desde la oferta.

De forma particular y contraria, hay una variable que explica el valor de la producción desde la oferta, por la forma de tenencia de la tierra y es el caso de los productores con tierra propia; donde el valor de la producción depende del valor de los subsidios; Indicando que un aumento en una unidad del valor de los subsidios, genera una disminución en el valor de la producción desde la oferta. 


\subsubsection{La Producción de Alimentos y la Seguridad Alimentaria.}

- $\quad$ La producción de alimentos debe ser una actividad económica competitiva y rentable:

Cuando disminuye el valor la producción de alimentos desde la oferta a precios corrientes, los productores pueden emprender actividad económica competitiva en el mercado y además rentable, para especializase en dicha producción. Así mismo lograr unas condiciones socioeconómicas que sirvan como garantía para dedicarse de forma definitiva a esta actividad. En el caso contrario si el valor de la producción aumenta desde la oferta, hace más difíciles las condiciones del mercado en términos de precios, ya que serían elevados frente a la competencia que bien puede ser los alimentos importados o alimentos de otras regiones con precios más competitivos; esta condición lleva al productor a bajar los precios y con ello disminuye la utilidad y la rentabilidad a tal punto que le imposibilita la recuperación total de los recursos invertidos en su producción, desencadenando problemas como la iliquidez, la imposibilidad de cumplir con las obligaciones financieras y la dificultad para acceder a otros bienes de la canasta básica alimentaria, deteriorando paulatinamente sus condiciones de vida.

- $\quad$ Los sistemas de producción como fuente de alimentos para el autoconsumo.

Cuando disminuye el valor de la producción de alimentos desde la oferta, indica a los productores que los alimentos son fáciles de producir y por consiguiente les permite dedicarse a la producción de alimentos para el mercado y simultáneamente garantizar la producción y abastecimiento de alimentos para el autoconsumo de sus familias.

Caso contrario, al aumentar el valor de la producción desde la oferta, indica que producir es más costoso y de mayor riesgo en el mercado, por tanto el productor no expande su producción e inclusive la reduce y al mismo tiempo escasean los alimentos en la finca para el autoconsumo. Esto bajo el entendido que en una forma de auto consumo se da cuando parte de la producción especialmente la que no cumple con requisitos de comercialización es la que se deja para la familia.

Existe otra forma de autoconsumo donde la familia produce alimentos de pan coger que satisfacen parte de las necesidades alimenticias de la familia siendo ésta es una producción que no resulta costosa para alimentar la familia y que ayuden a generan algún ingreso para acceder a otros bienes de la misma canasta básica alimentaria que la finca no produce.

En resumen, desde el punto de vista de la oferta un aumento del valor de la producción de alimentos indica, que el productor obtiene los alimentos a un costo elevado por diversas condiciones dentro de las que se cuentan: el aumento en el valor de los insumos, la disminución en el valor de los incentivos, el aumento en el valor de las deudas, el aumento en el margen de utilidad, el aumento en la sustitución de la producción de alimentos por otras actividades, la disminución del valor de los subsidios y la 
disminución en la tenencia de tierra. El productor espera que el valor aumentado de su producción, sea reconocido en el mercado en términos de precios; si ocurre lo contrario, es decir, que los precios no compensan el valor de la producción, el productor se ve obligado a bajar los precios frente a los precios de los alimentos de la competencia, para rescatar parte del valor de su producción.

La situación se hace compleja para el productor teniendo en cuenta que ha incurrido en deudas por los recursos obtenidos para financiar su producción, las mismas que le generan el pago permanente de cuotas e intereses altos. De igual manera el productor ha adquirido insumos de alto costo y pagado todo tipo de incentivos y fomento que no fueron otorgados por ninguna institución, a esto se le agrega la expectativa de un margen de utilidad alto, que como consecuencia del comportamiento desfavorable de las anteriores variables, no llega a obtenerse sin aumentar el valor de la producción. Finalmente, el productor disminuye su producción de alimentos para sustituirla por otras actividades, agotando las ventajas en términos de reducción de costos que obtendría gracias a la expansión, pues ahora, la escala de producción no aumenta sino que disminuye, incrementando aún más el valor de la producción desde la oferta.

Al productor de alimentos le conviene: "Que el valor de la producción disminuya para que los precios de los alimentos en el mercado puedan ser bajos y no se reflejen en el mercado. Para ello se espera: 1) En el caso del valor de los insumos que no aumente en términos de precios, para no generar aumentos en el valor de la producción o que el aumento de los precios sea controlado. 2) Que el valor de los incentivos institucionales aumente significativamente para apoyar al productor y generar una disminución en el valor de la producción. 3) Que el valor de las deudas, no aumente pudiéndose pactar créditos de fomento a bajo costo par no incrementar el valor de la producción. 4) Que el margen de utilidad aumente, pero con una estructura de costos bajos y así, no incremente el valor de producción. 5) Que los subsidios aumenten significativamente para apoyar al productor y disminuir el valor de la producción. 6) Que las otras actividades que sustituyen la producción de alimentos no sean más atractivas, para evitar que el productor disminuya sus áreas de siembra o en el peor caso abandone la producción, evitando el aumento en el valor de la producción.7) Que el productor pueda acceder a tierras fácilmente para la producción, con ello se evita también el aumento del valor de la producción desde la oferta. 


\section{CONCLUSIONES}

La política agropecuaria de los dos gobiernos del Presidente Álvaro Uribe Vélez, entre el periodo 2002 al 2010, tuvo una incidencia negativa en la producción de alimentos; las acciones fueron evidentemente insuficientes frente a la responsabilidad de garantizar la seguridad alimentaria de una población. Toda vez, que no hubo disposiciones para la regular las variables que determinan la estabilidad del valor de la producción de los alimentos desde la oferta.

Los productores de alimentos encuentran que el valor de la producción de los alimentos aumenta por efecto de los elevados costos; esto los lleva a no ser competitivos en el mercado, por tanto se ven enfrentados a manejar un nivel de precios bajos perdiendo así la oportunidad de generar beneficios. Por consiguiente, los ingresos se ven disminuidos y no compensan los recursos destinados a la producción.

El estudio evidencia que concretamente no hubo una la política agropecuaria clara y en beneficio de los pequeños productores; lo que existió fue unos intentos de política, que por demás no fueron suficientes. No hubo subsidios e incentivos para los pequeños pero si existieron beneficios para los grandes agricultores a favor de los agros negocios.

Claramente se ve comprometida la oferta de alimentos y la seguridad alimentaria de los productores y sus familias, especialmente de quienes consumían parte de su producción y de quienes su única fuente de ingresos es cultivar el campo.

Los productores agrícolas esperan que la política agropecuaria regule el precio de los insumos y las tasas de interés. Que otorgue incentivos como la investigación, transferencia tecnológica y la asistencia técnica. Que subsidie la producción de alimentos nacional y restrinja las cuotas de importación de alimento producidos en Colombia. Que apoye el acceso a los mercados internos y externos en condiciones de competitividad.

La falta de apoyo al sector agropecuario durante estos dos periodos de gobierno, más adelante en el gobierno del Presidente Jun Manuel Santos Calderón, desencadenó en serios problemas sociales. Prueba de ello fue el "Gran Paro Nacional Agrario" de junio de 2013; que llevo a miles de campesinos de todo el país y agremiaciones del sector, a crear los movimientos de Dignidades Campesinas y paralizar las vías nacionales y centrales de abastecimiento por varias semanas. Lo que género que el abandono del sector agropecuario provocara indignación en toda la sociedad, para engrandecer el llamado de atención al gobierno y el estado.

La deficiente política agropecuaria, o la inexistencia de la misma, no solo disminuyo la oferta de alimentos nacionales, sino que contribuyó al deterioro de las condiciones de vida de los productores de alimentos y al aumento de fenómenos como: la malnutrición en los hogares, el desempleo rural y urbano, el desplazamiento por la pobreza, la violencia e inseguridad y la pobreza extrema en poblaciones vulnerables. 
Puente Nacional (S), es un municipio con productores de alimentos que aún trabajan en la producción de alimentos pese a no ser una actividad económica favorable para sus familias; sin embargo, un número considerable de ellos abandonó no solo los sistemas de producción sino también el campo al no encontrar oportunidades de sustento para sus familias.

\section{RECOMENDACIONES}

En términos generales, Colombia debe fortalecer y direccionar la institucionalidad, la capacidad técnica y de gestión del Ministerio de Agricultura y sus entidades adscritas a nivel nacional y territorial, para liderar la ejecución de la política no solamente agropecuaria sino una política de desarrollo rural.

Para contrarrestar la inseguridad alimentaria en la población rural; desde el nivel nacional deben llegar a los territorios, programas y proyectos de desarrollo agropecuario enmarcados en una visión de país, para fortalecer la capacidad de organización de las comunidades y participar activamente en los procesos de planificación de sus territorios.

El mejoramiento de la condición de vida de los productores agrícolas, requiere en la región intervenciones de desarrollo productivo agropecuario de preparación del campo para competir, que contengan: alianzas público - privadas, cooperación internacional, esquemas asociativos (pequeños, medianos y grandes, ciencia - tecnología e innovación, formación - capacitación y acompañamiento, comercialización y mercadeo, crédito de fomento con tasas de interés bajas y financiación acorde a las condiciones de cada productor.

En materia de comercio internacional, conviene la revisión y seguimiento de la puesta en marcha de los tratados comerciales actuales y futuros, frente a las cuotas de importación y exportación de alimentos que generen beneficios y no perjuicios para los productores agrícolas nacionales.

Al frenar el deterioro de las condiciones de vida de los productores de alimentos y sus familias, se contribuye a la solución de problemas sociales rurales como el hambre, el desplazamiento, el desempleo, la violencia y la pobreza extrema.

Urge la intervención del estado y gobierno en el control y regulación de los precios de los insumos agrícolas como factor importante en la producción de los alimentos. Toda vez que las políticas macroeconómicas inciden de manera significativa, en los términos de intercambio rural-urbano y en el poder de compra; si la políticas macroeconómicas impactan negativamente a los sistemas agroalimentarios, las políticas agroalimentarias, por más adecuadas que sean, no lograrán corregir los efectos negativos de las políticas macroeconómicas.

Esta investigación demuestra que hay que corregir los desajustes en las variables que son determinantes de la producción de alimentos y como lo demostró, hace costosa la producción de alimentos sin ver compensado el esfuerzo en el mercado. Corrigiendo esta 
situación se posibilita que los productores encuentren beneficios económicos para retornar a su oficio y al campo. Con ello garantizaría mínimamente que sus familias tengan el acceso a los alimentos.

La regulación de los mencionados desajustes, abre oportunidades para los pobladores rurales como: el producir dentro de modelos de negocios acorde a las condiciones de cada productor y territorio, de participar en sistemas de organización que promuevan la agricultura familiar y autoconsumo y finalmente queda el camino abierto para potenciar el crecimiento del sector.

Los resultados de la investigación se presentan como una contribución a resolver el problema agroalimentario que es síntesis es: cómo debe corresponder la agricultura con la producción de alimentos para disponer y permitir que las familias tengas acceso a una alimentación adecuada y estable.

Este trabajo se articula al enfoque teórico de Machado C. Absalón. (2002), Colombia debe dejar de hacer intentos de aplicar políticas agrícolas de corte coyuntural y trabajar en las contradicciones con las políticas macroeconómicas, para llegar aún a una visión a largo plazo del Estado sobre la agricultura.

De igual manera se articula con la tesis de Echeverri P. Rafael. (IICA), Una estrategia para el fortalecimiento de la política agropecuaria con miras a garantizar la seguridad alimentaria debe quedar claro que, hay que actuar a nivel de las políticas macroeconómicas y que también se necesita tener políticas específicas para apoyar la producción de alimentos, que deben basarse en diagnósticos concretos en las regiones, las actividades a que se dedican y las estrategias de subsistencia que emplean. La formulación de las políticas públicas, debe tratar de lograr efectos directos en las decisiones de comportamiento de los agentes sociales y agentes económicos, recurriendo para esto a los distintos instrumentos con que cuenta, cómo el liderazgo político, la potestad de regular, la capacidad de crear instituciones, la capacidad de hacer inversiones en bienes públicos, e inclusive intervenir en la economía.

Según la FAO, más de la mitad de la tierra que podría ingresar a la producción agrícola está localizada en solo 7 países tropicales de América Latina y de África Subsahariana. Angola, Argentina, Bolivia, Colombia, Brasil, Congo y Sudán. Razón de gran importancia para que la política desarrolle productivamente las regiones de Colombia, primero con el fin de cuidar la seguridad alimentaria interna, antes que otros países pongan sus ojos en el territorio colombiano como su propia despensa

Finalizo afirmando que, "La agricultura y por consiguiente la producción de alimentos, significa al interior de las familias rurales un camino para salir de la pobreza, en realidad, muchas veces el único de que disponen, es la fuente principal de ingresos y derechos, que da la posibilidad de alcanzar una alimentación adecuada y sostenible." Por ello, Colombia necesita con urgencia una Política agropecuaria con visión de desarrollo Rural y en particular que responda a la seguridad alimentaria tanto de pobladores rurales como urbanos. 


\section{ANEXOS}

\section{Anexo 1. Formato de encuesta para conocer aspectos de la producción de alimentos y seguridad alimentaria en el municipio de Puente Nacional- Santander.}

Objetivo de la investigación: Identificar aspectos de la ejecución de la política agropecuaria en el municipio de Puente Nacional- Santander y los resultados obtenidos en materia de seguridad alimentaria.

Nombre de la Vereda:

Quien responde la encuesta:

$$
\text { a)Padre__b) Madre_c)Abuela (o)__d)Hija (o)__e)Tía (o)_f) otro_ }
$$

Composición familiar de quienes habitan la finca:
a) Padres, abuelos, hijos, tíos
b)Padre, hijos y tíos
c)Padres e hijos d) Solo padres

Número de hijos de quienes habitan la finca:

a) Sin hijas (os)__b)hasta 2 hijas (os)__ c)hasta 5 hijas (os)__d) >de 5 hijas(os)

1. Qué área tiene la finca?
a) < 2ha_b) entre 2 y 8 has c) >entre 8 y 15 d)entre 15 y 30 e) $>$ de 30 f) otro

2. Como es la propiedad de la finca?
a) Propia
b) arriendo
c) custodia d) otro

3. Conoce la existencia de programas del gobierno para incentivar la producción de alimentos.
a) $\mathrm{Si} \_$b) $\mathrm{No}$

4. Fue beneficiario de alguno programa, mencione cual.

Programa/ Recursos recibidos : Ejemplo: ReSa

\begin{tabular}{|c|l|l|l|l|l|}
\hline Dineros & Materiales e insumos & $\begin{array}{c}\text { Herramienta y } \\
\text { equipo }\end{array}$ & $\begin{array}{c}\text { Asistencia } \\
\text { Técnica }\end{array}$ & $\begin{array}{c}\text { Semilla y pié de } \\
\text { Cría }\end{array}$ & Otros \\
\hline 50.000 & Alimento concentrado & Red de pesca & veterinario & peces & \\
\hline & & & & & \\
\hline
\end{tabular}

5. El uso de su finca es agropecuario, es decir tiene algún sistema de producción?
a) cultivos_
b)especies menores
c) ganadería
d) otros

6. En la finca que área destina a la producción de alimentos?

a) <cuarta parte $(<25 \%) \_$b) la cuarta parte $(25 \%) \_$d)la mitad(50\%)__e)más de la mitad (75\%)__f)toda(100\%)__ 
7. De la siguiente lista que alimentos produce, vende y dónde?

\begin{tabular}{|c|c|c|c|c|c|c|c|c|c|}
\hline Alimento & $\begin{array}{c}\text { Produce } \\
\text { Si o No }\end{array}$ & $\%$ autoconsumo & $\begin{array}{c}\% \\
\text { vende }\end{array}$ & $\begin{array}{c}\% \\
\text { En Pte. } \\
\text { Nal. }\end{array}$ & Alimento & $\begin{array}{c}\text { Produce } \\
\text { Sio No }\end{array}$ & \begin{tabular}{|c|}
$\%$ \\
autoconsumo \\
\end{tabular} & \% vende & $\begin{array}{c}\% \\
\text { En Pte. } \\
\text { Nal. } \\
\end{array}$ \\
\hline frutas & & & & & cárnicos & & & & \\
\hline ejemplo: pera & $\mathrm{Si}$ & $10 \%$ & $90 \%$ & 0 & pescado & & & & \\
\hline guayaba & & & & & res & & & & \\
\hline naranja & & & & & pollo & & & & \\
\hline mandarina & & & & & cabro & & & & \\
\hline limón & & & & & camuro & & & & \\
\hline mora & & & & & cerdo & & & & \\
\hline pitahaya & & & & & conejo & & & & \\
\hline uchuva & & & & & huevo & & & & \\
\hline tomate & & & & & otros & & & & \\
\hline \multicolumn{10}{|l|}{ lulo } \\
\hline limón dulce & & & & & bebidas & & & & \\
\hline banano & & & & & café & & & & \\
\hline papaya & & & & & cacao & & & & \\
\hline \multirow[t]{2}{*}{ otros } & & & & & panela & & & & \\
\hline & & & & & otros & & & & \\
\hline \multicolumn{10}{|l|}{ verduras } \\
\hline habichuela & & & & & tubérculos & & & & \\
\hline repollo & & & & & Plátano & & & & \\
\hline zanahoria & & & & & yuca & & & & \\
\hline pepino c. & & & & & arracacha & & & & \\
\hline cebolla larga & & & & & papa & & & & \\
\hline $\begin{array}{l}\text { cebolla } \\
\text { cabezona }\end{array}$ & & & & & papa crio. & & & & \\
\hline tomate & & & & & bore & & & & \\
\hline pepino & & & & & otros & & & & \\
\hline \multicolumn{10}{|l|}{ ahuyama } \\
\hline calabaza & & & & & cereales & & & & \\
\hline pimentón & & & & & Maíz & & & & \\
\hline \multirow[t]{2}{*}{ otros } & & & & & trigo & & & & \\
\hline & & & & & cebada & & & & \\
\hline lácteos & & & & & otros & & & & \\
\hline \multicolumn{10}{|l|}{ Leche } \\
\hline quesos & & & & & \multicolumn{2}{|l|}{ aceite s- grasa } & & & \\
\hline cuajada & & & & & $\mathrm{m} /$ quilla & & & & \\
\hline yogur & & & & & manteca & & & & \\
\hline kumis & & & & & otros & & & & \\
\hline \multicolumn{10}{|l|}{ otros } \\
\hline & & & & & \multicolumn{2}{|c|}{ azúcares y dulces } & & & \\
\hline Leguminosas & & & & & miel & & & & \\
\hline Frijol & & & & & estevia & & & & \\
\hline soya & & & & & otros & & & & \\
\hline \multicolumn{10}{|l|}{ garbanzo } \\
\hline Abas & & & & & \multicolumn{2}{|l|}{ frutos secos } & & & \\
\hline \multirow[t]{2}{*}{ otros } & & & & & maní & & & & \\
\hline & & & & & otros & & & & \\
\hline
\end{tabular}


8. En que otros lugares diferentes a Puente Nacional vende sus productos?

a) Bogotá__ b) Bucaramanga__c) Tunja__d) Barbosa_e) otros__

9. Cuál (es) canales de comercialización utiliza para la venta de alimentos?

a) Productor a consumidor__ b) Productor a minoristas__ _ Productor a mayoristas__ d) Productor agente comisionista__ d)
otro__

10. Del total de los ingresos producidos por la finca, la venta de alimentos representa:

$<$ Cuarta parte $(<25 \%) \_$_ una cuarta parte $(25 \%) \_$_a mitad $(50 \%) \_$más de la mitad $(75 \%) \_$toda $(100 \%) \_$

11. Cuáles son los ingresos que genera la venta de alimentos al mes (escriba el producto $\mathbf{y}$ marque con una $\mathbf{x}$ )

\begin{tabular}{|c|l|l|l|l|l|}
\hline Producto & $<\$ 50.000=$ & $\begin{array}{l}\text { entre } \$ 50.000 y \\
100.000\end{array}$ & $\begin{array}{l}\text { entre } \$ 100.000 y \\
200.000\end{array}$ & $\begin{array}{l}\text { entre } \$ 200.000 y \\
500.000\end{array}$ & otros \\
\hline Ejemplo: Plátano & & & $X$ & & \\
\hline & & & & & \\
\hline
\end{tabular}

12. Cuáles son los costos que genera la producción de alimentos al mes (escriba el producto y marque con una $\mathbf{x}$ )

\begin{tabular}{|c|l|l|l|l|l|}
\hline Producto & $<\$ 50.000=$ & $\begin{array}{l}\text { entre } \$ 50.000 y \\
100.000\end{array}$ & $\begin{array}{l}\text { entre } \$ 100.000 y \\
200.000\end{array}$ & $\begin{array}{l}\text { entre } \$ 200.000 y \\
500.000\end{array}$ & otros \\
\hline Ejemplo: Plátano & $x$ & & & & \\
\hline & & & & & \\
\hline
\end{tabular}

13. Cuál es el margen de utilidad por sistema de producción de la finca.(escriba el producto y marque con una x)

\begin{tabular}{|c|l|l|l|l|l|}
\hline Producto & Menos del 10\% & entre el 10\% y 20\% & entre el 20\% y 30\% & entre el 30\% y 40\% & Más del 40\% \\
\hline Ejemplo: Plátano & & & $X$ & & \\
\hline & & & & & \\
\hline
\end{tabular}

14. Cómo financia los sistemas de producción. (indique en porcentajes)

\begin{tabular}{|l|l|l|l|l|}
\hline Producto & Crédito & Recursos propios & Subsidios & otro \\
\hline Ejemplo: Plátano & $40 \%$ & $45 \%$ & $15 \%$ & 0 \\
\hline & & & & \\
\hline
\end{tabular}

15. Qué tipo de créditos a ha tenido, que tipo de servicio y monto ha pactado o adquirido. (Marque el con una $\mathrm{x} e$ indique el número de veces) Línea fin agro _ _ otras__

\begin{tabular}{|l|l|l|l|l|l|l|l|l|}
\hline Banco & $\begin{array}{l}\text { Capital } \\
\text { de } \\
\text { trabajo }\end{array}$ & Monto & Inversión & Monto & $\begin{array}{l}\text { Normalizació } \\
\boldsymbol{n} \text { de cartera }\end{array}$ & Monto & Otro & Monto \\
\hline $\begin{array}{l}\text { Ejemplo: } \\
\text { Bancolombia }\end{array}$ & $\begin{array}{l}4 \\
\text { veces }\end{array}$ & 30.000 .000 & nunca & & $1 \mathrm{vez}$ & 5.000 .000 & & \\
\hline & & & & & & & & \\
\hline
\end{tabular}

16. Qué tipo de beneficios ha obtenido de finagro y/o banco agrario (Indique el número de veces)

\begin{tabular}{|l|l|l|l|l|}
\hline \multicolumn{1}{|c|}{ Banco } & $\begin{array}{l}\text { ICR } \\
\text { incentivo a la } \\
\text { capitalización } \\
\text { rural }\end{array}$ & $\begin{array}{l}\text { FAG Fondo } \\
\text { nacional de } \\
\text { garantías }\end{array}$ & $\begin{array}{l}\text { Seguro climático } \\
\text { de cosecha }\end{array}$ & Otro \\
\hline Ejemplo: Bancolombia & 1 vez & 2 veces & 0 & \\
\hline & & & & \\
\hline
\end{tabular}


17. Tiene deudas en este momento, a cuanto corresponden:

\begin{tabular}{|l|l|l|l|}
\hline \multicolumn{1}{|c|}{ Banco } & Monto & Concepto & Observaciones \\
\hline Ejemplo: Banco Agrario & 15.000 .000 & Préstamo compra de ganado & Atraso de 3 cuotas mensuales \\
\hline & & & \\
\hline
\end{tabular}

18. A qué actividad fueron destinados los subsidios recibidos entre el año 2002 y el 2010 . (indique en porcentajes)

\begin{tabular}{|l|l|l|l|l|l|}
\hline Producto & $\begin{array}{l}\text { Semillas o } \\
\text { pie de cría }\end{array}$ & Riego & insumos & $\begin{array}{l}\text { Mano de } \\
\text { obra }\end{array}$ & Otro \\
\hline Ejemplo: Plátano & $10 \%$ & $20 \%$ & 0 & 0 & \\
\hline & & & & & \\
\hline
\end{tabular}

19. Cada cuanto recibe asistencia técnica en su finca
a) Cada 3 meses
b)cada 6 meses
c)cada año
d)cada 18 meses
e)cada 2 años
f) cuando

20. Quien le presta asistencia técnica en su finca
a) La alcaldía municipal
b) un profesional particular
c) Corporice
d) una asociación
e)nadie
f) otro

21. Porqué razón ha desplazado o sustituido la producción de alimentos
a) altos costos de insumos
b) bajos precios en el mercado
c) falta de asistencia técnica
d) factores
b) climáticos__ e) falta de financiación__ f) otros__

22. Porqué productos o actividades ha sustituido la producción de alimentos

a) Turismo__ b)Biocombustibles__c)ganadería__d)Ninguno __ e)otras__ 


\section{Anexo 2. Datos - Productores AgropecuariosMedianos}

Productores agropecuarios organizados por tamaño en medianos y pequeños. Mediano productor, Es toda persona natural o jurídica cuyos activos totales sean inferiores o iguales a $5.000 \mathrm{smlmv}$, es decir $\$ 2.947$ '500.000 para 2013. Pequeño productor, Es toda persona cuyos activos totales no superen $\$ 85^{\prime} 477.500$. Esto contenido en el Manual de Servicios de Finagro.

\begin{tabular}{|c|c|c|c|c|c|c|c|c|c|}
\hline \multirow[b]{2}{*}{ Observación } & \multirow{2}{*}{$\begin{array}{l}\text { Var. Depen. } \\
\text { Valor de la } \\
\text { producción } \\
\text { anual }\end{array}$} & \multicolumn{6}{|c|}{ Var. Indexen. } & \multirow[b]{2}{*}{$\begin{array}{l}\text { \% } \\
\text { Mg.utilidad } \\
\$\end{array}$} & \multirow[b]{2}{*}{$\begin{array}{l}\text { Tenencia } \\
\text { de la tierra }\end{array}$} \\
\hline & & $\begin{array}{l}\text { EIncentivos } \\
\$\end{array}$ & $\begin{array}{l}\text { Otras } \\
\text { actividades }\end{array}$ & Subsidios & $\begin{array}{l}\text { Deuda crédito } \\
\$\end{array}$ & $\begin{array}{l}\text { EInsumos } \\
\$\end{array}$ & $\begin{array}{l}\text { EMg.utilidad } \\
\$\end{array}$ & & \\
\hline & $Y$ & $\mathrm{X} 1$ & $x 2$ & $\mathrm{X3}$ & $\mathrm{X} 4$ & $\mathrm{X5}$ & $\mathrm{X} 6$ & $\mathrm{X7}$ & $\mathrm{x} 8$ \\
\hline \multicolumn{10}{|l|}{ MEDIANOS } \\
\hline 1 & 1500000 & 355000 & 0 & 0 & 5500000 & 600000 & 60000 & 4 & 1 \\
\hline 2 & 14000000 & 280000 & 0 & 0 & 21000000 & 6000000 & 1000000 & 7.1 & 0 \\
\hline 3 & 5000000 & 100000 & 1 & 0 & 2000000 & 1000000 & -1500000 & -30 & 1 \\
\hline 4 & \begin{tabular}{|l|}
6400000 \\
\end{tabular} & 800000 & 0 & 1 & 1000000 & 3000000 & \begin{tabular}{|l|}
400000 \\
\end{tabular} & 6.3 & 1 \\
\hline 5 & \begin{tabular}{|l|}
13000000 \\
\end{tabular} & 720000 & 1 & 0 & 4000000 & 7000000 & 1500000 & 11.5 & 1 \\
\hline 6 & 3000000 & 850000 & 0 & 1 & \begin{tabular}{|l|}
10000000 \\
\end{tabular} & 5000000 & 0 & 0.0 & 1 \\
\hline 7 & 10000000 & 150000 & 1 & 0 & 7000000 & 3600000 & 2500000 & 25 & 0 \\
\hline 8 & 7000000 & 100000 & 1 & 0 & 1000000 & 1200000 & 1000000 & 14.6 & 1 \\
\hline 9 & 1800000 & 480000 & 1 & 0 & 5000000 & 2000000 & 0 & 0.0 & 1 \\
\hline 10 & 5000000 & 900000 & 1 & 0 & 2000000 & 1100000 & \begin{tabular}{|l|}
600000 \\
\end{tabular} & 12.0 & 1 \\
\hline 11 & 2400000 & 500000 & 1 & 1 & 1300000 & 1600000 & \begin{tabular}{|l|}
400000 \\
\end{tabular} & 16.3 & 1 \\
\hline 12 & 11000000 & 50000 & 1 & 0 & 8000000 & 2500000 & 2000000 & 18.3 & 1 \\
\hline 13 & 3000000 & 0 & 0 & 0 & 100000 & 6000000 & 0 & 0.0 & 1 \\
\hline 14 & 1000000 & 0 & 1 & 0 & 7600000 & 6000000 & 0 & 0.0 & 1 \\
\hline 15 & 7000000 & 157000 & 0 & 1 & 2300000 & 4500000 & 1500000 & 21.4 & 1 \\
\hline 16 & 5000000 & 960000 & 1 & 1 & 3500000 & \begin{tabular}{|l|}
1500000 \\
\end{tabular} & \begin{tabular}{|l|}
450000 \\
\end{tabular} & \begin{tabular}{|l|}
9.0 \\
\end{tabular} & \begin{tabular}{|l|}
1 \\
\end{tabular} \\
\hline 17 & 7400000 & 30000 & 1 & 0 & 6000000 & 3500000 & 1000000 & 13.5 & 1 \\
\hline 18 & 9500000 & 180000 & 1 & 0 & 12000000 & 5000000 & 950000 & 10.0 & 0 \\
\hline 19 & 3000000 & 970000 & 1 & 1 & 4000000 & 2000000 & \begin{tabular}{|l|}
-30000 \\
\end{tabular} & 0 & 1 \\
\hline 20 & \begin{tabular}{|l|}
10000000 \\
\end{tabular} & 2230000 & 1 & 1 & 11000000 & 4000000 & 500000 & 5 & 1 \\
\hline 21 & 7000000 & 160000 & 1 & 0 & 350000 & 3500000 & 800000 & 11.4 & 1 \\
\hline 22 & 14000000 & 750000 & 1 & 1 & 9000000 & 1000000 & 2000000 & 14.2 & 1 \\
\hline 23 & 1500000 & 355000 & 0 & 0 & 5500000 & 600000 & 60000 & 4 & 1 \\
\hline 24 & 14000000 & 280000 & 0 & 0 & 21000000 & 6000000 & 1000000 & 7.1 & 1 \\
\hline 25 & 5000000 & 100000 & 1 & 0 & 2000000 & 1000000 & \begin{tabular}{|l|}
-1500000 \\
\end{tabular} & -30 & 0 \\
\hline 26 & 6400000 & 800000 & 0 & 1 & 1000000 & 3000000 & \begin{tabular}{|l|}
400000 \\
\end{tabular} & 6.25 & 0 \\
\hline 27 & 13000000 & 720000 & 1 & 0 & 4000000 & 7000000 & 1500000 & 11 & 1 \\
\hline 28 & 3000000 & 850000 & 0 & 1 & 10000000 & 5000000 & 0 & 0 & 1 \\
\hline 29 & 10000000 & 150000 & 1 & 0 & 7000000 & 3600000 & 2500000 & 25 & 1 \\
\hline 30 & 7000000 & 100000 & 1 & 0 & 1000000 & 1200000 & 1000000 & 14.3 & 1 \\
\hline 31 & 1800000 & 480000 & 1 & 0 & 5000000 & 2000000 & 0 & 0 & 1 \\
\hline 32 & 5000000 & 900000 & 1 & 0 & 2000000 & \begin{tabular}{|l|}
1100000 \\
\end{tabular} & 600000 & 12 & 1 \\
\hline 33 & 2400000 & 500000 & 1 & 1 & 1300000 & 1600000 & 400000 & 16.6 & 0 \\
\hline 34 & 11000000 & 50000 & 1 & 0 & 8000000 & 2500000 & 2000000 & 18.1 & 1 \\
\hline 35 & 3000000 & 850000 & 0 & 1 & 10000000 & 5000000 & 0 & 0 & 1 \\
\hline 36 & \begin{tabular}{|l|}
10000000 \\
\end{tabular} & 150000 & 1 & 0 & 7000000 & 3600000 & 2500000 & 25 & 1 \\
\hline 37 & 7000000 & 100000 & 1 & 0 & 1000000 & \begin{tabular}{|l|}
6200000 \\
\end{tabular} & \begin{tabular}{|l|}
-3000000 \\
\end{tabular} & -42 & 1 \\
\hline 38 & 1800000 & 480000 & 1 & 0 & 5000000 & 2000000 & 0 & 0 & 1 \\
\hline 39 & 5000000 & 900000 & 1 & 0 & 2000000 & 1100000 & 600000 & 12 & 0 \\
\hline 40 & 2400000 & 500000 & 1 & 1 & 1300000 & 1600000 & \begin{tabular}{|l|}
400000 \\
\end{tabular} & 16.3 & 1 \\
\hline 41 & \begin{tabular}{|l|}
11000000 \\
\end{tabular} & 50000 & 1 & 0 & 8000000 & 2500000 & 2000000 & 18 & 1 \\
\hline 42 & 3000000 & 0 & 0 & 0 & 100000 & \begin{tabular}{|l|}
6000000 \\
\end{tabular} & 0 & 0 & 1 \\
\hline 43 & 1000000 & 0 & 1 & 0 & 7600000 & 6000000 & 0 & 0 & 1 \\
\hline 44 & 7000000 & 157000 & 0 & 1 & 2300000 & 4500000 & 1500000 & 21.4 & 0 \\
\hline 45 & 7000000 & 960000 & 1 & 1 & 3500000 & 1500000 & 1600000 & 22.8 & 1 \\
\hline 46 & 7400000 & 30000 & 1 & 0 & 6000000 & 3500000 & 1000000 & 13.5 & 1 \\
\hline 47 & 9500000 & 180000 & 1 & 0 & 12000000 & 5000000 & 950000 & 10 & 1 \\
\hline 48 & 3000000 & 970000 & 1 & 1 & 4000000 & 2000000 & -200000 & 6.6 & 0 \\
\hline 49 & 1000000 & 2230000 & 1 & 1 & 11000000 & 2000000 & -105000 & \begin{tabular}{|l|}
-10.5 \\
\end{tabular} & 1 \\
\hline 50 & 10000000 & 2230000 & 1 & 1 & 11000000 & 4000000 & 450000 & -4.5 & 1 \\
\hline 51 & 7000000 & 160000 & 1 & 0 & 350000 & 3500000 & 800000 & 11.4 & 1 \\
\hline 52 & \begin{tabular}{|l|}
14000000 \\
\end{tabular} & 750000 & \begin{tabular}{|l|l}
1 \\
\end{tabular} & 1 & 9000000 & 1000000 & 2000000 & \begin{tabular}{|l|}
-14.5 \\
\end{tabular} & 1 \\
\hline 53 & 12000000 & 80000 & 1 & 0 & 4100000 & 8000000 & 1500000 & 12.5 & 0 \\
\hline 54 & 2400000 & 1000000 & 0 & 1 & 4100000 & 10000000 & 200000 & 8.2 & 1 \\
\hline 55 & 35000000 & 380000 & 1 & 0 & 8000000 & 18000000 & \begin{tabular}{|l|}
-6000000 \\
\end{tabular} & \begin{tabular}{|l|}
-17.1 \\
\end{tabular} & 1 \\
\hline 56 & \begin{tabular}{|l|}
18000000 \\
\end{tabular} & 180000 & 0 & 0 & 1000000 & \begin{tabular}{|l|}
12000000 \\
\end{tabular} & 2500000 & 13.4 & 0 \\
\hline 57 & 2900000 & 420000 & 1 & 0 & 5200000 & 600000 & 300000 & 10.3 & 1 \\
\hline 58 & \begin{tabular}{|l|}
12000000 \\
\end{tabular} & 0 & 1 & 0 & 3500000 & 6000000 & 1200000 & 10 & 1 \\
\hline
\end{tabular}




\begin{tabular}{|c|c|c|c|c|c|c|c|c|c|}
\hline 59 & 8000000 & 0 & 1 & 0 & 2700000 & 4000000 & 800000 & 10 & 0 \\
\hline 60 & 1500000 & 355000 & 0 & 0 & 5500000 & 600000 & 60000 & 4 & 1 \\
\hline 61 & 14000000 & 280000 & 0 & 0 & 21000000 & 6000000 & 1000000 & 7.1 & 1 \\
\hline 62 & 5000000 & 100000 & 1 & 0 & 2000000 & 1000000 & 350000 & 7 & 0 \\
\hline 63 & 6400000 & 800000 & 0 & 1 & 1000000 & 3000000 & 400000 & 6.2 & 0 \\
\hline 64 & 13000000 & 720000 & 1 & 0 & 4000000 & 7000000 & 1500000 & 11.5 & 1 \\
\hline 65 & 25000000 & 0 & 0 & 0 & 4000000 & 12000000 & 1750000 & 7 & 0 \\
\hline 66 & 1500000 & 355000 & 0 & 0 & 5500000 & 600000 & 80000 & 5.3 & 1 \\
\hline 67 & 13000000 & 280000 & 0 & 0 & 21000000 & 6000000 & 1000000 & 7.6 & 1 \\
\hline 68 & 5000000 & 100000 & 1 & 0 & 2000000 & 1000000 & -350000 & -7 & 0 \\
\hline 69 & 6400000 & 800000 & 0 & 1 & 1000000 & 3000000 & 280000 & 4.7 & 0 \\
\hline 70 & 6700000 & 890000 & 0 & 1 & 14600000 & 5000000 & 0 & 0 & 1 \\
\hline 71 & 5000000 & 960000 & 1 & 1 & 3500000 & 1500000 & 600000 & 12 & 1 \\
\hline 72 & 7400000 & 30000 & 1 & 0 & 6000000 & 3500000 & 1000000 & 13.5 & 1 \\
\hline 73 & 9500000 & 180000 & 1 & 0 & 12000000 & 5000000 & 950000 & 10 & 1 \\
\hline 74 & 3000000 & 970000 & 1 & 1 & 4000000 & 2000000 & 300000 & 10 & 1 \\
\hline 75 & 1000000 & 2230000 & 1 & 1 & 11000000 & 2000000 & 150000 & 15 & 1 \\
\hline 76 & 2300000 & 65000 & 0 & 0 & 4000000 & 2800000 & -500000 & -21.7 & 1 \\
\hline 77 & 7000000 & 300000 & 0 & 0 & 12000000 & 5000000 & 450000 & 6.4 & 1 \\
\hline 78 & 1200000 & 245000 & 1 & 0 & 860000 & 900000 & 50000 & 4.1 & 0 \\
\hline 79 & 32000000 & 220000 & 0 & 0 & 18000000 & 15000000 & 2000000 & 6.25 & 1 \\
\hline 80 & 14500000 & 300000 & 0 & 0 & 7000000 & 8000000 & -1500000 & \begin{tabular}{|l|}
-10.4 \\
\end{tabular} & 1 \\
\hline 81 & 1580000 & 710000 & 1 & 0 & 1000000 & 800000 & 200000 & 12.3 & 0 \\
\hline 82 & 3800000 & 150000 & 0 & 0 & 950000 & 2500000 & 150000 & 3.9 & 1 \\
\hline 83 & 12000000 & 845000 & 1 & 0 & 4000000 & 5000000 & 100000 & 0.8 & 1 \\
\hline 84 & 4500000 & 250000 & 0 & 0 & 2000000 & 1800000 & 80000 & 1.7 & 1 \\
\hline 85 & 6000000 & 320000 & 1 & 0 & 3700000 & 4000000 & 500000 & 8.3 & 1 \\
\hline 86 & 1000000 & 2230000 & 1 & 1 & 11000000 & 2000000 & 150000 & 15 & 1 \\
\hline 87 & 2300000 & 65000 & 0 & 0 & 4000000 & 2800000 & -500000 & -21.4 & 1 \\
\hline 88 & 7000000 & 300000 & 0 & 0 & 12000000 & 5000000 & 450000 & 6.4 & 0 \\
\hline 89 & 1200000 & 245000 & 1 & 0 & 860000 & 900000 & 50000 & 4.1 & 1 \\
\hline 90 & 30500000 & 220000 & 0 & 0 & 18000000 & 15000000 & 2000000 & 6.5 & 0 \\
\hline 91 & 2900000 & 420000 & 1 & 0 & 5200000 & 600000 & 300000 & 10.3 & 1 \\
\hline 92 & 12000000 & 0 & 1 & 0 & 3500000 & 6000000 & 1200000 & 10 & 0 \\
\hline
\end{tabular}




\section{Anexo 3. Datos- Productores Agropecuarios Pequeños}

\begin{tabular}{|c|c|c|c|c|c|c|c|c|c|}
\hline \multirow{3}{*}{$\begin{array}{r}\text { M } \\
\text { igu } \\
\text { cuyo } \\
\begin{array}{c}\text { Obser } \\
\text { vación }\end{array} \\
\end{array}$} & \multicolumn{9}{|c|}{$\begin{array}{l}\text { Productores agropecuarios organizados por tamaño en medianos y pequeños. } \\
\text { diano productor, Es toda persona natural o jurídica cuyos activos totales sean inferiores o } \\
\text { es a } 5.000 \mathrm{smlmv} \text {, es decir } \$ 2.947500 .000 \text { para } 2013 \text {. Pequeño productor, Es toda persona } \\
\text { ictivos totales no superen } \$ 85^{\prime} 477.500 \text {. Esto contenido en el Manual de Servicios de Finagro. }\end{array}$} \\
\hline & \multirow{2}{*}{\begin{tabular}{|l|} 
Var. Depen. \\
Valor de la \\
producción \\
anual \\
\end{tabular}} & \multicolumn{6}{|c|}{ Var. Indepen. } & \multirow[b]{2}{*}{$\begin{array}{l}\% \\
\text { Mg.utilidad \$ }\end{array}$} & \multirow[b]{2}{*}{$\begin{array}{l}\text { Tenencia de } \\
\text { la tierra }\end{array}$} \\
\hline & & $\begin{array}{l}\Sigma \\
\text { Incentivos } \$\end{array}$ & $\begin{array}{l}\text { Otras } \\
\text { actividades }\end{array}$ & Subsidios & $\begin{array}{l}\text { Deuda } \\
\text { crédito } \$\end{array}$ & $\underset{\$}{\sum \text { Insumos }}$ & $\underset{\$}{\sum M g . u t i l i d a d}$ & & \\
\hline & $Y$ & $\mathrm{X} 1$ & \begin{tabular}{|l|}
$\mathrm{X} 2$ \\
\end{tabular} & X3 & $\mathrm{X} 4$ & $\mathrm{X} 5$ & X6 & $\mathrm{X} 7$ & $\mathrm{X} 8$ \\
\hline \multicolumn{10}{|c|}{\begin{tabular}{l|l}
$P E Q U$ & \\
$E \tilde{N} O S$ & \\
\end{tabular}} \\
\hline 1 & 2000000 & 250000 & \begin{tabular}{|l|}
1 \\
\end{tabular} & 1 & 1500000 & 1200000 & -200000 & -10 & 1 \\
\hline 2 & 5000000 & 150000 & \begin{tabular}{|l|}
0 \\
\end{tabular} & 0 & 2000000 & 2800000 & 600000 & 12 & 1 \\
\hline 3 & 1500000 & 100000 & 1 & 0 & 1500000 & 800000 & 0 & 0 & 1 \\
\hline 4 & 2400000 & 480000 & \begin{tabular}{|l|}
0 \\
\end{tabular} & \begin{tabular}{|l|}
0 \\
\end{tabular} & 0 & 2000000 & 50000 & 2.0 & 1 \\
\hline 5 & 1200000 & 600000 & 1 & 1 & 200000 & 300000 & 100000 & 8.3 & 1 \\
\hline 6 & \begin{tabular}{|l|}
6000000 \\
\end{tabular} & 500000 & 0 & 1 & 5000000 & 2500000 & \begin{tabular}{|l|}
700000 \\
\end{tabular} & 11.6 & 1 \\
\hline 7 & 1260000 & 50000 & 1 & 0 & 0 & 800000 & 0 & 0 & 1 \\
\hline 8 & 5050000 & 0 & 0 & 1 & 2800000 & 4000000 & 200000 & 3.9 & 0 \\
\hline 9 & 3000000 & 0 & 0 & 1 & 500000 & 2000000 & 75000 & 0 & 0 \\
\hline 10 & 4100000 & 157000 & 1 & 0 & 600000 & 2500000 & 400000 & 9.7 & 1 \\
\hline 11 & 1000000 & 560000 & \begin{tabular}{|l|}
0 \\
\end{tabular} & \begin{tabular}{|l|}
1 \\
\end{tabular} & 13000000 & 1300000 & -500000 & 9.5 & 1 \\
\hline 12 & 500000 & 30000 & 1 & 0 & 0 & 400000 & 0 & 0 & 0 \\
\hline 13 & 2100000 & 180000 & 0 & 0 & 1100000 & 1350000 & 200000 & 7.5 & 0 \\
\hline 14 & 2000000 & 250000 & \begin{tabular}{|l|}
1 \\
\end{tabular} & \begin{tabular}{|l|}
1 \\
\end{tabular} & 1500000 & 1200000 & -200000 & \begin{tabular}{|l|}
-10 \\
\end{tabular} & 0 \\
\hline 15 & 5000000 & 150000 & 0 & 0 & 2100000 & 2800000 & 460000 & 9.2 & 1 \\
\hline 16 & 1500000 & 100000 & \begin{tabular}{|l|}
1 \\
\end{tabular} & 0 & 1500000 & 800000 & 0 & 0 & 0 \\
\hline 17 & 2400000 & 480000 & 0 & 0 & 1000000 & 2000000 & 50000 & 2 & 1 \\
\hline 18 & 1200000 & 0 & \begin{tabular}{|l|}
1 \\
\end{tabular} & \begin{tabular}{|l|}
1 \\
\end{tabular} & 0 & 300000 & 100000 & \begin{tabular}{|l|}
8.3 \\
\end{tabular} & 0 \\
\hline 19 & 6000000 & 0 & 0 & 1 & 5000000 & 2500000 & 700000 & 11.6 & 0 \\
\hline 20 & \begin{tabular}{|l}
1260000 \\
\end{tabular} & 50000 & \begin{tabular}{|l|}
1 \\
\end{tabular} & \begin{tabular}{|l|}
0 \\
\end{tabular} & 400000 & 800000 & 0 & \begin{tabular}{|l|l|}
0 \\
\end{tabular} & 1 \\
\hline 21 & 5050000 & 0 & 0 & 1 & 2800000 & 4000000 & 200000 & \begin{tabular}{|l|}
3.9 \\
\end{tabular} & 0 \\
\hline 22 & 3000000 & \begin{tabular}{|l|}
0 \\
\end{tabular} & 0 & 1 & 500000 & 2000000 & 400000 & 13.3 & 1 \\
\hline 23 & \begin{tabular}{|l}
4100000 \\
\end{tabular} & 157000 & \begin{tabular}{|l|}
1 \\
\end{tabular} & \begin{tabular}{|l|}
0 \\
\end{tabular} & 600000 & 2500000 & 400000 & \begin{tabular}{|l|}
9.7 \\
\end{tabular} & 1 \\
\hline 24 & 1000000 & 60 & 0 & 1 & 9000000 & 1300000 & -500000 & -50 & 1 \\
\hline 25 & 500000 & 30000 & \begin{tabular}{|l|}
1 \\
\end{tabular} & 0 & 0 & 400000 & 0 & 0 & 1 \\
\hline 26 & 2100000 & 180000 & \begin{tabular}{|l|}
0 \\
\end{tabular} & \begin{tabular}{|l|}
0 \\
\end{tabular} & 1100000 & 1350000 & 200000 & 9.5 & 0 \\
\hline 27 & 1260000 & 50000 & \begin{tabular}{|l|}
1 \\
\end{tabular} & \begin{tabular}{|l|}
0 \\
\end{tabular} & 0 & 800000 & $\begin{array}{l}-20000 \\
0\end{array}$ & \begin{tabular}{|l|}
0 \\
\end{tabular} & 1 \\
\hline 28 & 5050000 & 0 & 0 & 1 & 2800000 & 4000000 & 200000 & 3.96 & 1 \\
\hline 29 & 3000000 & \begin{tabular}{|l|}
0 \\
\end{tabular} & 0 & 1 & 500000 & 2000000 & 300000 & 10 & 1 \\
\hline 30 & 4100000 & 157000 & \begin{tabular}{|l|}
1 \\
\end{tabular} & 0 & 600000 & 2500000 & 400000 & 9.7 & 1 \\
\hline 31 & 1000000 & 70000 & 0 & 1 & 11000000 & 9300000 & -450000 & -45 & 1 \\
\hline 32 & \begin{tabular}{|l}
500000 \\
\end{tabular} & 30000 & \begin{tabular}{|l|}
1 \\
\end{tabular} & \begin{tabular}{|l|}
0 \\
\end{tabular} & 0 & 400000 & 0 & 0 & 0 \\
\hline 33 & 2100000 & 180000 & \begin{tabular}{|l|}
0 \\
\end{tabular} & \begin{tabular}{|l|}
0 \\
\end{tabular} & 1100000 & 1350000 & 200000 & 9.52 & 1 \\
\hline 34 & 2000000 & 250000 & \begin{tabular}{|l|}
1 \\
\end{tabular} & \begin{tabular}{|l|}
1 \\
\end{tabular} & 1500000 & 1200000 & -200000 & -10 & 0 \\
\hline 35 & 5000000 & 150000 & \begin{tabular}{|l|}
0 \\
\end{tabular} & \begin{tabular}{|l|}
0 \\
\end{tabular} & 2000000 & 2800000 & 600000 & 12 & 1 \\
\hline 36 & 1500000 & 100000 & 1 & 0 & 1500000 & 800000 & 0 & 0 & 1 \\
\hline 37 & 2400000 & 480000 & \begin{tabular}{|l|}
0 \\
0
\end{tabular} & 0 & 0 & 2000000 & 50000 & 2.0 & 0 \\
\hline 38 & 1200000 & 600000 & 1 & 1 & 0 & 300000 & 100000 & 8.33 & 1 \\
\hline 39 & \begin{tabular}{|l}
7000000 \\
\end{tabular} & 500000 & \begin{tabular}{|l|}
0 \\
\end{tabular} & \begin{tabular}{|l|}
1 \\
\end{tabular} & 5000000 & 2500000 & 700000 & \begin{tabular}{|l|}
10 \\
\end{tabular} & 1 \\
\hline 40 & 1900000 & 30000 & \begin{tabular}{|l|}
0 \\
\end{tabular} & \begin{tabular}{|l|}
0 \\
\end{tabular} & 650000 & 1000000 & 300000 & 1 & 0 \\
\hline 41 & 3800000 & 180000 & \begin{tabular}{|l|}
0 \\
\end{tabular} & \begin{tabular}{|l|}
0 \\
\end{tabular} & 2000000 & 1500000 & 600000 & 15.3 & 1 \\
\hline 42 & 5500000 & 30000 & \begin{tabular}{|l|}
1 \\
\end{tabular} & \begin{tabular}{|l}
0 \\
\end{tabular} & 2700000 & 3200000 & 1000000 & 18.1 & 0 \\
\hline 43 & 7600000 & 0 & 0 & 1 & 6050000 & 3000000 & -980000 & \begin{tabular}{|l|}
-12.4 \\
\end{tabular} & 1 \\
\hline 44 & 9000000 & 0 & \begin{tabular}{|l|}
1 \\
\end{tabular} & 0 & 7000000 & 5000000 & 2000000 & 22.2 & 0 \\
\hline 45 & 2000000 & 0 & 0 & 1 & 500000 & 1600000 & 0 & 0 & 1 \\
\hline 46 & \begin{tabular}{|l}
4800000 \\
\end{tabular} & \begin{tabular}{|l|}
0 \\
\end{tabular} & \begin{tabular}{|l|}
1 \\
\end{tabular} & \begin{tabular}{|l|}
0 \\
\end{tabular} & 2500000 & 2200000 & 800000 & 16.3 & 1 \\
\hline 47 & 14000000 & 0 & 0 & 1 & 5400000 & 13200000 & 1100000 & 7.8 & 1 \\
\hline 48 & 8300000 & 420000 & \begin{tabular}{|l|}
1 \\
\end{tabular} & \begin{tabular}{|l|}
1 \\
1
\end{tabular} & 2400000 & 6000000 & 500000 & 6 & 1 \\
\hline 49 & 15000000 & \begin{tabular}{|l}
0 \\
\end{tabular} & \begin{tabular}{|l|}
1 \\
\end{tabular} & \begin{tabular}{|l|}
1 \\
\end{tabular} & 6000000 & 8000000 & 150000 & \begin{tabular}{|l|}
1 \\
\end{tabular} & 1 \\
\hline 50 & 1200000 & 500000 & 1 & 0 & 0 & 780000 & 0 & 0 & 1 \\
\hline 51 & \begin{tabular}{|l}
1500000 \\
\end{tabular} & \begin{tabular}{|l}
100000 \\
\end{tabular} & \begin{tabular}{|l|}
1 \\
\end{tabular} & \begin{tabular}{|l|}
0 \\
\end{tabular} & 1500000 & 800000 & 0 & \begin{tabular}{|l}
0 \\
\end{tabular} & 1 \\
\hline 52 & 2400000 & 480000 & 0 & 0 & 0 & 2000000 & 50000 & 2 & 0 \\
\hline 53 & \begin{tabular}{|l}
1200000 \\
\end{tabular} & 60000 & \begin{tabular}{|l|}
1 \\
\end{tabular} & \begin{tabular}{|l|}
1 \\
\end{tabular} & 0 & 300000 & \begin{tabular}{|l}
100000 \\
\end{tabular} & \begin{tabular}{|l|}
2 \\
8.1 \\
\end{tabular} & 1 \\
\hline 54 & 7000000 & 0 & 0 & 1 & 5000000 & 2500000 & 700000 & 10 & 1 \\
\hline 55 & \begin{tabular}{|c|}
1900000 \\
\end{tabular} & 30000 & \begin{tabular}{|l|}
0 \\
\end{tabular} & \begin{tabular}{|l|}
0 \\
\end{tabular} & 650000 & 1000000 & 300000 & 15.2 & 1 \\
\hline 56 & 3800000 & 180000 & \begin{tabular}{|l|}
0 \\
\end{tabular} & 0 & 2000000 & 1500000 & 60000 & 1.5 & 1 \\
\hline 57 & 5500000 & 50000 & 1 & 0 & 2700000 & 3200000 & 1000000 & 18.1 & 1 \\
\hline 58 & \begin{tabular}{|l|}
7600000 \\
\end{tabular} & 230000 & \begin{tabular}{|l|}
0 \\
\end{tabular} & \begin{tabular}{|l|}
1 \\
\end{tabular} & 6050000 & 3000000 & -1400000 & \begin{tabular}{|l|}
-18.4 \\
\end{tabular} & 1 \\
\hline
\end{tabular}




\begin{tabular}{|c|c|c|c|c|c|c|c|c|c|}
\hline 59 & 6000000 & 0 & 1 & 0 & 7000000 & 5000000 & 200000 & 3.3 & 1 \\
\hline 60 & 2000000 & 0 & 0 & 1 & 500000 & 1600000 & 0 & 0 & 1 \\
\hline 61 & 4800000 & 0 & 1 & 0 & 2500000 & 2200000 & 800000 & 16.6 & 0 \\
\hline 62 & 16000000 & \begin{tabular}{|l|}
0 \\
\end{tabular} & 0 & 1 & 5400000 & 13200000 & 1100000 & 6.8 & 0 \\
\hline 63 & 8300000 & 420000 & 1 & 1 & 2400000 & 6000000 & 500000 & 6.0 & 1 \\
\hline 64 & 13000000 & 150000 & 1 & 1 & 6000000 & 8000000 & 150000 & 1.1 & 1 \\
\hline 65 & 1200000 & 150000 & 1 & 0 & 0 & 780000 & 0 & 0 & 1 \\
\hline 66 & 3800000 & \begin{tabular}{|l|}
180000 \\
\end{tabular} & 0 & 0 & 2000000 & 1500000 & 600000 & 15.7 & 1 \\
\hline 67 & 5500000 & \begin{tabular}{|l|}
70000 \\
\end{tabular} & 1 & 0 & 2700000 & 3200000 & 1000000 & 18.1 & 0 \\
\hline 68 & 7600000 & \begin{tabular}{|l|}
300000 \\
\end{tabular} & 0 & 1 & 6050000 & 3000000 & -1900000 & -25 & 1 \\
\hline 69 & 9000000 & \begin{tabular}{|l|}
0 \\
\end{tabular} & 1 & 0 & 7000000 & 5000000 & 2000000 & 22.2 & 0 \\
\hline 70 & 2000000 & 0 & 0 & 1 & 500000 & 1600000 & 0 & 0 & 1 \\
\hline 71 & 4800000 & \begin{tabular}{|l|}
0 \\
\end{tabular} & 1 & 0 & 2500000 & \begin{tabular}{|l|}
2200000 \\
\end{tabular} & 800000 & 16.6 & 0 \\
\hline 72 & 17000000 & 0 & 0 & 1 & 5400000 & 13200000 & 1100000 & 6.4 & 1 \\
\hline 73 & 7300000 & \begin{tabular}{|l|}
420000 \\
\end{tabular} & 1 & 1 & 2400000 & 6000000 & 500000 & 6.8 & 1 \\
\hline 74 & 12000000 & 400000 & 1 & 1 & 6000000 & 8000000 & 150000 & 1.25 & 1 \\
\hline 75 & 1200000 & \begin{tabular}{|l|}
0 \\
\end{tabular} & 1 & 0 & 0 & \begin{tabular}{|l}
780000 \\
\end{tabular} & 0 & 0 & 1 \\
\hline 76 & 1500000 & \begin{tabular}{|l|}
100000 \\
\end{tabular} & 1 & 0 & 1500000 & 800000 & 0 & 0 & 1 \\
\hline 77 & 2400000 & 480000 & 0 & 0 & 0 & 2000000 & 50000 & 2 & 1 \\
\hline 78 & 1200000 & 0 & 1 & 1 & 0 & 300000 & 100000 & 7 & 1 \\
\hline 79 & 7000000 & 500000 & 0 & 1 & 5000000 & 2500000 & 700000 & 10 & 1 \\
\hline 80 & 1900000 & \begin{tabular}{|l|}
30000 \\
\end{tabular} & 0 & 0 & 650000 & 1000000 & 300000 & 13 & 0 \\
\hline 81 & 3800000 & 180000 & 0 & 0 & 2000000 & 1500000 & 250000 & 5.5 & 1 \\
\hline 82 & 5500000 & 0 & 1 & 0 & 2700000 & \begin{tabular}{|l|}
3200000 \\
\end{tabular} & 900000 & 16.3 & 0 \\
\hline 83 & 7600000 & \begin{tabular}{|l|}
0 \\
\end{tabular} & 0 & 1 & 6050000 & 3000000 & -2800000 & -36 & 1 \\
\hline 84 & 9000000 & \begin{tabular}{|l|}
0 \\
\end{tabular} & 1 & 0 & 7000000 & \begin{tabular}{|l|}
5000000 \\
\end{tabular} & 1000000 & 11.1 & 0 \\
\hline 85 & 1100000 & 80000 & 1 & 0 & 650000 & 600000 & 100000 & 9 & 0 \\
\hline 86 & 2100000 & 0 & 0 & 0 & 3000000 & 800000 & 100000 & 4.7 & 1 \\
\hline 87 & 4000000 & 157000 & 0 & 0 & 1500000 & 3100000 & 500000 & 12.5 & 1 \\
\hline 88 & 1600000 & 0 & 0 & 1 & 1000000 & 3800000 & 0 & 0 & 1 \\
\hline 89 & 7200000 & 30000 & 0 & 0 & 4000000 & 2000000 & 800000 & 11 & 1 \\
\hline 90 & 1500000 & 355000 & 0 & 0 & 5500000 & 600000 & 60000 & 4 & 1 \\
\hline 91 & 14000000 & 280000 & 0 & 0 & 21000000 & 6000000 & 1000000 & 7.1 & 1 \\
\hline 92 & 5000000 & \begin{tabular}{|l|}
100000 \\
\end{tabular} & 1 & 0 & 2000000 & \begin{tabular}{|l|}
1000000 \\
\end{tabular} & -1500000 & -30 & 1 \\
\hline 93 & 6400000 & 0 & 0 & 1 & 1000000 & 3000000 & 400000 & 6.2 & 1 \\
\hline 94 & 10500000 & 0 & 1 & 0 & 4000000 & 7000000 & 1500000 & 14.2 & 1 \\
\hline 95 & 3000000 & \begin{tabular}{|l|}
0 \\
\end{tabular} & 0 & 1 & 10000000 & 5000000 & 0 & 0 & 1 \\
\hline 96 & 1200000 & \begin{tabular}{|l|}
500000 \\
\end{tabular} & 1 & 0 & 0 & 780000 & 0 & 0 & 1 \\
\hline 97 & 1500000 & 100000 & 1 & 0 & 1500000 & 800000 & 0 & 0 & 1 \\
\hline 98 & 1100000 & \begin{tabular}{|l|}
80000 \\
\end{tabular} & 1 & 0 & 650000 & 600000 & 100000 & 9 & 0 \\
\hline 99 & 2100000 & 0 & 0 & 0 & 3000000 & \begin{tabular}{|l|}
800000 \\
\end{tabular} & 300000 & 14 & 1 \\
\hline 100 & 4000000 & \begin{tabular}{|l|}
157000 \\
\end{tabular} & 0 & 0 & 1500000 & 3100000 & 500000 & 12.5 & 0 \\
\hline 101 & 1600000 & \begin{tabular}{|l|}
0 \\
\end{tabular} & 0 & 1 & 1000000 & 3800000 & 0 & 0 & 1 \\
\hline 102 & 7200000 & 30000 & 0 & 0 & 4000000 & 2000000 & 750000 & 10.4 & \begin{tabular}{|l}
0 \\
\end{tabular} \\
\hline 103 & 3600000 & 50000 & 1 & 0 & 1000000 & 1200000 & 80000 & 2.2 & 1 \\
\hline 104 & 10000000 & \begin{tabular}{|l|}
0 \\
\end{tabular} & 0 & 1 & 15000000 & 6700000 & 900000 & 9 & 1 \\
\hline 105 & 600000 & 150000 & 0 & 0 & 300000 & 400000 & -400000 & -66.6 & 1 \\
\hline 106 & 1200000 & \begin{tabular}{|l|}
350000 \\
\end{tabular} & 1 & 0 & 3800000 & \begin{tabular}{|l|}
550000 \\
\end{tabular} & 180000 & 15 & 1 \\
\hline 107 & 2000000 & \begin{tabular}{|l|}
45000 \\
\end{tabular} & 0 & 1 & 1500000 & 4700000 & 260000 & 13 & 0 \\
\hline 108 & 860000 & 0 & 1 & 1 & 0 & \begin{tabular}{|l|l}
440000 \\
\end{tabular} & 90000 & 14.4 & 0 \\
\hline 109 & 4100000 & 180000 & 0 & 0 & 2500000 & 1900000 & 0 & 0 & 0 \\
\hline 110 & 1300000 & \begin{tabular}{|l|}
80000 \\
\end{tabular} & 1 & 1 & 3000000 & \begin{tabular}{|l|l}
700000 \\
\end{tabular} & -250000 & -19.2 & 1 \\
\hline 111 & 6700000 & 326000 & 0 & 0 & 1800000 & 5000000 & 600000 & 8.9 & 0 \\
\hline 112 & 780000 & 150000 & 0 & 0 & 200000 & 400000 & 50000 & 6 & 1 \\
\hline 113 & 1650000 & \begin{tabular}{|l|}
160000 \\
\end{tabular} & 1 & 0 & 640000 & 390000 & 90000 & 5.4 & 0 \\
\hline 114 & 2900000 & \begin{tabular}{|l|}
20000 \\
\end{tabular} & 0 & 1 & 4200000 & 1000000 & 500000 & 17.2 & 1 \\
\hline 115 & 1000000 & \begin{tabular}{|l|}
80000 \\
\end{tabular} & 1 & 0 & 1560000 & \begin{tabular}{|l|}
400000 \\
\end{tabular} & 0 & 0 & 0 \\
\hline 116 & 2500000 & 110000 & 0 & 1 & 1250000 & 680000 & 140000 & 5.4 & 1 \\
\hline 117 & 3020000 & \begin{tabular}{|l|}
620000 \\
\end{tabular} & 1 & 1 & 1500000 & \begin{tabular}{|l|}
720000 \\
\end{tabular} & 180000 & 5.9 & 0 \\
\hline 118 & 500000 & \begin{tabular}{|l|}
91000 \\
\end{tabular} & 0 & 0 & 200000 & 350000 & -220000 & -44 & 1 \\
\hline 119 & 1000000 & 143000 & 1 & 1 & 1200000 & 430000 & 200000 & 20 & 1 \\
\hline 120 & 2100000 & 0 & 0 & 0 & 3000000 & \begin{tabular}{|l|}
800000 \\
\end{tabular} & 300000 & 14.3 & 1 \\
\hline 121 & 4000000 & \begin{tabular}{|l|}
157000 \\
\end{tabular} & 0 & 0 & 1500000 & 3100000 & 500000 & 12.3 & 1 \\
\hline 122 & 1600000 & 0 & 0 & 1 & 1000000 & \begin{tabular}{|l|}
3800000 \\
\end{tabular} & 0 & 0 & 1 \\
\hline 123 & 7200000 & 30000 & 0 & 0 & 4000000 & 2000000 & 750000 & 10.4 & 1 \\
\hline 124 & 3600000 & 50000 & 1 & 0 & 1000000 & 1200000 & 800000 & 22.4 & 1 \\
\hline 125 & 10000000 & 0 & 0 & 1 & 15000000 & 6700000 & 900000 & 9 & 1 \\
\hline 126 & 8300000 & 420000 & 1 & 1 & 2400000 & 6000000 & 500000 & 6.2 & 1 \\
\hline 127 & 13000000 & \begin{tabular}{|l|}
150000 \\
\end{tabular} & 1 & 1 & 6000000 & \begin{tabular}{|l|}
8000000 \\
\end{tabular} & 150000 & 1.1 & 1 \\
\hline 128 & 1200000 & 150000 & 1 & 0 & 0 & 780000 & 0 & 0 & 1 \\
\hline 129 & 3800000 & \begin{tabular}{|l|}
180000 \\
\end{tabular} & 0 & 0 & 2000000 & \begin{tabular}{|l|}
1500000 \\
\end{tabular} & 600000 & 15.7 & 1 \\
\hline 130 & 1200000 & 350000 & 1 & 0 & 3800000 & \begin{tabular}{|l|}
550000 \\
\end{tabular} & 180000 & 15 & 0 \\
\hline 131 & 2000000 & \begin{tabular}{|l|}
45000 \\
\end{tabular} & 0 & 1 & 1500000 & 4700000 & 260000 & 13 & 0 \\
\hline 132 & 860000 & 0 & 1 & 1 & 0 & 440000 & 75000 & 8.7 & 0 \\
\hline 133 & 4100000 & \begin{tabular}{|l|}
180000 \\
\end{tabular} & 0 & 0 & 2500000 & 1900000 & 0 & 0 & 0 \\
\hline 134 & 1300000 & 80000 & 1 & 1 & 3000000 & \begin{tabular}{|l|}
700000 \\
\end{tabular} & -480000 & -27 & 0 \\
\hline
\end{tabular}




\begin{tabular}{|c|c|c|c|c|c|c|c|c|c|}
\hline 135 & 7300000 & 420000 & 1 & 1 & 2400000 & 6000000 & 500000 & 6.5 & 0 \\
\hline 136 & 12000000 & 400000 & 1 & 1 & 6000000 & 8000000 & 150000 & 1.2 & 1 \\
\hline 137 & 1200000 & 0 & 1 & 0 & 0 & 780000 & 0 & 0 & 1 \\
\hline 138 & 1500000 & 100000 & 1 & 0 & 1500000 & 800000 & 0 & 0 & 0 \\
\hline 139 & 2400000 & 480000 & 0 & 0 & 0 & 2000000 & 50000 & 2 & 1 \\
\hline 140 & 1200000 & 0 & 1 & 1 & 500000 & 300000 & -100000 & -8 & 1 \\
\hline 141 & 7000000 & 500000 & 0 & 1 & 5000000 & 2500000 & 550000 & 7 & 1 \\
\hline 142 & 1900000 & 30000 & 0 & 0 & 650000 & 1000000 & 300000 & 15.2 & 0 \\
\hline 143 & 3700000 & 180000 & 0 & 0 & 2000000 & 1500000 & 120000 & 3.2 & 1 \\
\hline 144 & 1500000 & 100000 & 1 & 0 & 1500000 & 800000 & 0 & 0 & 0 \\
\hline 145 & 1100000 & 80000 & 1 & 0 & 650000 & 600000 & 100000 & 9 & 1 \\
\hline 146 & 2100000 & 0 & 0 & 0 & 3000000 & 800000 & 300000 & 11 & 0 \\
\hline 147 & 3800000 & 157000 & 0 & 0 & 1500000 & 3100000 & 500000 & 13.1 & 1 \\
\hline 148 & 1600000 & 10 & 0 & 1 & 1000000 & 3800000 & 0 & 0 & 1 \\
\hline 149 & 1000000 & 560000 & 0 & 1 & 12300000 & 1300000 & -310000 & -31 & 1 \\
\hline 150 & 500000 & 30000 & 1 & 0 & 0 & 400000 & 0 & 0 & 1 \\
\hline 151 & 2100000 & 180000 & 0 & 0 & 1100000 & 1350000 & 200000 & 9.5 & 1 \\
\hline 152 & 2000000 & 250000 & 1 & 1 & 13500000 & 1200000 & -240000 & -12 & 1 \\
\hline 153 & 3000000 & 0 & 0 & 0 & 100000 & 6000000 & 0 & 0 & 1 \\
\hline 154 & 1000000 & 0 & 1 & 0 & 7600000 & 6000000 & 92000 & 9.2 & 1 \\
\hline 155 & 1000000 & 0 & 1 & 1 & 300000 & 470000 & 120000 & 12 & 0 \\
\hline 156 & 740000 & 40000 & 1 & 0 & 0 & 300000 & 110000 & 14.2 & 0 \\
\hline 157 & 855000 & 0 & 0 & 1 & 2000000 & 800000 & -210000 & -23.7 & 1 \\
\hline 158 & 215000 & 15000 & 1 & 0 & 0 & 190000 & 0 & 0 & 1 \\
\hline 159 & 490000 & 0 & 0 & 1 & 0 & 230000 & 50000 & 10.2 & 1 \\
\hline 160 & 2000000 & 250000 & 1 & 1 & 5500000 & 2200000 & -440000 & -22 & 0 \\
\hline 161 & 2500000 & 110000 & 0 & 1 & 1250000 & 680000 & 140000 & 5.7 & 0 \\
\hline 162 & 3020000 & 620000 & 1 & 1 & 1500000 & 720000 & 180000 & 5 & 0 \\
\hline 163 & 500000 & 91000 & 0 & 0 & 200000 & 350000 & -190000 & -38 & 0 \\
\hline 164 & 1000000 & 143000 & 1 & 1 & 1200000 & 430000 & 200000 & 20 & 1 \\
\hline 165 & 2100000 & 0 & 0 & 0 & 3000000 & 800000 & 300000 & 15 & 1 \\
\hline 166 & 4000000 & 157000 & 0 & 0 & 1500000 & 3100000 & 500000 & 12.1 & 1 \\
\hline 167 & 1600000 & 0 & 0 & 1 & 1000000 & 3800000 & 0 & 0 & 1 \\
\hline 168 & 7100000 & 30000 & 0 & 0 & 4000000 & 2000000 & 750000 & 10.4 & 1 \\
\hline 169 & 1200000 & 0 & 1 & 0 & 300000 & 780000 & 0 & 0 & 1 \\
\hline 170 & 1500000 & 100000 & 1 & 0 & 1500000 & 800000 & 0 & 0 & 0 \\
\hline 171 & 2400000 & 480000 & 0 & 0 & 0 & 2000000 & 50000 & 2.8 & 1 \\
\hline 172 & 1200000 & 0 & 1 & 1 & 0 & 300000 & 100000 & 8.1 & 0 \\
\hline 173 & 1700000 & 0 & 0 & 1 & 1000000 & 3800000 & 0 & 0 & 1 \\
\hline 174 & 1000000 & 50000 & 0 & 1 & 9300000 & 1300000 & -310000 & -31 & 0 \\
\hline 175 & 500000 & 30000 & 1 & 0 & 0 & 400000 & 0 & 0 & 0 \\
\hline 176 & 750000 & 20000 & 0 & 1 & 500000 & 200000 & 0 & 0 & 1 \\
\hline 177 & 2500000 & 130000 & 1 & 0 & 2200000 & 2000000 & 50000 & 2 & 1 \\
\hline 178 & 560000 & 140000 & 0 & 1 & 0 & 250000 & 120000 & 21.4 & 1 \\
\hline 179 & 2100000 & 65000 & 1 & 0 & 40000 & 630000 & 350000 & 16.9 & 0 \\
\hline 180 & 1200000 & 90000 & 0 & 1 & 1600000 & 1500000 & -300000 & -25 & 0 \\
\hline 181 & 4100000 & 265000 & 1 & 0 & 2500000 & 3000000 & 410000 & 10 & 0 \\
\hline 182 & 500000 & 180000 & 0 & 1 & 400000 & 240000 & 40000 & 8 & 0 \\
\hline 183 & 980000 & 90000 & 1 & 1 & 3600000 & 325000 & 0 & 0 & 1 \\
\hline 184 & 10000000 & 0 & 0 & 1 & 15000000 & 6700000 & 900000 & 9 & 1 \\
\hline 185 & 8300000 & 420000 & 1 & 1 & 2400000 & 6000000 & 500000 & 6 & 1 \\
\hline 186 & 13000000 & 150000 & 1 & 1 & 6000000 & 8000000 & 150000 & 1.1 & 1 \\
\hline 187 & 1200000 & \begin{tabular}{|l}
150000 \\
\end{tabular} & 1 & 0 & 0 & 780000 & 0 & 0 & 1 \\
\hline 188 & 3800000 & 180000 & 0 & 0 & 2000000 & 1500000 & 400000 & 10.5 & 1 \\
\hline 189 & 1200000 & 350000 & 1 & 0 & 3800000 & 550000 & 180000 & 15 & 1 \\
\hline 190 & 2000000 & 45000 & 0 & 1 & 1500000 & 4700000 & 260000 & 13 & 1 \\
\hline 191 & 8600000 & 0 & 1 & 1 & 0 & 440000 & 350000 & 4.0 & 1 \\
\hline 192 & 1000000 & \begin{tabular}{|l}
0 \\
\end{tabular} & 1 & 1 & 300000 & 470000 & 120000 & 12 & 1 \\
\hline 193 & 740000 & 40000 & 1 & 0 & 0 & 300000 & 110000 & 14.3 & 1 \\
\hline 194 & 855000 & 0 & 0 & 1 & 2000000 & 800000 & -210000 & -25.5 & 1 \\
\hline 195 & 215000 & 15000 & 1 & 0 & 0 & 190000 & 0 & 0 & 1 \\
\hline 196 & 490000 & 0 & 0 & 1 & 0 & 230000 & 50000 & 10.2 & 1 \\
\hline 197 & 2500000 & 130000 & 1 & 0 & 2200000 & 2000000 & 50000 & 2 & 0 \\
\hline 198 & 560000 & 140000 & 0 & 1 & 0 & 250000 & 120000 & 21.4 & 0 \\
\hline 199 & 2100000 & 65000 & 1 & 0 & 40000 & 630000 & 350000 & 16 & 0 \\
\hline 200 & 1200000 & 90000 & 0 & 1 & 1600000 & 1500000 & -300000 & -25 & 1 \\
\hline 201 & 4100000 & 265000 & 1 & 0 & 2500000 & 3000000 & 410000 & 10 & 0 \\
\hline 202 & 2100000 & 65000 & 1 & 0 & 40000 & 630000 & 350000 & 13 & 1 \\
\hline 203 & 1200000 & 90000 & 0 & 1 & 1600000 & 1500000 & -300000 & -25 & 0 \\
\hline 204 & 4100000 & 265000 & 1 & 0 & 2500000 & 3000000 & 410000 & 10 & 1 \\
\hline 205 & 1200000 & 350000 & 1 & 0 & 3800000 & 550000 & 0 & 0 & 0 \\
\hline 206 & 2000000 & 45000 & 0 & 1 & 1500000 & 4700000 & 260000 & 13 & 1 \\
\hline 207 & 860000 & 0 & 1 & 1 & 0 & 440000 & 50000 & 5.8 & 1 \\
\hline 208 & 7200000 & 30000 & 0 & 0 & 4000000 & 2000000 & 1500000 & 20.8 & 1 \\
\hline 209 & 1500000 & 355000 & 0 & 0 & 5500000 & 600000 & 60000 & 4 & 1 \\
\hline 210 & 4000000 & 280000 & 0 & 0 & 3000000 & 3000000 & 600000 & 15 & 1 \\
\hline
\end{tabular}




\begin{tabular}{|c|c|c|c|c|c|c|c|c|c|}
\hline 211 & 5000000 & 100000 & 1 & 0 & 2000000 & 1000000 & -1500000 & -30 & 1 \\
\hline 212 & 6400000 & 0 & 0 & 1 & 1000000 & 3000000 & 400000 & 6.2 & 0 \\
\hline 213 & \begin{tabular}{|l|}
8500000 \\
\end{tabular} & 0 & 1 & 0 & 4000000 & \begin{tabular}{|l|}
7000000 \\
\end{tabular} & 1500000 & 17.3 & 0 \\
\hline 214 & 3000000 & 0 & 0 & 1 & 10000000 & 5000000 & -725000 & -24.1 & 0 \\
\hline 215 & 1200000 & 500000 & 1 & 0 & 0 & 780000 & 80000 & 6.6 & 1 \\
\hline 216 & 1500000 & \begin{tabular}{|l|}
100000 \\
\end{tabular} & 1 & 0 & 1500000 & 800000 & 0 & 0 & 0 \\
\hline 217 & 1100000 & 80000 & 1 & 0 & 650000 & 600000 & 100000 & 9 & 1 \\
\hline 218 & 2100000 & 0 & 0 & 0 & 3000000 & 800000 & 300000 & 14 & 1 \\
\hline 219 & 4000000 & 157000 & 0 & 0 & 1500000 & 3100000 & 500000 & 12.4 & 1 \\
\hline 220 & \begin{tabular}{|l|}
1600000 \\
\end{tabular} & 0 & 0 & 1 & 1000000 & \begin{tabular}{|l|}
3800000 \\
\end{tabular} & 10 & 0 & 1 \\
\hline 221 & 7200000 & 30000 & 0 & 0 & 4000000 & 2000000 & 750000 & 10 & 1 \\
\hline 222 & 3600000 & 50000 & 1 & 0 & 1000000 & 1200000 & 800000 & 22 & 1 \\
\hline 223 & 2100000 & 180000 & 0 & 0 & 1100000 & 1350000 & 200000 & 10 & 1 \\
\hline 224 & 2000000 & 250000 & 1 & 1 & 13500000 & 1200000 & -240000 & -12 & 1 \\
\hline 225 & \begin{tabular}{|c|}
3000000 \\
\end{tabular} & \begin{tabular}{|l|}
0 \\
\end{tabular} & 0 & 0 & 100000 & 6000000 & 0 & 0 & 1 \\
\hline 226 & 1000000 & 0 & 1 & 0 & 7600000 & 6000000 & 78000 & 7.8 & 1 \\
\hline 227 & \begin{tabular}{|l|}
860000 \\
\end{tabular} & 0 & 1 & 1 & 0 & \begin{tabular}{|l|l}
440000 \\
\end{tabular} & 98000 & 11.3 & 1 \\
\hline 228 & 4100000 & 180000 & 0 & 0 & 2500000 & 1900000 & 10 & 0 & 0 \\
\hline 229 & 1300000 & 80000 & 1 & 1 & 3000000 & 700000 & -250000 & -19 & 0 \\
\hline 230 & 6700000 & 326000 & 0 & 0 & 1800000 & 5000000 & 600000 & 8.9 & 1 \\
\hline 231 & 1400000 & 0 & 1 & 1 & 300000 & 470000 & 120000 & 8.5 & 0 \\
\hline 232 & 740000 & 40000 & 1 & 0 & 0 & 300000 & 110000 & 11 & 0 \\
\hline 233 & 1800000 & 480000 & 1 & 0 & 5000000 & 2000000 & 0 & 0 & 1 \\
\hline 234 & \begin{tabular}{|l|}
900000 \\
\end{tabular} & \begin{tabular}{|l|}
900000 \\
\end{tabular} & 1 & 0 & 2000000 & 1100000 & -600000 & -52.3 & 0 \\
\hline 235 & 490000 & \begin{tabular}{|l|}
0 \\
\end{tabular} & 0 & 1 & 0 & 230000 & 50000 & 10.5 & 1 \\
\hline 236 & \begin{tabular}{|l|}
2000000 \\
\end{tabular} & \begin{tabular}{|l|}
250000 \\
\end{tabular} & 1 & 1 & 5500000 & \begin{tabular}{|l|}
2200000 \\
\end{tabular} & -440000 & -21 & 0 \\
\hline 237 & 2500000 & \begin{tabular}{|l|}
110000 \\
\end{tabular} & 0 & 1 & 1250000 & 680000 & 140000 & 5.6 & 1 \\
\hline 238 & 3020000 & \begin{tabular}{|l|}
620000 \\
\end{tabular} & 1 & 1 & 1500000 & 720000 & 180000 & 5.2 & 1 \\
\hline 239 & 4100000 & 180000 & 0 & 0 & 2500000 & 1400000 & 510000 & 12.1 & 1 \\
\hline 240 & 1000000 & 0 & 1 & 1 & 300000 & 470000 & 120000 & 12 & 1 \\
\hline 241 & \begin{tabular}{|l|}
740000 \\
\end{tabular} & \begin{tabular}{|l|}
40000 \\
\end{tabular} & 1 & 0 & 0 & 300000 & 110000 & 14.7 & 1 \\
\hline 242 & 855000 & 0 & 0 & 1 & 2000000 & 800000 & -210000 & -25 & 1 \\
\hline 243 & \begin{tabular}{|l|}
215000 \\
\end{tabular} & 15000 & 1 & 0 & 0 & \begin{tabular}{|l|}
190000 \\
\end{tabular} & 0 & 0 & 1 \\
\hline 244 & 490000 & \begin{tabular}{|l|}
0 \\
\end{tabular} & 0 & 1 & 0 & 230000 & 50000 & 10.6 & 1 \\
\hline 245 & 520000 & 0 & 1 & 0 & 2560000 & 300000 & -400000 & -71.2 & 1 \\
\hline
\end{tabular}


Anexo 4. Datos - Productores Agropecuarios con Tierra Propia.

\begin{tabular}{|c|c|c|c|c|c|c|c|c|}
\hline \multicolumn{9}{|c|}{ Productores Agropecuarios organizados según la tenencia de la tierra. } \\
\hline \multirow[b]{2}{*}{ Observación } & \multirow{2}{*}{$\begin{array}{c}\text { Var. Depen. } \\
\begin{array}{c}\text { Valor de la } \\
\text { producción }\end{array}\end{array}$} & \multicolumn{7}{|c|}{ Var. Indepen. } \\
\hline & & $\Sigma$ Incentivos $\$$ & $\begin{array}{c}\text { Otras } \\
\text { actividades }\end{array}$ & Subsidios & $\begin{array}{c}\text { Deuda } \\
\text { crédito } \$\end{array}$ & $\begin{array}{c}\Sigma \text { Insumos } \\
\$\end{array}$ & $\Sigma$ Mg.utilidad \$ & $\begin{array}{c}\text { \%g.utilidad } \\
\$\end{array}$ \\
\hline PROPIA & $Y$ & X1 & X2 & $\mathbf{X 3}$ & $\mathrm{X} 4$ & $\mathrm{X5}$ & X6 & $\mathbf{X 7}$ \\
\hline 1 & 1500000 & 355000 & 0 & 0 & 5500000 & 600000 & 60000 & 4,0 \\
\hline 2 & 14000000 & 280000 & 0 & 0 & 21000000 & 6000000 & 1000000 & 7,1 \\
\hline 3 & 5000000 & 100000 & 1 & 0 & 2000000 & 1000000 & -1500000 & $-30,0$ \\
\hline 4 & 6400000 & 800000 & 0 & 1 & 1000000 & 3000000 & 400000 & 6,3 \\
\hline 5 & 13000000 & 720000 & 1 & 0 & 4000000 & 7000000 & 1500000 & 11,5 \\
\hline 6 & 3000000 & 850000 & 0 & 1 & 10000000 & 5000000 & 0 & 0,0 \\
\hline 7 & 10000000 & 150000 & 1 & 0 & 7000000 & 3600000 & 2500000 & 25,0 \\
\hline 8 & 7000000 & 100000 & 1 & 0 & 1000000 & 1200000 & 1000000 & 14,3 \\
\hline 9 & 1800000 & 480000 & 1 & 0 & 5000000 & 2000000 & 0 & 0,0 \\
\hline 10 & 5000000 & 900000 & 1 & 0 & 2000000 & 1100000 & 600000 & 12,0 \\
\hline 11 & 2400000 & 500000 & 1 & 1 & 1300000 & 1600000 & 400000 & 16,7 \\
\hline 12 & 1500000 & 355000 & 0 & 0 & 5500000 & 600000 & 60000 & 4,0 \\
\hline 13 & 14000000 & 280000 & 0 & 0 & 21000000 & 6000000 & 1000000 & 7,1 \\
\hline 14 & 5000000 & 100000 & 1 & 0 & 2000000 & 1000000 & -1100000 & $-22,0$ \\
\hline 15 & 6400000 & 800000 & 0 & 1 & 1000000 & 3000000 & 400000 & 6,3 \\
\hline 16 & 13000000 & 720000 & 1 & 0 & 4000000 & 7000000 & 1500000 & 11,5 \\
\hline 17 & 3000000 & 850000 & 0 & 1 & 10000000 & 5000000 & 0 & 0,0 \\
\hline 18 & 10000000 & 150000 & 1 & 0 & 7000000 & 3600000 & 2500000 & 25,0 \\
\hline 19 & 7000000 & 100000 & 1 & 0 & 1000000 & 1200000 & 1000000 & 14,3 \\
\hline 20 & 1800000 & 480000 & 1 & 0 & 5000000 & 2000000 & 0 & 0,0 \\
\hline 21 & 5000000 & 900000 & 1 & 0 & 2000000 & 1100000 & 600000 & 12,0 \\
\hline 22 & 2400000 & 500000 & 1 & 1 & 1300000 & 1600000 & 400000 & 16,7 \\
\hline 23 & 11000000 & 50000 & 1 & 0 & 8000000 & 2500000 & 2000000 & 18,2 \\
\hline 24 & 3000000 & 850000 & 0 & 1 & 10000000 & 5000000 & 0 & 0,0 \\
\hline 25 & 10000000 & 150000 & 1 & 0 & 7000000 & 3600000 & 2500000 & 25,0 \\
\hline 26 & 7000000 & 100000 & 1 & 0 & 1000000 & 6200000 & -3000000 & $-42,9$ \\
\hline 27 & 1800000 & 480000 & 1 & 0 & 5000000 & 2000000 & 0 & 0,0 \\
\hline 28 & 5000000 & 900000 & 1 & 0 & 2000000 & 1100000 & 600000 & 12,0 \\
\hline 29 & 2400000 & 500000 & 1 & 1 & 1300000 & 1600000 & 400000 & 16,7 \\
\hline 30 & 11000000 & 50000 & 1 & 0 & 8000000 & 2500000 & 2000000 & 18,2 \\
\hline 31 & 3000000 & 0 & 0 & 0 & 100000 & 6000000 & 0 & 0,0 \\
\hline 32 & 1000000 & 0 & 1 & 0 & 7600000 & 6000000 & 0 & 0,0 \\
\hline 33 & 7000000 & 157000 & 0 & 1 & 2300000 & 4500000 & 1500000 & 21,4 \\
\hline 34 & 7000000 & 960000 & 1 & 1 & 3500000 & 1500000 & 1600000 & 22,9 \\
\hline 35 & 7400000 & 30000 & 1 & 0 & 6000000 & 3500000 & 1000000 & 13,5 \\
\hline 36 & 9500000 & 180000 & 1 & 0 & 12000000 & 5000000 & 950000 & 10,0 \\
\hline 37 & 14000000 & 280000 & 0 & 0 & 21000000 & 6000000 & 1000000 & 7,1 \\
\hline 38 & 5000000 & 100000 & 1 & 0 & 2000000 & 1000000 & 350000 & 7,0 \\
\hline 39 & 6400000 & 800000 & 0 & 1 & 1000000 & 3000000 & 400000 & 6,3 \\
\hline 40 & 13000000 & 720000 & 1 & 0 & 4000000 & 7000000 & 1500000 & 11,5 \\
\hline 41 & 25000000 & 0 & 0 & 0 & 4000000 & 12000000 & 1750000 & 7,0 \\
\hline 42 & 1500000 & 355000 & 0 & 0 & 5500000 & 600000 & 80000 & 5,3 \\
\hline 43 & 13000000 & 280000 & 0 & 0 & 21000000 & 6000000 & 1000000 & 7,7 \\
\hline 44 & 5000000 & 100000 & 1 & 0 & 2000000 & 1000000 & -350000 & $-7,0$ \\
\hline 45 & 6400000 & 800000 & 0 & 1 & 1000000 & 3000000 & 280000 & 4,4 \\
\hline 46 & 6700000 & 890000 & 0 & 1 & 14600000 & 5000000 & 0 & 0,0 \\
\hline 47 & 5000000 & 960000 & 1 & 1 & 3500000 & 1500000 & 600000 & 12,0 \\
\hline 48 & 7400000 & 30000 & 1 & 0 & 6000000 & 3500000 & 1000000 & 13,5 \\
\hline 49 & 9500000 & 180000 & 1 & 0 & 12000000 & 5000000 & 950000 & 10,0 \\
\hline 50 & 3000000 & 970000 & 1 & 1 & 4000000 & 2000000 & 300000 & 10,0 \\
\hline 51 & 1000000 & 2230000 & 1 & 1 & 11000000 & 2000000 & 150000 & 15,0 \\
\hline 52 & 2300000 & 65000 & 0 & 0 & 4000000 & 2800000 & -500000 & $-21,7$ \\
\hline 53 & 7000000 & 300000 & 0 & 0 & 12000000 & 5000000 & 450000 & 6,4 \\
\hline 54 & 1200000 & 245000 & 1 & 0 & 860000 & 900000 & 50000 & 4,2 \\
\hline 55 & 32000000 & 220000 & 0 & 0 & 18000000 & 15000000 & 2000000 & 6,3 \\
\hline 56 & 14500000 & 300000 & 0 & 0 & 7000000 & 8000000 & -1500000 & $-10,3$ \\
\hline 57 & 1580000 & 710000 & 1 & 0 & 1000000 & 800000 & 200000 & 12,7 \\
\hline 58 & 3800000 & 150000 & 0 & 0 & 950000 & 2500000 & 150000 & 3,9 \\
\hline 59 & 12000000 & 845000 & 1 & 0 & 4000000 & 5000000 & 100000 & 0,8 \\
\hline 60 & 4500000 & 250000 & 0 & 0 & 2000000 & 1800000 & 80000 & 1,8 \\
\hline 61 & 6000000 & 320000 & 1 & 0 & 3700000 & 4000000 & 500000 & 8,3 \\
\hline 62 & 1000000 & 2230000 & 1 & 1 & 11000000 & 2000000 & 150000 & 15,0 \\
\hline
\end{tabular}




\begin{tabular}{|c|c|c|c|c|c|c|c|c|}
\hline 63 & 2300000 & 65000 & 0 & 0 & 4000000 & 2800000 & -500000 & $-21,7$ \\
\hline 64 & 7000000 & 300000 & 0 & 0 & 12000000 & 5000000 & 450000 & 6,4 \\
\hline 65 & 1200000 & 245000 & 1 & 0 & 860000 & 900000 & 50000 & 4,2 \\
\hline 66 & 30500000 & 220000 & 0 & 0 & 18000000 & 15000000 & 2000000 & 6,6 \\
\hline 67 & 2900000 & 420000 & 1 & 0 & 5200000 & 600000 & 300000 & 10,3 \\
\hline 68 & 12000000 & 0 & 1 & 0 & 3500000 & 6000000 & 1200000 & 10,0 \\
\hline 70 & 2000000 & 250000 & 1 & 1 & 1500000 & 1200000 & -200000 & $-10,0$ \\
\hline 71 & 5000000 & 150000 & 0 & 0 & 2000000 & 2800000 & 600000 & 12,0 \\
\hline 72 & 1500000 & 100000 & 1 & 0 & 1500000 & 800000 & 0 & 0,0 \\
\hline 73 & 2400000 & 480000 & 0 & 0 & 0 & 2000000 & 50000 & 2,1 \\
\hline 74 & 1200000 & 600000 & 1 & 1 & 200000 & 300000 & 100000 & 8,3 \\
\hline 75 & 6000000 & 500000 & 0 & 1 & 5000000 & 2500000 & 700000 & 11,7 \\
\hline 76 & 1260000 & 50000 & 1 & 0 & 0 & 800000 & 0 & 0,0 \\
\hline 77 & 5050000 & 0 & 0 & 1 & 2800000 & 4000000 & 200000 & 4,0 \\
\hline 78 & 3000000 & 0 & 0 & 1 & 500000 & 2000000 & 75000 & 2,5 \\
\hline 79 & 4100000 & 157000 & 1 & 0 & 600000 & 2500000 & 400000 & 9,8 \\
\hline 80 & 1000000 & 560000 & 0 & 1 & 13000000 & 1300000 & -500000 & $-50,0$ \\
\hline 81 & 500000 & 30000 & 1 & 0 & 0 & 400000 & 0 & 0,0 \\
\hline 82 & 2100000 & 180000 & 0 & 0 & 1100000 & 1350000 & 200000 & 9,5 \\
\hline 83 & 2000000 & 250000 & 1 & 1 & 1500000 & 1200000 & -200000 & $-10,0$ \\
\hline 84 & 5000000 & 150000 & 0 & 0 & 2100000 & 2800000 & 460000 & 9,2 \\
\hline 85 & 1500000 & 100000 & 1 & 0 & 1500000 & 800000 & 0 & 0,0 \\
\hline 86 & 2400000 & 480000 & 0 & 0 & 1000000 & 2000000 & 50000 & 2,1 \\
\hline 87 & 1200000 & 0 & 1 & 1 & 0 & 300000 & 100000 & 8,3 \\
\hline 88 & 6000000 & 0 & 0 & 1 & 5000000 & 2500000 & 700000 & 11,7 \\
\hline 89 & 1260000 & 50000 & 1 & 0 & 400000 & 800000 & 0 & 0,0 \\
\hline 90 & 5050000 & 0 & 0 & 1 & 2800000 & 4000000 & 200000 & 4,0 \\
\hline 91 & 3000000 & 0 & 0 & 1 & 500000 & 2000000 & 400000 & 13,3 \\
\hline 92 & 4100000 & 157000 & 1 & 0 & 600000 & 2500000 & 400000 & 9,8 \\
\hline 93 & 1000000 & 60 & 0 & 1 & 9000000 & 1300000 & -500000 & $-50,0$ \\
\hline 94 & 500000 & 30000 & 1 & 0 & 0 & 400000 & 0 & 0,0 \\
\hline 95 & 2100000 & 180000 & 0 & 0 & 1100000 & 1350000 & 200000 & 9,5 \\
\hline 96 & 1260000 & 50000 & 1 & 0 & 0 & 800000 & 0 & 0,0 \\
\hline 97 & 5050000 & 0 & 0 & 1 & 2800000 & 4000000 & 200000 & 4,0 \\
\hline 98 & 3000000 & 0 & 0 & 1 & 500000 & 2000000 & 300000 & 10,0 \\
\hline 99 & 4100000 & 157000 & 1 & 0 & 600000 & 2500000 & 400000 & 9,8 \\
\hline 100 & 1000000 & 70000 & 0 & 1 & 11000000 & 9300000 & -450000 & $-45,0$ \\
\hline 101 & 500000 & 30000 & 1 & 0 & 0 & 400000 & 0 & 0,0 \\
\hline 102 & 2100000 & 180000 & 0 & 0 & 1100000 & 1350000 & 200000 & 9,5 \\
\hline 103 & 2000000 & 250000 & 1 & 1 & 1500000 & 1200000 & -200000 & $-10,0$ \\
\hline 104 & 5000000 & 150000 & 0 & 0 & 2000000 & 2800000 & 600000 & 12,0 \\
\hline 105 & 1500000 & 100000 & 1 & 0 & 1500000 & 800000 & 0 & 0,0 \\
\hline 106 & 2400000 & 480000 & 0 & 0 & 0 & 2000000 & 50000 & 2,1 \\
\hline 107 & 1200000 & 600000 & 1 & 1 & 0 & 300000 & 100000 & 8,3 \\
\hline 108 & 7000000 & 500000 & 0 & 1 & 5000000 & 2500000 & 700000 & 10,0 \\
\hline 109 & 1900000 & 30000 & 0 & 0 & 650000 & 1000000 & 300000 & 15,8 \\
\hline 110 & 3800000 & 180000 & 0 & 0 & 2000000 & 1500000 & 600000 & 15,8 \\
\hline 111 & 5500000 & 30000 & 1 & 0 & 2700000 & 3200000 & 1000000 & 18,2 \\
\hline 112 & 7600000 & 0 & 0 & 1 & 6050000 & 3000000 & -980000 & $-12,9$ \\
\hline 113 & 9000000 & 0 & 1 & 0 & 7000000 & 5000000 & 2000000 & 22,2 \\
\hline 114 & 2000000 & 0 & 0 & 1 & 500000 & 1600000 & 0 & 0,0 \\
\hline 115 & 4800000 & 0 & 1 & 0 & 2500000 & 2200000 & 800000 & 16,7 \\
\hline 116 & 14000000 & 0 & 0 & 1 & 5400000 & 13200000 & 1100000 & 7,9 \\
\hline 117 & 8300000 & 420000 & 1 & 1 & 2400000 & 6000000 & 500000 & 6,0 \\
\hline 118 & 15000000 & 0 & 1 & 1 & 6000000 & 8000000 & 150000 & 1,0 \\
\hline 119 & 1200000 & 500000 & 1 & 0 & 0 & 780000 & 0 & 0,0 \\
\hline 120 & 1500000 & 100000 & 1 & 0 & 1500000 & 800000 & 0 & 0,0 \\
\hline 121 & 2400000 & 480000 & 0 & 0 & 0 & 2000000 & 50000 & 2,1 \\
\hline 122 & 1200000 & 60000 & 1 & 1 & 0 & 300000 & 100000 & 8,3 \\
\hline 123 & 7000000 & 0 & 0 & 1 & 5000000 & 2500000 & 700000 & 10,0 \\
\hline 124 & 4100000 & 180000 & 0 & 0 & 2500000 & 1900000 & 0 & 0,0 \\
\hline 125 & 1300000 & 80000 & 1 & 1 & 3000000 & 700000 & -250000 & $-19,2$ \\
\hline 126 & 6700000 & 326000 & 0 & 0 & 1800000 & 5000000 & 600000 & 9,0 \\
\hline 127 & 780000 & 150000 & 0 & 0 & 200000 & 400000 & 50000 & 6,4 \\
\hline 128 & 1650000 & 160000 & 1 & 0 & 640000 & 390000 & 90000 & 5,5 \\
\hline 129 & 2900000 & 20000 & 0 & 1 & 4200000 & 1000000 & 500000 & 17,2 \\
\hline 130 & 1000000 & 80000 & 1 & 0 & 1560000 & 400000 & 0 & 0,0 \\
\hline 131 & 2500000 & 110000 & 0 & 1 & 1250000 & 680000 & 140000 & 5,6 \\
\hline 132 & 3020000 & 620000 & 1 & 1 & 1500000 & 720000 & 180000 & 6,0 \\
\hline 133 & 500000 & 91000 & 0 & 0 & 200000 & 350000 & -220000 & $-44,0$ \\
\hline 134 & 1000000 & 143000 & 1 & 1 & 1200000 & 430000 & 200000 & 20,0 \\
\hline 135 & 2100000 & 0 & 0 & 0 & 3000000 & 800000 & 300000 & 14,3 \\
\hline 136 & 4000000 & 157000 & 0 & 0 & 1500000 & 3100000 & 500000 & 12,5 \\
\hline 137 & 1600000 & 0 & 0 & 1 & 1000000 & 3800000 & 0 & 0,0 \\
\hline
\end{tabular}




\begin{tabular}{|c|c|c|c|c|c|c|c|c|}
\hline 138 & 7200000 & 30000 & 0 & 0 & 4000000 & 2000000 & 750000 & 10,4 \\
\hline 139 & 3600000 & 50000 & 1 & 0 & 1000000 & 1200000 & 800000 & 22,2 \\
\hline 140 & 10000000 & 0 & 0 & 1 & 15000000 & 6700000 & 900000 & 9,0 \\
\hline 141 & 8300000 & 420000 & 1 & 1 & 2400000 & 6000000 & 500000 & 6,0 \\
\hline 142 & 13000000 & 150000 & 1 & 1 & 6000000 & 8000000 & 150000 & 1,2 \\
\hline 143 & 1200000 & 150000 & 1 & 0 & 0 & 780000 & 0 & 0,0 \\
\hline 144 & 3800000 & 180000 & 0 & 0 & 2000000 & 1500000 & 600000 & 15,8 \\
\hline 145 & 1200000 & 350000 & 1 & 0 & 3800000 & 550000 & 180000 & 15,0 \\
\hline 146 & 2000000 & 45000 & 0 & 1 & 1500000 & 4700000 & 260000 & 13,0 \\
\hline 147 & 860000 & 0 & 1 & 1 & 0 & 440000 & 75000 & 8,7 \\
\hline 148 & 4100000 & 180000 & 0 & 0 & 2500000 & 1900000 & 0 & 0,0 \\
\hline 149 & 1300000 & 80000 & 1 & 1 & 3000000 & 700000 & -480000 & $-36,9$ \\
\hline 150 & 7300000 & 420000 & 1 & 1 & 2400000 & 6000000 & 500000 & 6,8 \\
\hline 151 & 12000000 & 400000 & 1 & 1 & 6000000 & 8000000 & 150000 & 1,3 \\
\hline 152 & 1200000 & 0 & 1 & 0 & 0 & 780000 & 0 & 0,0 \\
\hline 153 & 1500000 & 100000 & 1 & 0 & 1500000 & 800000 & 0 & 0,0 \\
\hline 154 & 2400000 & 480000 & 0 & 0 & 0 & 2000000 & 50000 & 2,1 \\
\hline 155 & 1200000 & 0 & 1 & 1 & 500000 & 300000 & -100000 & $-8,3$ \\
\hline 156 & 7000000 & 500000 & 0 & 1 & 5000000 & 2500000 & 550000 & 7,9 \\
\hline 157 & 1900000 & 30000 & 0 & 0 & 650000 & 1000000 & 300000 & 15,8 \\
\hline 158 & 3700000 & 180000 & 0 & 0 & 2000000 & 1500000 & 120000 & 3,2 \\
\hline 159 & 1500000 & 100000 & 1 & 0 & 1500000 & 800000 & 0 & 0,0 \\
\hline 160 & 1100000 & 80000 & 1 & 0 & 650000 & 600000 & 100000 & 9,1 \\
\hline 161 & 2100000 & 0 & 0 & 0 & 3000000 & 800000 & 300000 & 14,3 \\
\hline 162 & 3800000 & 157000 & 0 & 0 & 1500000 & 3100000 & 500000 & 13,2 \\
\hline 163 & 1600000 & 10 & 0 & 1 & 1000000 & 3800000 & 0 & 0,0 \\
\hline 164 & 1000000 & 560000 & 0 & 1 & 12300000 & 1300000 & -310000 & $-31,0$ \\
\hline 165 & 500000 & 30000 & 1 & 0 & 0 & 400000 & 0 & 0,0 \\
\hline 166 & 2100000 & 180000 & 0 & 0 & 1100000 & 1350000 & 200000 & 9,5 \\
\hline 167 & 2000000 & 250000 & 1 & 1 & 13500000 & 1200000 & -240000 & $-12,0$ \\
\hline 168 & 3000000 & 0 & 0 & 0 & 100000 & 6000000 & 0 & 0,0 \\
\hline 169 & 1000000 & 0 & 1 & 0 & 7600000 & 6000000 & 92000 & 9,2 \\
\hline 170 & 1000000 & 0 & 1 & 1 & 300000 & 470000 & 120000 & 12,0 \\
\hline 171 & 740000 & 40000 & 1 & 0 & 0 & 300000 & 110000 & 14,9 \\
\hline 172 & 855000 & 0 & 0 & 1 & 2000000 & 800000 & -210000 & $-24,6$ \\
\hline 173 & 215000 & 15000 & 1 & 0 & 0 & 190000 & 0 & 0,0 \\
\hline 174 & 490000 & 0 & 0 & 1 & 0 & 230000 & 50000 & 10,2 \\
\hline 175 & 2000000 & 250000 & 1 & 1 & 5500000 & 2200000 & -440000 & $-22,0$ \\
\hline 176 & 2500000 & 110000 & 0 & 1 & 1250000 & 680000 & 140000 & 5,6 \\
\hline 177 & 3020000 & 620000 & 1 & 1 & 1500000 & 720000 & 180000 & 6,0 \\
\hline 178 & 500000 & 91000 & 0 & 0 & 200000 & 350000 & -190000 & $-38,0$ \\
\hline 179 & 1000000 & 143000 & 1 & 1 & 1200000 & 430000 & 200000 & 20,0 \\
\hline 180 & 2100000 & 0 & 0 & 0 & 3000000 & 800000 & 300000 & 14,3 \\
\hline 181 & 4000000 & 157000 & 0 & 0 & 1500000 & 3100000 & 500000 & 12,5 \\
\hline 182 & 1600000 & 0 & 0 & 1 & 1000000 & 3800000 & 0 & 0,0 \\
\hline 183 & 7100000 & 30000 & 0 & 0 & 4000000 & 2000000 & 750000 & 10,6 \\
\hline 184 & 1200000 & 0 & 1 & 0 & 300000 & 780000 & 0 & 0,0 \\
\hline 185 & 1500000 & 100000 & 1 & 0 & 1500000 & 800000 & 0 & 0,0 \\
\hline 186 & 2400000 & 480000 & 0 & 0 & 0 & 2000000 & 50000 & 2,1 \\
\hline 187 & 1200000 & 0 & 1 & 1 & 0 & 300000 & 100000 & 8,3 \\
\hline 188 & 1700000 & 0 & 0 & 1 & 1000000 & 3800000 & 0 & 0,0 \\
\hline 189 & 1000000 & 50000 & 0 & 1 & 9300000 & 1300000 & -310000 & $-31,0$ \\
\hline 190 & 500000 & 30000 & 1 & 0 & 0 & 400000 & 0 & 0,0 \\
\hline 191 & 4000000 & 157000 & 0 & 0 & 1500000 & 3100000 & 500000 & 12,5 \\
\hline 192 & 1600000 & 0 & 0 & 1 & 1000000 & 3800000 & 0 & 0,0 \\
\hline 193 & 7200000 & 30000 & 0 & 0 & 4000000 & 2000000 & 750000 & 10,4 \\
\hline 194 & 3600000 & 50000 & 1 & 0 & 1000000 & 1200000 & 800000 & 22,2 \\
\hline 195 & 2100000 & 180000 & 0 & 0 & 1100000 & 1350000 & 200000 & 9,5 \\
\hline 196 & 2000000 & 250000 & 1 & 1 & 13500000 & 1200000 & -240000 & $-12,0$ \\
\hline 197 & 3000000 & 0 & 0 & 0 & 100000 & 6000000 & 0 & 0,0 \\
\hline 198 & 1000000 & 0 & 1 & 0 & 7600000 & 6000000 & 78000 & 7,8 \\
\hline 199 & 860000 & 0 & 1 & 1 & 0 & 440000 & 98000 & 11,4 \\
\hline 200 & 4100000 & 180000 & 0 & 0 & 2500000 & 1900000 & 0 & 0,0 \\
\hline 201 & 1300000 & 80000 & 1 & 1 & 3000000 & 700000 & -250000 & $-19,2$ \\
\hline 202 & 6700000 & 326000 & 0 & 0 & 1800000 & 5000000 & 600000 & 9,0 \\
\hline
\end{tabular}


Anexo 5. Datos - Productores Agropecuarios con Tierra Arrendada

\begin{tabular}{|c|c|c|c|c|c|c|c|c|}
\hline \multirow[b]{2}{*}{ Observación } & \multirow{2}{*}{$\begin{array}{l}\text { Var. Depen. } \\
\begin{array}{l}\text { Valor de la } \\
\text { producción }\end{array}\end{array}$} & \multicolumn{7}{|c|}{ Var. Indepen. } \\
\hline & & $\begin{array}{c}\Sigma \text { Incentivos } \\
\$\end{array}$ & $\begin{array}{c}\text { Otras } \\
\text { actividades }\end{array}$ & Subsidios & $\begin{array}{c}\text { Deuda } \\
\text { crédito } \$\end{array}$ & $\begin{array}{c}\Sigma \text { Insumos } \\
\$\end{array}$ & $\begin{array}{c}\Sigma \\
\substack{\text { Mg.utilidad } \\
\$}\end{array}$ & $\%$ Mg.utilidad \$ \\
\hline ARRIENDO & $Y$ & $\mathrm{X1}$ & $\mathbf{X 2}$ & $\mathbf{X 3}$ & $\mathrm{X4}$ & $\mathbf{X 5}$ & $\mathrm{X6}$ & $\mathbf{X 7}$ \\
\hline 1 & 11000000 & 50000 & 1 & 0 & 8000000 & 2500000 & 2000000 & 18,2 \\
\hline 4 & 7000000 & 157000 & 0 & 1 & 2300000 & 4500000 & 1500000 & 21,4 \\
\hline 5 & 5000000 & 960000 & 1 & 1 & 3500000 & 1500000 & 450000 & 9,0 \\
\hline 6 & 7400000 & 30000 & 1 & 0 & 6000000 & 3500000 & 1000000 & 13,5 \\
\hline 7 & 9500000 & 180000 & 1 & 0 & 12000000 & 5000000 & 950000 & 10,0 \\
\hline 8 & 3000000 & 970000 & 1 & 1 & 4000000 & 2000000 & -30000 & $-1,0$ \\
\hline 13 & 1000000 & 2230000 & 1 & 1 & 11000000 & 2000000 & -105000 & $-10,5$ \\
\hline 14 & 10000000 & 2230000 & 1 & 1 & 11000000 & 4000000 & 450000 & 4,5 \\
\hline 15 & 7000000 & 160000 & 1 & 0 & 350000 & 3500000 & 800000 & 11,4 \\
\hline 16 & 14000000 & 750000 & 1 & 1 & 9000000 & 1000000 & 2000000 & 14,3 \\
\hline 17 & 12000000 & 80000 & 1 & 0 & 4100000 & 8000000 & 1500000 & 12,5 \\
\hline 18 & 2400000 & 1000000 & 0 & 1 & 4100000 & 10000000 & 200000 & 8,3 \\
\hline 19 & 35000000 & 380000 & 1 & 0 & 8000000 & 18000000 & -6000000 & $-17,1$ \\
\hline 20 & 18000000 & 180000 & 0 & 0 & 1000000 & 12000000 & 2500000 & 13,9 \\
\hline 21 & 2900000 & 420000 & 1 & 0 & 5200000 & 600000 & 300000 & 10,3 \\
\hline 22 & 12000000 & 0 & 1 & 0 & 3500000 & 6000000 & 1200000 & 10,0 \\
\hline 23 & 8000000 & 0 & 1 & 0 & 2700000 & 4000000 & 800000 & 10,0 \\
\hline 24 & 1500000 & 355000 & 0 & 0 & 5500000 & 600000 & 60000 & 4,0 \\
\hline 26 & 3800000 & 180000 & 0 & 0 & 2000000 & 1500000 & 60000 & 1,6 \\
\hline 27 & 5500000 & 50000 & 1 & 0 & 2700000 & 3200000 & 1000000 & 18,2 \\
\hline 28 & 7600000 & 230000 & 0 & 1 & 6050000 & 3000000 & -1400000 & $-18,4$ \\
\hline 29 & 6000000 & 0 & 1 & 0 & 7000000 & 5000000 & 200000 & 3,3 \\
\hline 30 & 2000000 & 0 & 0 & 1 & 500000 & 1600000 & 0 & 0,0 \\
\hline 31 & 4800000 & 0 & 1 & 0 & 2500000 & 2200000 & 800000 & 16,7 \\
\hline 32 & 16000000 & 0 & 0 & 1 & 5400000 & 13200000 & 1100000 & 6,9 \\
\hline 33 & 8300000 & 420000 & 1 & 1 & 2400000 & 6000000 & 500000 & 6,0 \\
\hline 34 & 13000000 & 150000 & 1 & 1 & 6000000 & 8000000 & 150000 & 1,2 \\
\hline 35 & 1200000 & 150000 & 1 & 0 & 0 & 780000 & 0 & 0,0 \\
\hline 36 & 3800000 & 180000 & 0 & 0 & 2000000 & 1500000 & 600000 & 15,8 \\
\hline 37 & 5500000 & 70000 & 1 & 0 & 2700000 & 3200000 & 1000000 & 18,2 \\
\hline 38 & 7600000 & 300000 & 0 & 1 & 6050000 & 3000000 & -1900000 & $-25,0$ \\
\hline 39 & 9000000 & 0 & 1 & 0 & 7000000 & 5000000 & 2000000 & 22,2 \\
\hline 40 & 2000000 & 0 & 0 & 1 & 500000 & 1600000 & 0 & 0,0 \\
\hline 41 & 4800000 & 0 & 1 & 0 & 2500000 & 2200000 & 800000 & 16,7 \\
\hline 42 & 17000000 & 0 & 0 & 1 & 5400000 & 13200000 & 1100000 & 6,5 \\
\hline 43 & 7300000 & 420000 & 1 & 1 & 2400000 & 6000000 & 500000 & 6,8 \\
\hline 44 & 12000000 & 400000 & 1 & 1 & 6000000 & 8000000 & 150000 & 1,3 \\
\hline 45 & 1200000 & 0 & 1 & 0 & 0 & 780000 & 0 & 0,0 \\
\hline 46 & 1500000 & 100000 & 1 & 0 & 1500000 & 800000 & 0 & 0,0 \\
\hline 47 & 2400000 & 480000 & 0 & 0 & 0 & 2000000 & 50000 & 2,1 \\
\hline 48 & 1200000 & 0 & 1 & 1 & 0 & 300000 & 100000 & 8,3 \\
\hline 49 & 7000000 & 500000 & 0 & 1 & 5000000 & 2500000 & 700000 & 10,0 \\
\hline 50 & 1900000 & 30000 & 0 & 0 & 650000 & 1000000 & 300000 & 15,8 \\
\hline 51 & 3800000 & 180000 & 0 & 0 & 2000000 & 1500000 & 250000 & 6,6 \\
\hline 52 & 5500000 & 0 & 1 & 0 & 2700000 & 3200000 & 900000 & 16,4 \\
\hline 53 & 7600000 & 0 & 0 & 1 & 6050000 & 3000000 & -2800000 & $-36,8$ \\
\hline 54 & 9000000 & 0 & 1 & 0 & 7000000 & 5000000 & 1000000 & 11,1 \\
\hline 55 & 1100000 & 80000 & 1 & 0 & 650000 & 600000 & 100000 & 9,1 \\
\hline 56 & 2100000 & 0 & 0 & 0 & 3000000 & 800000 & 100000 & 4,8 \\
\hline 57 & 4000000 & 157000 & 0 & 0 & 1500000 & 3100000 & 500000 & 12,5 \\
\hline 58 & 1600000 & 0 & 0 & 1 & 1000000 & 3800000 & 0 & 0,0 \\
\hline 59 & 7200000 & 30000 & 0 & 0 & 4000000 & 2000000 & 800000 & 11,1 \\
\hline 60 & 1500000 & 355000 & 0 & 0 & 5500000 & 600000 & 60000 & 4,0 \\
\hline 61 & 14000000 & 280000 & 0 & 0 & 21000000 & 6000000 & 1000000 & 7,1 \\
\hline 62 & 5000000 & 100000 & 1 & 0 & 2000000 & 1000000 & -1500000 & $-30,0$ \\
\hline 63 & 6400000 & 0 & 0 & 1 & 1000000 & 3000000 & 400000 & 6,3 \\
\hline 64 & 10500000 & 0 & 1 & 0 & 4000000 & 7000000 & 1500000 & 14,3 \\
\hline 65 & 3000000 & 0 & 0 & 1 & 10000000 & 5000000 & 0 & 0,0 \\
\hline
\end{tabular}




\begin{tabular}{|c|c|c|c|c|c|c|c|c|}
\hline 66 & 1200000 & 500000 & 1 & 0 & 0 & 780000 & 0 & 0,0 \\
\hline 67 & 1500000 & 100000 & 1 & 0 & 1500000 & 800000 & 0 & 0,0 \\
\hline 68 & 1100000 & 80000 & 1 & 0 & 650000 & 600000 & 100000 & 9,1 \\
\hline 69 & 2100000 & 0 & 0 & 0 & 3000000 & 800000 & 300000 & 14,3 \\
\hline 70 & 4000000 & 157000 & 0 & 0 & 1500000 & 3100000 & 500000 & 12,5 \\
\hline 71 & 1600000 & 0 & 0 & 1 & 1000000 & 3800000 & 0 & 0,0 \\
\hline 72 & 7200000 & 30000 & 0 & 0 & 4000000 & 2000000 & 750000 & 10,4 \\
\hline 73 & 3600000 & 50000 & 1 & 0 & 1000000 & 1200000 & 80000 & 2,2 \\
\hline 74 & 10000000 & 0 & 0 & 1 & 15000000 & 6700000 & 900000 & 9,0 \\
\hline 75 & 600000 & 150000 & 0 & 0 & 300000 & 400000 & -400000 & $-66,7$ \\
\hline 76 & 1200000 & 350000 & 1 & 0 & 3800000 & 550000 & 180000 & 15,0 \\
\hline 77 & 2000000 & 45000 & 0 & 1 & 1500000 & 4700000 & 260000 & 13,0 \\
\hline 78 & 860000 & 0 & 1 & 1 & 0 & 440000 & 90000 & 10,5 \\
\hline 79 & 750000 & 20000 & 0 & 1 & 500000 & 200000 & 0 & 0,0 \\
\hline 80 & 2500000 & 130000 & 1 & 0 & 2200000 & 2000000 & 50000 & 2,0 \\
\hline 81 & 560000 & 140000 & 0 & 1 & 0 & 250000 & 120000 & 21,4 \\
\hline 82 & 2100000 & 65000 & 1 & 0 & 40000 & 630000 & 350000 & 16,7 \\
\hline 83 & 1200000 & 90000 & 0 & 1 & 1600000 & 1500000 & -300000 & $-25,0$ \\
\hline 84 & 4100000 & 265000 & 1 & 0 & 2500000 & 3000000 & 410000 & 10,0 \\
\hline 85 & 500000 & 180000 & 0 & 1 & 400000 & 240000 & 40000 & 8,0 \\
\hline 86 & 980000 & 90000 & 1 & 1 & 3600000 & 325000 & 0 & 0,0 \\
\hline 87 & 10000000 & 0 & 0 & 1 & 15000000 & 6700000 & 900000 & 9,0 \\
\hline 88 & 8300000 & 420000 & 1 & 1 & 2400000 & 6000000 & 500000 & 6,0 \\
\hline 89 & 13000000 & 150000 & 1 & 1 & 6000000 & 8000000 & 150000 & 1,2 \\
\hline 90 & 1200000 & 150000 & 1 & 0 & 0 & 780000 & 0 & 0,0 \\
\hline 91 & 3800000 & 180000 & 0 & 0 & 2000000 & 1500000 & 400000 & 10,5 \\
\hline 92 & 1200000 & 350000 & 1 & 0 & 3800000 & 550000 & 180000 & 15,0 \\
\hline 93 & 2000000 & 45000 & 0 & 1 & 1500000 & 4700000 & 260000 & 13,0 \\
\hline 94 & 8600000 & 0 & 1 & 1 & 0 & 440000 & 350000 & 4,1 \\
\hline 95 & 1000000 & 0 & 1 & 1 & 300000 & 470000 & 120000 & 12,0 \\
\hline 96 & 740000 & 40000 & 1 & 0 & 0 & 300000 & 110000 & 14,9 \\
\hline 97 & 855000 & 0 & 0 & 1 & 2000000 & 800000 & -210000 & $-24,6$ \\
\hline 98 & 215000 & 15000 & 1 & 0 & 0 & 190000 & 0 & 0,0 \\
\hline 99 & 490000 & 0 & 0 & 1 & 0 & 230000 & 50000 & 10,2 \\
\hline 100 & 2500000 & 130000 & 1 & 0 & 2200000 & 2000000 & 50000 & 2,0 \\
\hline 101 & 560000 & 140000 & 0 & 1 & 0 & 250000 & 120000 & 21,4 \\
\hline 102 & 2100000 & 65000 & 1 & 0 & 40000 & 630000 & 350000 & 16,7 \\
\hline 103 & 1200000 & 90000 & 0 & 1 & 1600000 & 1500000 & -300000 & $-25,0$ \\
\hline 104 & 4100000 & 265000 & 1 & 0 & 2500000 & 3000000 & 410000 & 10,0 \\
\hline 105 & 2100000 & 65000 & 1 & 0 & 40000 & 630000 & 350000 & 16,7 \\
\hline 106 & 1200000 & 90000 & 0 & 1 & 1600000 & 1500000 & -300000 & $-25,0$ \\
\hline 107 & 4100000 & 265000 & 1 & 0 & 2500000 & 3000000 & 410000 & 10,0 \\
\hline 108 & 1200000 & 350000 & 1 & 0 & 3800000 & 550000 & 0 & 0,0 \\
\hline 109 & 2000000 & 45000 & 0 & 1 & 1500000 & 4700000 & 260000 & 13,0 \\
\hline 110 & 860000 & 0 & 1 & 1 & 0 & 440000 & 50000 & 5,8 \\
\hline 111 & 7200000 & 30000 & 0 & 0 & 4000000 & 2000000 & 1500000 & 20,8 \\
\hline 112 & 1500000 & 355000 & 0 & 0 & 5500000 & 600000 & 60000 & 4,0 \\
\hline 113 & 4000000 & 280000 & 0 & 0 & 3000000 & 3000000 & 600000 & 15,0 \\
\hline 114 & 5000000 & 100000 & 1 & 0 & 2000000 & 1000000 & -1500000 & $-30,0$ \\
\hline 115 & 6400000 & 0 & 0 & 1 & 1000000 & 3000000 & 400000 & 6,3 \\
\hline 116 & 8500000 & 0 & 1 & 0 & 4000000 & 7000000 & 1500000 & 17,6 \\
\hline 117 & 3000000 & 0 & 0 & 1 & 10000000 & 5000000 & -725000 & $-24,2$ \\
\hline 118 & 1200000 & 500000 & 1 & 0 & 0 & 780000 & 80000 & 6,7 \\
\hline 119 & 1500000 & 100000 & 1 & 0 & 1500000 & 800000 & 0 & 0,0 \\
\hline 120 & 1100000 & 80000 & 1 & 0 & 650000 & 600000 & 100000 & 9,1 \\
\hline 121 & 2100000 & 0 & 0 & 0 & 3000000 & 800000 & 300000 & 14,3 \\
\hline 122 & 740000 & 40000 & 1 & 0 & 0 & 300000 & 110000 & 14,9 \\
\hline 123 & 855000 & 0 & 0 & 1 & 2000000 & 800000 & -210000 & $-24,6$ \\
\hline 124 & 215000 & 15000 & 1 & 0 & 0 & 190000 & 0 & 0,0 \\
\hline 125 & 490000 & 0 & 0 & 1 & 0 & 230000 & 50000 & 10,2 \\
\hline 126 & 520000 & 0 & 1 & 0 & 2560000 & 300000 & -400000 & $-76,9$ \\
\hline 127 & 1400000 & 0 & 1 & 1 & 300000 & 470000 & 120000 & 8,6 \\
\hline 128 & 740000 & 40000 & 1 & 0 & 0 & 300000 & 110000 & 14,9 \\
\hline 129 & 1800000 & 480000 & 1 & 0 & 5000000 & 2000000 & 0 & 0,0 \\
\hline 130 & 900000 & 900000 & 1 & 0 & 2000000 & 1100000 & -600000 & $-66,7$ \\
\hline 131 & 490000 & 0 & 0 & 1 & 0 & 230000 & 50000 & 10,2 \\
\hline 132 & 2000000 & 250000 & 1 & 1 & 5500000 & 2200000 & -440000 & $-22,0$ \\
\hline 133 & 2500000 & 110000 & 0 & 1 & 1250000 & 680000 & 140000 & 5,6 \\
\hline 134 & 3020000 & 620000 & 1 & 1 & 1500000 & 720000 & 180000 & 6,0 \\
\hline 135 & 4100000 & 180000 & 0 & 0 & 2500000 & 1400000 & 510000 & 12,4 \\
\hline 136 & 1000000 & 0 & 1 & 1 & 300000 & 470000 & 120000 & 12,0 \\
\hline
\end{tabular}




\section{LISTA DE REFERENCIAS}

[1] Visión Colombia II centenario, Aprovechar las potencialidades del campo. Departamento Nacional de Planeación. 2007.

[2] Organización de las Naciones Unidas para la Agricultura y la Alimentación-FAO, El Programa Especial para la Seguridad Alimentaria.Roma;1996.

[3] FAO (1994): La política agrícola en el nuevo estilo de desarrollo latinoamericano, Santiago de Chile, 675 pp.

[4] Evaluación de la situación de la seguridad alimentaria mundial Comité de Seguridad Alimentaria (CFS: 2000/2).

[5] La política agropecuaria en la internacionalización de la economía colombiana. Marzo de 2007.

[6] Indicadores básicos recomendados para vigilar los resultados relacionados con los objetivos de la Cumbre Mundial sobre la Alimentación Roma, 18-21 de septiembre de 2000.

[7] Plan nacional de protección a la producción agropecuaria. 2003- 2006.

[8]Panorama de la situación de la población rural en Colombia. La política Agraria y los derechos de la Mujeres en Colombia 2011- Comisión Colombiana de Juristas s Ong, con estatus consultivo ante la ONU.

[9] Diagnóstico Socioeconómico Departamento de Santander, Alta Consejería para la Reintegración, junio de 2008.

[10] Hernández Sampieri, R., et al. (1998). Metodología de la investigación. México: Mc Graw Hill Interamericana. 


\section{BIBLOGRAFÍA}

Bejarano, Ávila Jesús Antonio, (1998). El desarrollo institucional y la política agrícola, colección de documentos IICA, serie competitividad No.1 Ministerio de agricultura y desarrollo rural.

Bernal Morales, A. (2009) "Aproximación balance y perspectivas de la reforma agraria en Colombia y los mecanismos de dotación de tierras" en Observatorio de la Economía Latinoamericana, $\mathrm{N}^{\circ} 124$.

CALDENTEY, Pedro. (1996). - Economía agraria y nuevas teorías económicas. Documento presentado en las $\mathrm{V}$ Jornadas de Economía crítica. Universidad Complutense de Madrid. Disponible en http://www.ucm.es/info/ec/jec5/.

Carrillo, Mónica, Absalón Machado y Carlos del Valle (2006), "Aproximación al Concepto de Autoconsumo Rural", Documento de trabajo No. 19, Bogotá: Plan Nacional de Seguridad Alimentaria y Nutricional.

Cole, G.D.H. (1985). Introducción a la historia económica. Argentina, Editorial Fondo de Cultura Económica.

Díaz Bonilla, E., L. Reca., Carlos Espinal y V. Piñeiro. (2003), Apertura Comercial y seguridad alimentaria en los países de América latina. Rev. Venez. De Econ. Y Ciencias Sociales, 2007, vol.13, $n^{o} 3$ (sept.-dic.), pp. 99-118

Espinal, Santiago, Michela Espinosa y Sara Granados (2005), Diagnostico Regional De La Seguridad Alimentaria Y Nutricional En Colombia, Bogotá: Documento de trabajo No. 6, Plan Nacional de Seguridad Alimentaria y Nutricional.

Flores, Edmundo (1968). Tratado de Economía Agrícola. 4taed, México: Fondo de Cultura Económica.

Garcia, Antonio (1973). Reforma agraria y dominación social en América Latina. S.I.A.P. Buenos Aires.

García, Nossa Antonio (1981). Reforma agraria y desarrollo capitalista en América latina, México:

Universidad Autónoma.

García, Nossa Antonio (1982). Modelos Operacionales de Reforma Agraria y Desarrollo Rural en América Latina, San José: IICA.

Gossen, Hermann H. (1983), The Laws of Human Relations and the Rules of Human Action Derived There from [1854] ॥, Cambridge (Mass.) y Londres, MIT Press. 
José E. Rodríguez Rojas Revista Venezolana de Economía y Ciencias Sociales v.13 n.3 Venezuela.

Hernández, R., Fernández, C. y Baptista, P. (2003). Metodología de la Investigación. México: Mc Graw Hill.

Heady, Earl O (1952), "Economics of agricultural production and resourse use".

Laswell, Harold. (1994).La concepción emergente de las ciencias políticas, en Aguilar Villanueva, L. (ed.) El estudio de las políticas públicas, México: Editorial Miguel Ángel Porrúa.

MARX, Karl (1981). La nacionalización de la tierra. En: Obras escogidas. Moscú: Ed. Progreso. [Originalmente publicado en The International Herald, $\mathrm{n}^{\mathbf{o}}$ 11, 15 de junio de 1872].

Malthus, Thomas R. (1798). Ensayos sobre la población. Las citas de este trabajo corresponde a la versión castellana Ortiz, T. yKingsley, D. (1951). México, Editorial Fondo de Cultura Económica.

Malthus, Thomas Robert (1820). Principios de economía política. México, Fondo de cultura económica

Maxwell, S. y M. Smith (1992), "HouseholdFood Security: a Conceptual Review", en Maxwell, S. y T. R. Frankenberger (eds.) (1992), Household Food Security: Concepts, Indicators, Measurements. A Technical Review, Nueva York-Roma, UNICEF-IFAD,

Maxwell, S. (1991). "National Food Security Planning: First Thoughts from Sudan", en Maxwell, S. (ed.), To Cure All.Roma, UNICEF

Malthus, Thomas R. (1798). Ensayos sobre la población. Las citas de este trabajo corresponde a la versión castellana Ortiz, T. yKingsley, D. (1951). México, Editorial Fondo de Cultura Económica.

Mora, J. (2005) Política agraria y desarrollo rural en Costa Rica, elementos para su definición en el nuevo entorno internacional. Agronomía Costarricense 29 (1): 101- 133.

Medina Rey Jose M. (2011) Especulación Financiera y Crisis alimentaria. España.

Machado, Absalón (2002). El concepto de estructura agraria. En: De la estructura agraria al sistema agroindustrial. CID, Universidad Nacional de Colombia.

Machado, A., Salgado, C. y Vasquez, R. (2003). "El análisis institucional y de las instituciones del sector agropecuario 1986-2003". Proyecto "Prospectiva sobre posibilidades de desarrollo rural y agrario para la paz en Colombia", CID/UN Colciencias, Bogotá. 
Maxwell, Simon (1996), "Foodsecurity: a post-modernperspective". Great Britain: En FoodPolicy, Vol. 21, No. 2, pp. 155-170. Great Britain.

Palloix, C (1978). La internacionalización del capital, Madrid: H. Blume Ediciones.

Rima, Ingrid (1995). Desarrollo del análisis económico. Madrid: Irwin Dorsey.

Amartya Sen (1981). Poverty and Famines (Pobreza y hambrunas).An Essay on Entitlement and Deprivation Oxford University: Claredon Press.

Sen, A (1776) Investigación sobre la naturaleza y causas de la riqueza de las naciones. Barcelona: Oikos-tau, 1988. v.1.

Sen, A (1986). Economía y derecho de alimentación (FoodEconomics and Entitlements). Helsinki: WiderWorkingpaper.

RICARDO, David (1817). - Principios de economía política y tributaciónll. México: fondo de cultura económica.

Ribero, María del Pilar (2006), "Documento Síntesis De Experiencias De Seguridad Alimentaria", Plan Nacional de Seguridad Almentaria y Nutrición - PNSAN, (Documento de Trabajo No. 14), Bogotá, D.C

Ribero M., María del Pilar (2007), "Informe de Avance de la Evaluación de Impacto del Programa ReSA". Colombia: Plan Nacional de Seguridad Alimentaria y Nutricional.

Rubio, Blanca (2004). "La fase agroalimentaria global y su repercusión en el campo mexicano". Comercio Exterior, vol. 54, n 11, México: pp. 948-956.

Say, Juan Bautista (1821). Tratado de Economía Política o Exposición sencilla del modo con que se forman, se distribuyen y se consumen las riquezas. Tomo segundo, Biblioteca Virtual Miguel de Cervantes.

Teubal, Miguel (2006). La renta de la tierra en la economía política clásica: David Ricardo. Revista NERA, junio 2006, año 9, \# 8.

http://www2.prudente.unesp.br/dgeo/nera/Revista/arq_8/Revista\%20Nera\%20n.\%208\%2 0Teubal.PDF (marzo 20 de 2007).

Tobón, Gabriel. (2007). Lo público, políticas públicas y políticas agrarias. En colección Apuntes de clase. Pontificia Universidad Javeriana. Bogotá. D.: En recepción del Departamento de Desarrollo Rural y Regional.

Thomson, A y Metz, M. (1999). Implicaciones de las políticas económicas en la seguridad alimentaria. Manual de capacitación. Preparado para el Servicio de Apoyo para Políticas Agrarias. Dirección de Asistencia para las Políticas de la FAO y la Sociedad alemana de cooperación técnica (GTZ). Roma: FAO. 
Walras, Léon (1958), Hermann Heinrich Gossen: un economista desconocido [1885], en Schneider, E. (ed.), Teoría económica. Vol. IV: Capítulos escogidos de la historia de las doctrinas económicas, Madrid, Aguilar, pp. 373-389.

\section{TRABAJOS CITADOS}

Agencia presidencial para la Acción Social y la Cooperación Internacional. Misión para la Reducción de la Pobreza y la Desigualdad MERPD, Red de Seguridad Alimentaria ReSA.

Apertura comercial y seguridad alimentaria... Globalización y agricultura en las Américas. Escenarios para el desarrollo tecnológico de la agricultura hemisférica. Costa Rica, Fontagro-IICA-Ifpri.

Banco Mundial (1986), La pobreza y el hambre. Temas y opiniones sobre la seguridad alimentaria en los países en desarrollo, Washington, D.C

Colombia la Constitución Política, Artículo 64. Bogotá 1991.

Comité de la Seguridad Alimentaria Mundial (CSA):http://www.fao.org/cfs/es

Cumbre del Milenio de las Naciones Unidas, septiembre 2000.

DANE, Encuesta Nacional Agropecuaria- ENA ,2009.

Fedesarrollo - Acción Social, Modelo de Intervención ReSA, 2007.

Fedesarrollo, Informe final modelo de intervención a la Red de Seguridad Alimentaria $[\mathrm{ReSA}]$ en pos de la superación del hambre en la zonas rurales potencial agrícola en Colombia 2007.

Banco mundial 2008, Informe sobre el desarrollo mundial, Agricultura para el desarrollo. Panorama general Washington D.C..

La Organización de las Naciones Unidas para la Agricultura y la Alimentación [FAO], Informe Estado de Inseguridad Alimentaria. 2008.

Banco Mundial. 1986, La pobreza y el hambre, Temas y opiniones sobre la seguridad alimentaria en los países en desarrollo, Washington, D.C. www.bancomundial.org

Organización de las Naciones Unidas para la Agricultura y la Alimentación ( $\underline{\text { FAO }}$ ). Cumbre Mundial de la Alimentación (1996). 
Plan de Acción de la Cumbre Mundial de Alimentos, Roma 1996.

Política Nacional de Seguridad Alimentaria y Nutricional.Documento Conpes 113 de 2008

Política Nacional de Competitividad y Productividad. Documento Conpes 3527 de 2008.

Propuesta de Estrategia e instrumentos para mejorar la Seguridad Alimentaria en Colombia. FAO, CAN. Octubre de 2004.

Proyecto de listas de la Secretaría de la FAO para elaborar índices del acceso a los alimentos y la vulnerabilidad y para vigilar el Programa 21 (FAO 2000).

Observatorio de Seguridad Alimentaria y Nutricional de Colombia: componentes y lineamientos para su implementación". 2011

El artículo 1 del Acuerdo de Cartagena estipula que el proceso de integración andino se hará con miras a la formación gradual de un mercado común latinoamericano.

IICA (2006) Políticas agropecuarias, estrategias de desarrollo rural, seguridad alimentaria, pobreza rural y servicios de extensión agrícola Instituto Interamericano de Cooperación para la Agricultura

Síntesis elaborada por la Comisión Organizadora con base en la presentación magistral del Dr. Rafael Echeverri Perico (IICA) "Enfoques del Desarrollo Rural" UCR 13/10/2005, y su artículo "Economía y Territorio".

Encuesta Nacional de Situación Nutricional - ENSIN- 2005. 